\title{
Nuclear Criticality Safety Assessment of Criticality Control Containers without Moderation Control at the Waste Isolation Pilot Plant
}

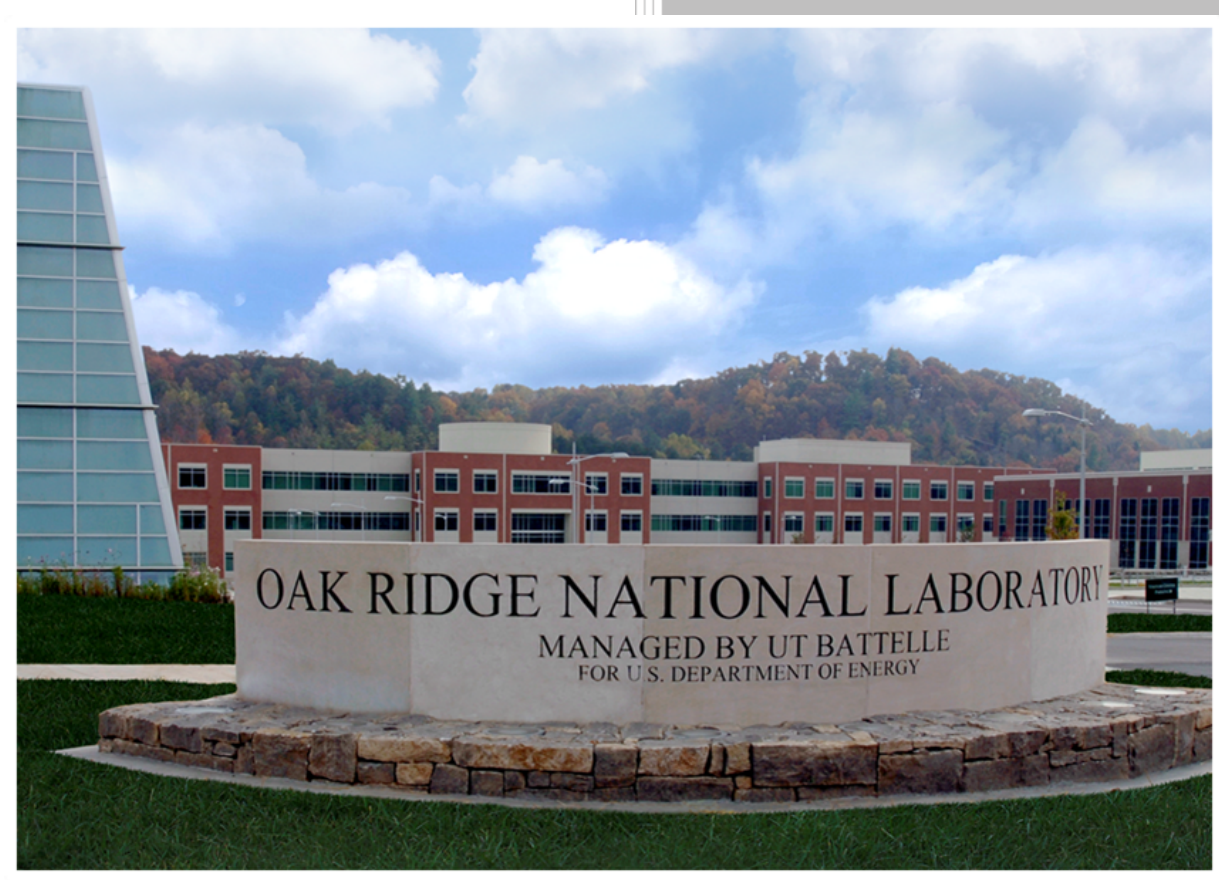

Approved for public release.

Distribution is unlimited.

Ellen M. Saylor

September 2020 


\title{
DOCUMENT AVAILABILITY
}

Reports produced after January 1, 1996, are generally available free via US Department of Energy (DOE) SciTech Connect.

Website www.osti.gov

Reports produced before January 1, 1996, may be purchased by members of the public from the following source:

\author{
National Technical Information Service \\ 5285 Port Royal Road \\ Springfield, VA 22161 \\ Telephone 703-605-6000 (1-800-553-6847) \\ TDD 703-487-4639 \\ Fax 703-605-6900 \\ E-mail info@ntis.gov \\ Website http://classic.ntis.gov/
}

Reports are available to DOE employees, DOE contractors, Energy Technology Data Exchange representatives, and International Nuclear Information System representatives from the following source:

Office of Scientific and Technical Information

PO Box 62

Oak Ridge, TN 37831

Telephone 865-576-8401

Fax 865-576-5728

E-mail reports@osti.gov

Website http://www.osti.gov/contact.html

This report was prepared as an account of work sponsored by an agency of the United States Government. Neither the United States Government nor any agency thereof, nor any of their employees, makes any warranty, express or implied, or assumes any legal liability or responsibility for the accuracy, completeness, or usefulness of any information, apparatus, product, or process disclosed, or represents that its use would not infringe privately owned rights. Reference herein to any specific commercial product, process, or service by trade name, trademark, manufacturer, or otherwise, does not necessarily constitute or imply its endorsement, recommendation, or favoring by the United States Government or any agency thereof. The views and opinions of authors expressed herein do not necessarily state or reflect those of the United States Government or any agency thereof. 
Reactor and Nuclear Systems Division

\section{NUCLEAR CRITICALITY SAFETY ASSESSMENT OF CRITICALITY CONTROL CONTAINERS WITHOUT MODERATION CONTROL AT THE WASTE ISOLATION PILOT PLANT}

Ellen M. Saylor

September 2020

Prepared by

OAK RIDGE NATIONAL LABORATORY

Oak Ridge, TN 37831-6283

managed by

UT-BATTELLE, LLC

for the

US DEPARTMENT OF ENERGY

under contract DE-AC05-00OR22725 



\section{REVISION LOG}

\begin{tabular}{|c|c|l|c|}
\hline Revision & $\begin{array}{c}\text { Sections } \\
\text { changed }\end{array}$ & \multicolumn{1}{|c|}{ Description of change } & Date \\
\hline 0 & N/A & Initial issue & September 2020 \\
\hline
\end{tabular}





\section{CONTENTS}

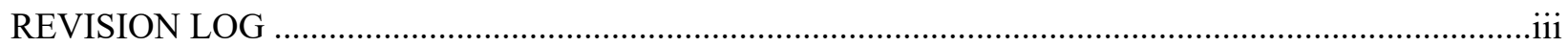

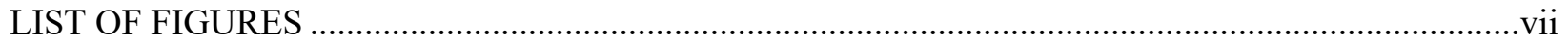

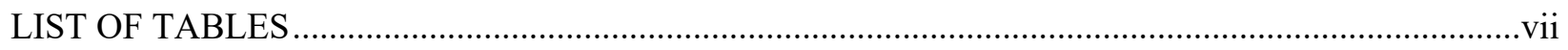

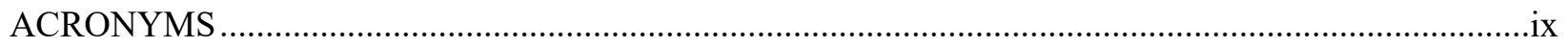

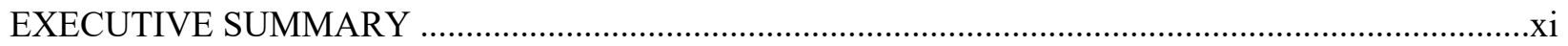

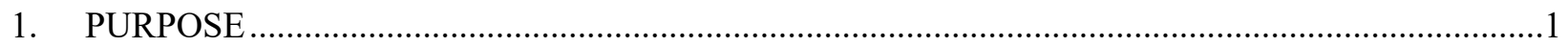

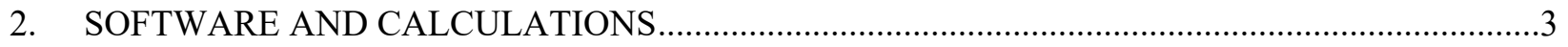

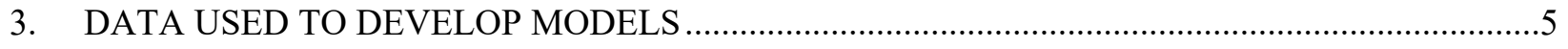

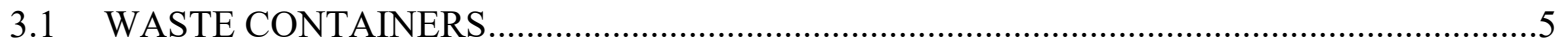

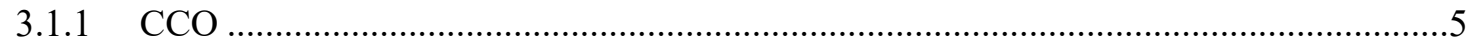

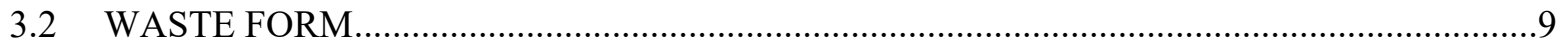

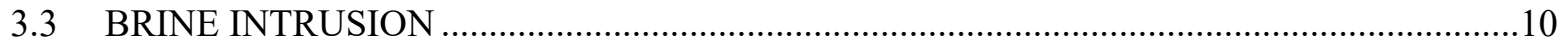

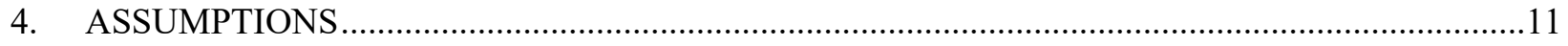

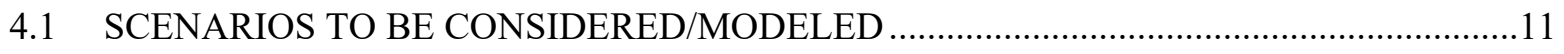

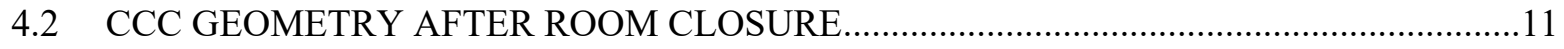

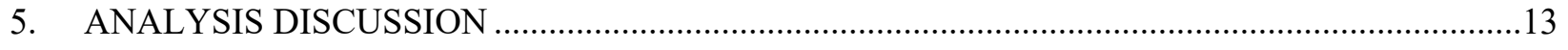

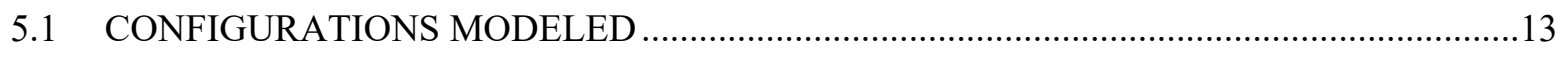

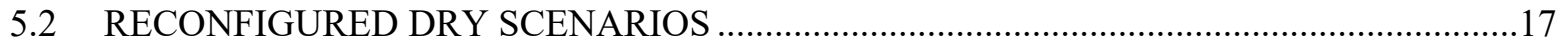

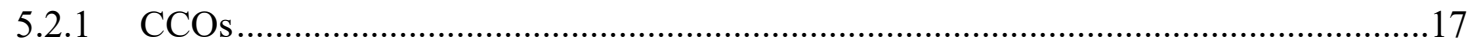

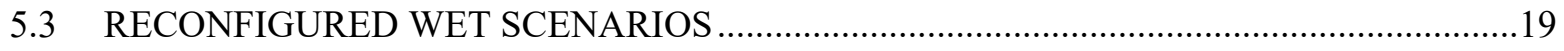

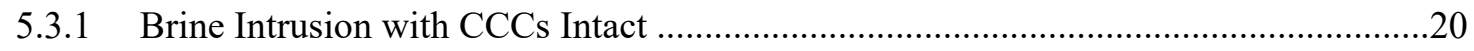

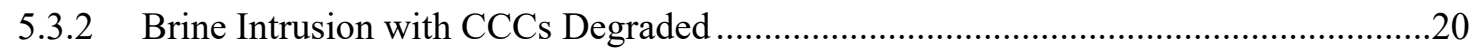

5.3.3 Migration of Materials after Brine Intrusion to External Areas...................................23

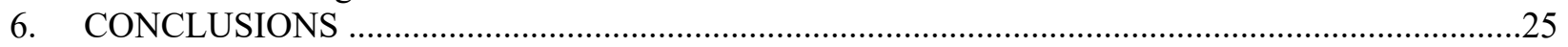

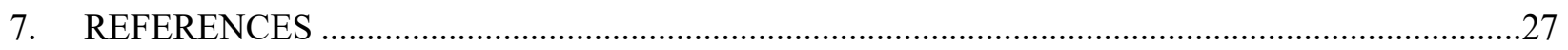

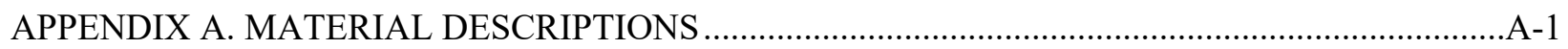

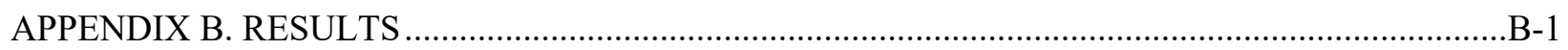

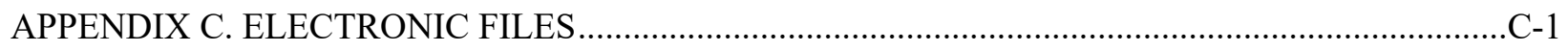

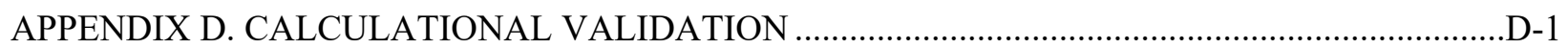





\section{LIST OF FIGURES}

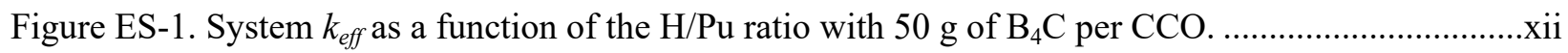

Figure ES-2. Results for incorporating $\mathrm{B}_{4} \mathrm{C}$ into the fissile material mixture $(\mathrm{H} / \mathrm{Pu}$ of 200$)$..................xiii

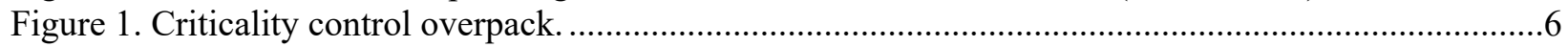

Figure 2. Criticality control overpack total and inner drum height specifics. ........................................

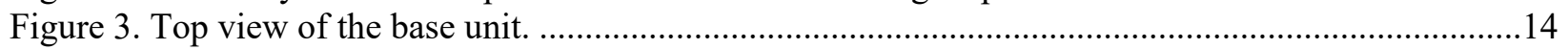

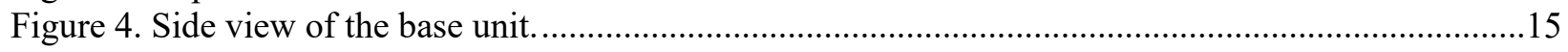

Figure 5. Partial top view of triangular-pitched array in room. ............................................................16

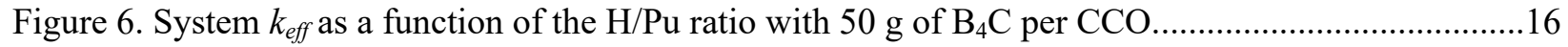

Figure 7. Top and side views of full radial compaction configuration. ................................................18

Figure 8. Results for incorporating $\mathrm{B}_{4} \mathrm{C}$ into the fissile material mixture $(\mathrm{H} / \mathrm{Pu}$ of 200$) \ldots \ldots \ldots \ldots \ldots \ldots \ldots \ldots . . . .18$

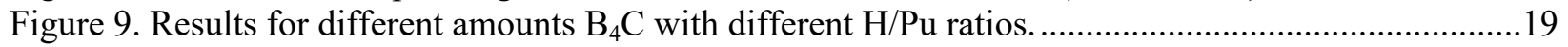

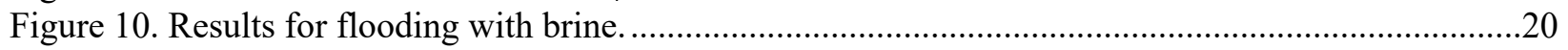

Figure 11. Top and side views of full vertical compaction along with full radial compaction. .................21

Figure 12. Results for full vertical and radial compaction, with and without brine. ................................21

Figure 13. Results for varying the waste mix water/polyethylene content..........................................22

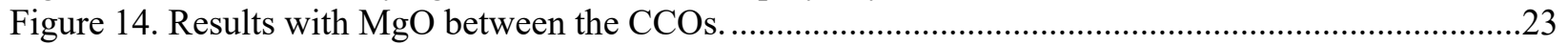

\section{LIST OF TABLES}

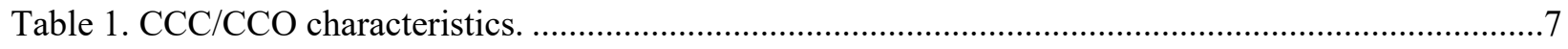

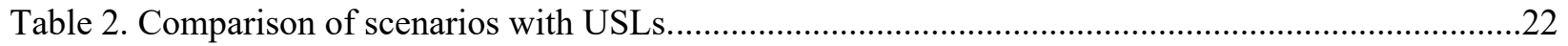

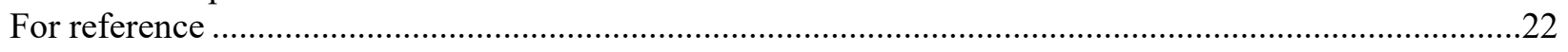

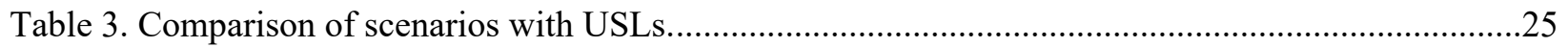

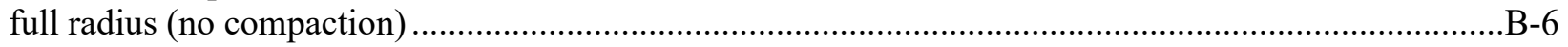





\section{ACRONYMS}

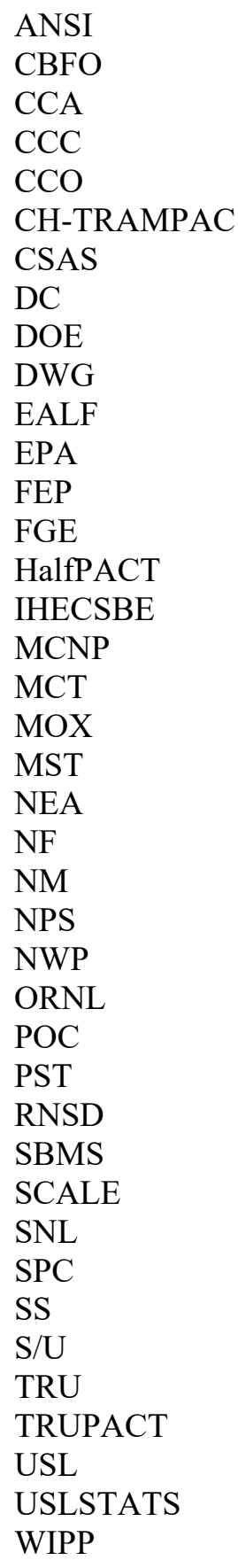

American National Standards Institute

Carlsbad Field Office

Compliance Certification Application

criticality control container

criticality control overpack

Contact-Handled Transuranic Waste Authorized Methods for Payload Control

criticality safety analysis sequence

degraded configuration

US Department of Energy

drawing

energy of average neutron lethargy causing fission

US Environmental Protection Agency

feature, event, and process

fissile gram equivalent

Half-Package Transporter

International Handbook of Evaluated Criticality Safety Benchmark Experiments

Monte Carlo N-Particle code

mixed composition thermal

mixed oxide

mixed solution thermal

Nuclear Energy Agency

nonfissionable

New Mexico

nominal pipe size

Nuclear Waste Partnership, LLC

Oak Ridge National Laboratory

pipe overpack container

plutonium solution thermal

Reactor and Nuclear Systems Division

Systems-Based Management System

Standardized Computer Analysis for Licensing Evaluation

Sandia National Laboratory

specification

stainless steel

sensitivity/uncertainty

transuranic

TRU Package Transporter

upper subcritical limit

Upper Subcritical Limit Statistics

Waste Isolation Pilot Plant 



\section{EXECUTIVE SUMMARY}

The Waste Isolation Pilot Plant (WIPP) provides for safe, permanent disposal of government-owned transuranic (TRU) and TRU mixed wastes. Receipt and disposal of waste at the WIPP site began in March 1999. The Sandia report, Consideration of Nuclear Criticality When Disposing of Transuranic Waste at the Waste Isolation Pilot Plant, addressed potential nuclear criticality safety issues based on the projected inventory characteristics known at the time [1]. As designs for inventory, waste forms, and disposal packages have changed, new analyses have been performed, and updates have been made to address any potential effects to the WIPP safety basis.

New analyses performed include Saylor 2017 [2] and Brickner 2019 [3], which address certain waste containers with specified loadings under post-closure conditions. Both examined several hypothetical scenarios and included analyses to bound (from a criticality potential standpoint) credible configurations that could occur at WIPP during the repository regulatory post-closure disposal time period for feature, event, and process (FEP) considerations-10,000 years. During this post-closure period at WIPP, the screening of FEPs is governed by the risk-based standards and implementing regulations of the US Environmental Protection Agency (EPA) (i.e., 40 CFR 191 and 40 CFR 194, respectively) [4,5]. An FEP screening can be based on either a low-consequence or low-probability rationale. A low-probability rationale includes either (a) a qualitative rationale that the FEP is not credible or (b) a quantitative demonstration that the probability is less than $10^{-4}$ in $10^{4}$ years. In this evaluation, a qualitative lowprobability rationale of not credible is used by demonstrating that bounding configurations of the waste are not critical. The demonstration of subcriticality is through quantitative calculations, but a probability of criticality is not evaluated. Rather, the rationale for this evaluation is that bounding configurations with an effective neutron multiplication factor $\left(k_{e f f}\right)$ well below the upper subcriticality limit (USL) make criticality incredible.

Reference [2] documented a nuclear criticality assessment of the WIPP repository for disposal of dilute surplus plutonium materials using the Dilute and Dispose Approach and packaging in criticality control overpacks (CCOs). The CCO is the waste disposal container recently designed to allow for up to 380 fissile gram equivalent (FGE) ${ }^{239} \mathrm{Pu}$ per drum, which is a higher fissile loading than typical waste containers. The CCO consists of a criticality control container (CCC) positioned by upper and lower plywood spacers within a standard 55 gal drum. The CCC is used to establish a geometry control for fissile materials during transportation and WIPP emplacement operations. The current WIPP waste acceptance criteria for CCO payloads limit beryllium to less than or equal to $1 \%$ by weight of the waste contents and require the waste form to be non-machine compacted.

Reference [2] considered two scenario progressions - room closure from salt creep, hereafter referred to as the reconfigured dry scenario, and flooding with brine, hereafter referred to as the reconfigured wet scenario. The subsequent drying out of the reconfigured wet scenarios was also considered. For all scenarios, subcriticality was maintained when $50 \mathrm{~g}$ of $\mathrm{B}_{4} \mathrm{C}$ (acting as a neutron absorber) per CCC was intermixed within the plutonium disposition waste form. The analysis used a waste form description that limits the amount of moderation that could be present within the waste form (i.e., it limits the amount of water and polyethylene that could be present based on planned processing conditions).

This analysis to evaluate increased limits on the amount of moderation that could be present was performed as a companion to Reference [2] to address concerns associated with verifying moisture and/or plastic contents of waste materials following packaging of dilute surplus plutonium in the CCO. To that end, this analysis used the models and methods from Reference [2] to evaluate a more generic base waste form consisting of water and polyethylene that is more similar (and nearly identical) to the generic waste forms utilized in other models/analyses supporting the TRU Package Transporter Model II (TRUPACTII) safety analysis [6] (all are without moderation controls). The waste form in this analysis uses a base 
mixture of $75 \%$ water and $25 \%$ polyethylene, the total amount of which is varied to determine the optimum moderation to fissile material $(\mathrm{H} / \mathrm{Pu})$ ratio. The fissile loading is maintained at up to $380 \mathrm{FGE}$ ${ }^{239} \mathrm{Pu}$ (modeled as $\mathrm{PuO}_{2}$ ) per $\mathrm{CCO}$ with an additional $545 \mathrm{~g}$ of beryllium (to bound the $1 \%$ by weight contents restriction) and $50 \mathrm{~g}$ of $\mathrm{B}_{4} \mathrm{C}$ intermixed per $\mathrm{CCO}$. The beryllium content ( $1 \%$ by weight) is based on the total allowed waste weight (this does not include packaging and container weights).

Figures ES-1 and ES-2 display summary results, showing that with this model including $50 \mathrm{~g}$ of $\mathrm{B}_{4} \mathrm{C}$ per $\mathrm{CCO}$, the system $k_{\text {eff }}$ remains under 0.85 for all moderator amounts and provides a significant margin against post-closure criticality under postulated bounding conditions for compaction. Figure ES-1 compares an infinite model with a room model at the initial emplacement spacing and under full radial compaction. Full radial compaction places each $\mathrm{CCC}$ in direct contact and does not credit any anticipated spacing associated with current post-closure geomechanical modeling of the repository [7]. The effects of variations in the $\mathrm{H} / \mathrm{Pu}$ ratio were evaluated by varying the amount of the water/polyethylene component of the waste model, with fissile loading maintained at $380{ }^{239} \mathrm{Pu}$ FGE. Similarly, Figure ES-2 illustrates how various amounts of $\mathrm{B}_{4} \mathrm{C}$ per $\mathrm{CCO}$ influence $k_{\text {eff }}$ at different radial compactions, all at the $\mathrm{H} / \mathrm{Pu}$ ratio of 200 (in the room array model). Therefore, while the results from Saylor 2017 [2] modeled more realistic process limits associated with packaging of dilute surplus plutonium, this analysis demonstrates that limits on moderation (plastic and water content) are not necessary to ensure subcriticality in the WIPP repository, provided the requisite $\mathrm{B}_{4} \mathrm{C}$ absorber is present.

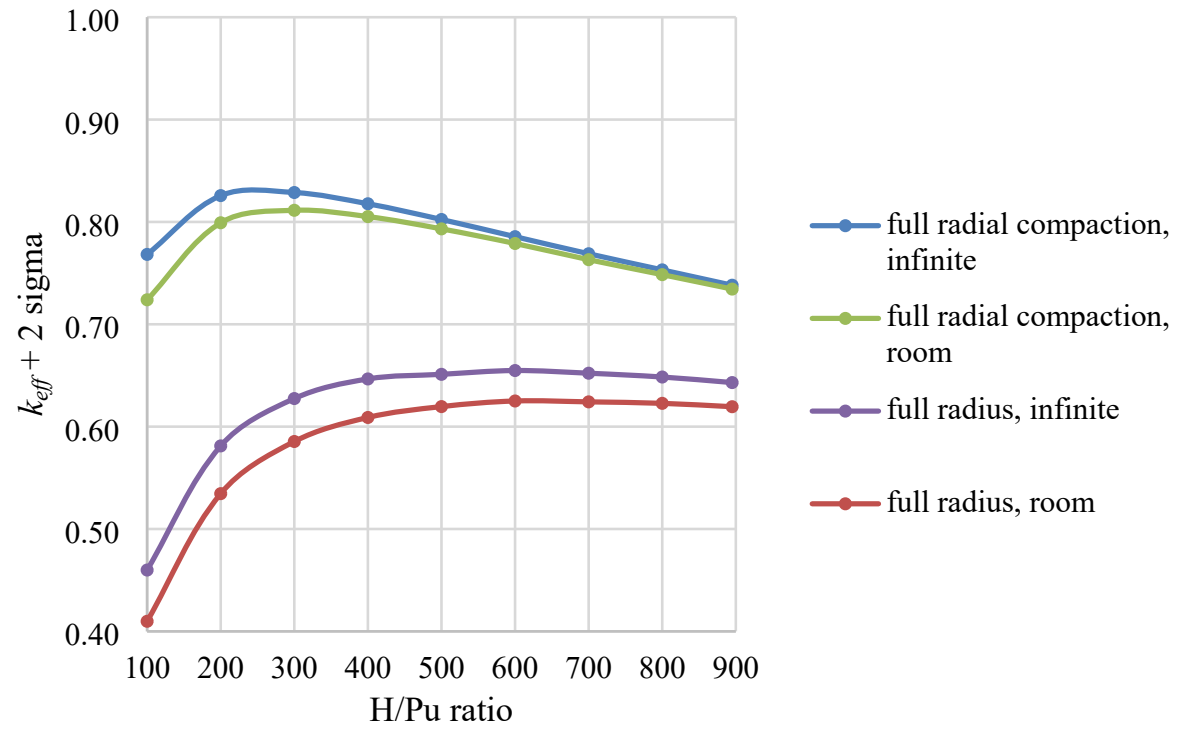

Figure ES-1. System $k_{e f f}$ as a function of the $\mathrm{H} / \mathrm{Pu}$ ratio with $50 \mathrm{~g}$ of $\mathrm{B}_{4} \mathrm{C}$ per CCO. 


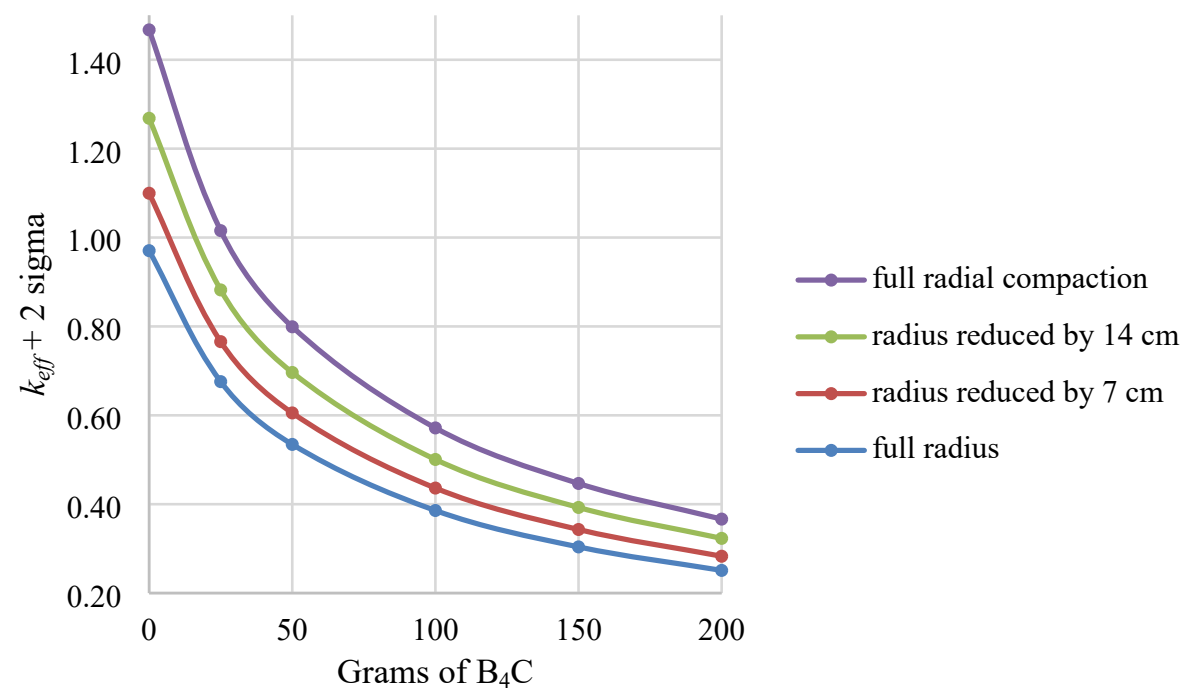

Figure ES-2. Results for incorporating $\mathrm{B}_{4} \mathrm{C}$ into the fissile material mixture (H/Pu of 200).

\section{REFERENCES}

[1] R. Rechard, L. Sanchez, C. Stockman, Holly T. 2000. Consideration of Nuclear Criticality When Disposing of Transuranic Waste at the Waste Isolation Pilot Plant, SAND99-2898, Sandia National Laboratories, Albuquerque, New Mexico.

[2] E. M. Saylor. 2017, Nuclear Criticality Safety Assessment of Potential Disposition at the Waste Isolation Plant, ORNL/TM-2017/751/R1, Oak Ridge National Laboratory, Oak Ridge, Tennessee.

[3] B. Brickner. 2019. Post Placement Nuclear Criticality Evaluations Involving 6- and 12-Inch Pipe Overpack TRU Waste Containers at the Waste Isolation Pilot Plant, ORNL/TM-2019/1222/R0, Oak Ridge National Laboratory, Oak Ridge, Tennessee.

[4] EPA (U.S. Environmental Protection Agency). 1993. 40 CFR Part 191: Environmental Radiation Protection Standards for Management and Disposal of Spent Nuclear Fuel, High-Level and Transuranic Radioactive Wastes; Final Rule, Federal Register. Vol 58, no. 242, 66398-66416.

[5] EPA (U.S. Environmental Protection Agency). 1996. 40 CFR Part 194: Criteria for the Certification and Recertification of the Waste Isolation Pilot Plant's Compliance with the 40 CFR Part 191 Disposal Regulations; Final Rule, Federal Register. Vol 61, no. 28, 5224-5245.

[6] DOE-CBFO. 2013. TRUPACT-II Safety Analysis Report, Revision 23, US Department of Energy, Carlsbad Field Office, Carlsbad, New Mexico.

[7] B. Reedlunn and J. Bean. 2020. Further Simulations of Criticality Control Overpack Container Compaction at the Waste Isolation Pilot Plant, Memorandum to Distribution, Sandia National Laboratories, Albuquerque, New Mexico. 



\section{PURPOSE}

This report documents the post-closure disposal criticality evaluation of a generic waste form without moderation control at the Waste Isolation Pilot Plant (WIPP) using criticality control overpacks (CCOs) and is very similar to a previous report that analyzed a more specific plutonium disposition waste form [1]. This activity supports the viability assessment for geologic disposal of plutonium. Results of this evaluation and others like it will be used to support the Sandia National Laboratory (SNL) future impact assessments of the WIPP repository.

The scope of this assessment is focused on long-term waste disposition in CCOs through the repository's performance period of up to 10,000 years. CCOs are designed to contain fissile gram loadings of up to 380 fissile gram equivalent (FGE) ${ }^{239} \mathrm{Pu}$, which is higher than other waste containers' loadings currently approved for disposal at WIPP. The scenarios analyzed that can impact criticality potential include (1) initial room closure/collapse from initial emplacement, hereafter referred to as the reconfigured dry scenario (dry does not necessarily mean a fast neutron spectrum as there is moderating material within the waste form that can affect the neutron spectrum), and (2) flooding with brine, hereafter referred to as the reconfigured wet scenario. Drying out of the reconfigured wet scenario is also considered. External repository scenarios resulting from potential movement and reconfiguration after a brine intrusion event are also discussed.

The software used to perform the calculations in this report is described in Section 2. Direct inputs that were used in the development of this technical product and for making final conclusions are documented in Section 3. Section 4 describes the assumptions used in the absence of direct confirming data or evidence to perform the modeling and analyses documented in this report. A description of the different analyses performed and the systems, processes, and phenomena considered to assess criticality potential over the WIPP post-closure period are provided in Section 5. Conclusions of this report are documented in Section 6. The appendices are as follows: Appendix A provides information on calculating input specifications for the neutronics analyses; Appendix B documents calculational results; Appendix C provides a listing of how the input and output files for this report are organized; and Appendix D documents the computational model validation. 



\section{SOFTWARE AND CALCULATIONS}

The calculations for this investigation were performed using the SCALE code system [2], version 6.2.3. The Criticality Safety Analysis Sequence (CSAS) with KENO V.a (CSAS5) was used to calculate neutron multiplications factors (k-effective $\left[k_{\text {eff }}\right]$ values). All cases were performed with ENDF/B-VII.1 cross section data in the 252-group library using CENTRM to provide problem-dependent multigroup cross section processing on the Romulus computer cluster. Romulus is maintained under the configuration control of ORNL's Reactor and Nuclear Systems Division (RNSD) staff.

All calculations were run with sufficient numbers of neutron histories (generations, neutrons per generation, and generations skipped) to yield converged results that passed the appropriate statistical checks. Plots of $k_{\text {eff }}$ by generation and $k_{\text {eff }}$ by generation skipped found in the output files showed that the $k_{\text {eff }}$ eigenvalue was essentially flat for all active generations for all cases. Fission source convergence was verified by the Shannon entropy tests. The results are reported as $k_{\text {eff }}$ plus two times the standard deviation (k-effective +2 sigma, or $k_{\text {eff }}+2 \sigma$ ).

As with any computer code/calculation used for safety analyses and assessments, the ability of the calculation methodology to prove a configuration subcritical is obtained through a validation process. Appendix D contains the calculational validation for this report.

All input and output files are available on request as electronic media. 



\section{DATA USED TO DEVELOP MODELS}

The WIPP underground disposal repository consists of multiple salt panels mined from the Salado formation, a 2,000 ft-thick series of salt beds. A typical underground panel includes several rooms, each of which is approximately $33 \mathrm{ft}$ wide by $13 \mathrm{ft}$ high by $300 \mathrm{ft}$ long. Magnesium oxide $(\mathrm{MgO})$ is used as backfill; bags of $\mathrm{MgO}$ are placed on top of and possibly around the container stacks.

The main focus of this report is on the CCOs, but additional waste containers are allowed at the WIPP. Transuranic (TRU) waste is currently authorized to be shipped to the WIPP from DOE generator sites in a limited number of approved shipping containers. The approved contact-handled $(\mathrm{CH})$ Type B shipping packages (for materials with high levels of radioactivity) include the TRU Package Transporter Model II (TRUPACT-II), the Half-Package Transporter (HalfPACT), and the TRUPACT-III. Waste containers shipped in TRUPACT-IIs and HalfPACTs include 55, 85, and 100 gal drums; shielded containers; standard waste boxes; ten-drum overpacks; CCOs; and pipe configurations overpacked in 55 gal drums. The standard large box is shipped in the TRUPACT-III. Documents containing the transportation analyses include container descriptions and nuclear criticality safety evaluations for these various containers. These documents include the following:

- $\quad$ TRUPACT-II Safety Analysis Report [3],

- Contact-Handled Transuranic Waste Authorized Methods for Payload Control (CH-TRAMPAC) [4], and

- $\quad$ CH-TRU Payload Appendices [5].

The following sections discuss the information used to develop the calculational models.

\subsection{WASTE CONTAINERS}

\subsubsection{CCO}

The CCO consists of a criticality control container (CCC) within a standard 55 gal drum held in place by laminated plywood dunnage assemblies (Figure 1). Criticality Control Overpack [6] is a drawing of the container and Specification for Fabrication of the Criticality Control Overpack [7] is the container's specification document. The CCC is a stainless-steel schedule 40 cylindrical pipe (nominal pipe size/diameter of 6 in. [NPS 6]) constructed of 304 stainless steel with a blind flange welded bottom cap and a blind flange bolted to a slip-on flange, with a gasket providing a sealed lid. 


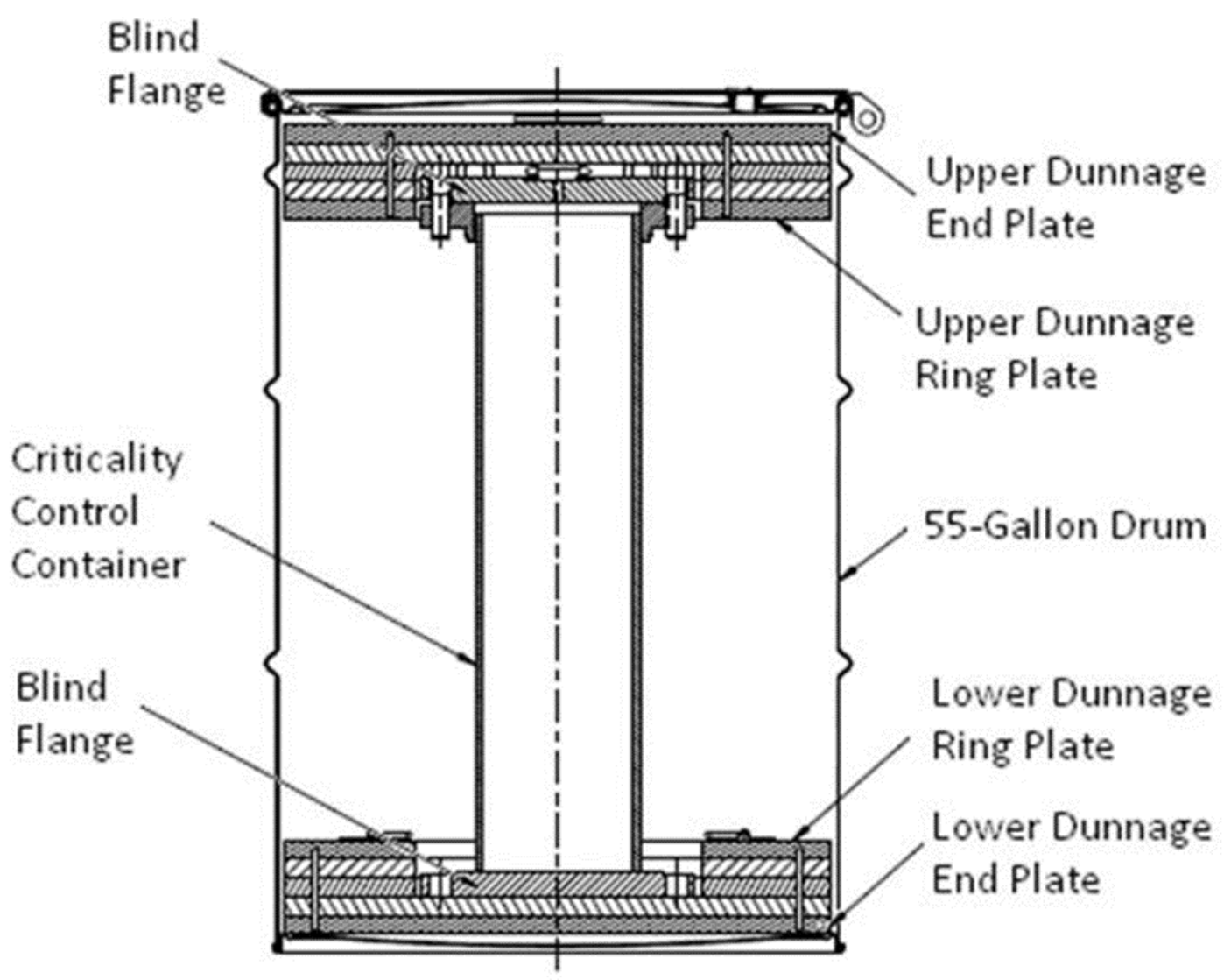

Figure 1. Criticality control overpack.

CCOs are typically handled in seven-pack arrangements for transport and storage. This is similar to the method used for handling 55 gal drums. The seven-packs of drums are stacked two high inside TRUPACT-II containers for transport and are stacked three high for disposal at WIPP.

Criticality safety analyses for the transport and initial emplacement of CCOs already exist. Criticality Control Overpack Criticality Analysis for TRUPACT-II and HalfPACT, 01937.01.M009-1 [8], is the criticality safety analysis for transport of CCOs, and Nuclear Criticality Safety Evaluation for ContactHandled Transuranic Waste Containers at the Waste Isolation Pilot Plant, WIPP-016 [9], is the criticality safety analysis for initial emplacement and storage of CCOs at WIPP.

A base calculational model was developed from the $\mathrm{CCC} / \mathrm{CCO}$ drawings [6] and specifications [7] in Reference [1]. Table 1 lists the dimensions. The $\mathrm{CCC} / \mathrm{CCO}$ dimensions were relied on only as a starting point before the room closes in and the geometry begins to change. 
Table 1. CCC/CCO characteristics.

\begin{tabular}{|c|c|c|c|}
\hline & Inches & Centimeters & Notes \\
\hline \multicolumn{4}{|c|}{ CCO characteristics } \\
\hline Outer diameter & 22.618 & 57.45 & \multirow{2}{*}{$\begin{array}{l}\text { Inner diameter plus wall thickness from CQ5508A5 }{ }^{a} \\
(0.15 \mathrm{~cm} / 0.0590 \text { in. [16 gauge] })\end{array}$} \\
\hline Outer radius & 11.309 & 28.725 & \\
\hline Inner diameter & 22.50 & 57.15 & \multirow[t]{2}{*}{ From CCO-DWG-0001R3 } \\
\hline Inner radius & 11.25 & 28.575 & \\
\hline Wall/top/bottom thickness & 0.059 & 0.15 & 0.0543 to 0.0590 in.) \\
\hline $\begin{array}{l}\text { Outside height (including bolt } \\
\text { ring) }\end{array}$ & $34.75^{b}$ & 88.265 & $\begin{array}{l}\text { Outside height of drum from CQ5508A5 }{ }^{a}(34.25 \mathrm{in} .)+0.5 \mathrm{in} . \\
\text { (conservative underestimate of height added from bolt ring) }\end{array}$ \\
\hline $\begin{array}{l}\text { Outside height (drum only, not } \\
\text { including additional height } \\
\text { from bolt ring) }\end{array}$ & 34.25 & 86.995 & $\begin{array}{l}\text { From CQ5508A5, includes additional height from curvature } \\
\text { of top and bottom of drum (underestimate of } 0.691 \text { in. for } \\
\text { each) and top and bottom thickness }\end{array}$ \\
\hline $\begin{array}{l}\text { Inner height (at outermost } \\
\text { edge) }\end{array}$ & 32.75 & 83.185 & $\begin{array}{l}\text { From CCO-DWG-0001R3 (does not include drum top and } \\
\text { bottom thickness) }\end{array}$ \\
\hline Material & \multicolumn{3}{|r|}{ Carbon steel } \\
\hline \multicolumn{4}{|c|}{ CCC characteristics } \\
\hline Outer diameter & 6.625 & 16.8275 & \multirow{2}{*}{$\begin{array}{l}\text { From CCO-DWG-0001R3, nominal pipe size (NPS) } 6 \text {, } \\
\text { SCH } 40\end{array}$} \\
\hline Outer radius & 3.3125 & 8.4138 & \\
\hline Wall thickness & 0.28 & 0.7112 & \multirow{3}{*}{ Outer dimension minus wall thickness } \\
\hline Inner diameter & 6.065 & 15.4051 & \\
\hline Inner radius & 3.0325 & 7.7026 & \\
\hline Flange thickness & 1.0 & 2.54 & \multirow{3}{*}{$\begin{array}{l}\text { From CCO-DWG-0001R3, CLASS } 150 \text {, NPS } 6 \text {, top and } \\
\text { bottom (diameter/radius may be modeled same as CCC pipe } \\
\text { outer dimension) }\end{array}$} \\
\hline Flange diameter & 11.02 & 27.9908 & \\
\hline Flange radius & 5.51 & 13.9954 & \\
\hline Ring gasket & $1 / 16$ & 0.1588 & From CCO-DWG-0001R3, NPS 6, 1/16 THK \\
\hline Cavity height & 26.9425 & 68.4340 & $\begin{array}{l}\text { From CCO-DWG-0001R3 }(26.50+0.38+(1 / 16 \text { in. }) \text {, includes } \\
\text { additional space from gasket }\end{array}$ \\
\hline Material & & & $\begin{array}{l}\text { From CCO-DWG-0001R3, stainless steel 304, use code } \\
\text { standard composition }\end{array}$ \\
\hline
\end{tabular}

\begin{tabular}{|c|c|c|c|}
\hline \multicolumn{4}{|c|}{ Dunnage characteristics } \\
\hline Thickness & $3 / 4$ & 1.905 & \multirow{3}{*}{$\begin{array}{l}\text { From CCO-DWG- } 0001 \mathrm{R} 3 \text {, all plates (total of } 10 \text { plates }-2 \\
\text { end and } 3 \text { ring plates on bottom and } 2 \text { end and } 3 \text { ring plates on } \\
\text { top }\end{array}$} \\
\hline Outer diameter & 22.0 & 55.88 & \\
\hline Outer radius & 11.0 & 27.94 & \\
\hline Ring plate inner diameter & 11.5 & 29.21 & From CCO-DWG-0001R3 \\
\hline Ring plate inner radius & 5.75 & 14.605 & \\
\hline Material & & & $\begin{array}{l}\text { Plywood with density of } 0.387 \mathrm{~g} / \mathrm{cm}^{3} \text { (SCALE redwood } \\
\text { standard composition) }\end{array}$ \\
\hline
\end{tabular}

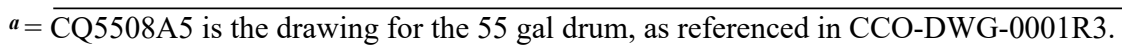

$\boldsymbol{b}=$ The total drum height ( $34.75 \mathrm{in}$.) includes the spacing created by the curvature of the top and bottom of the drum and the spacing created by the bolt ring. 
The total drum height (34.75 in., listed as outside height in Table 1) is modeled as follows:

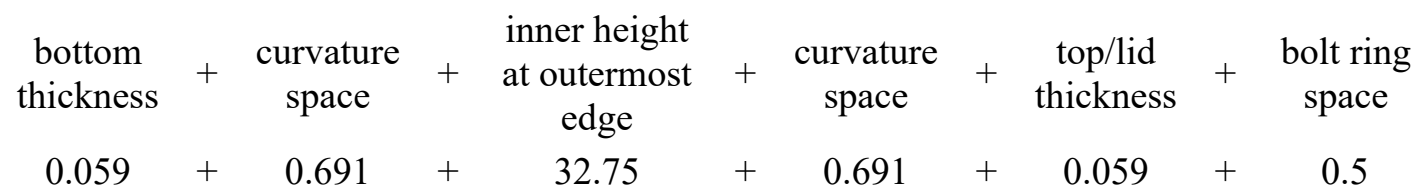

The inner drum height (32.75 in.) is modeled as follows:

$$
\begin{aligned}
& \begin{array}{c}
\text { bottom } \\
\text { end plate } \\
\text { dunnage }
\end{array}+\begin{array}{c}
\text { bottom } \\
\text { flange }
\end{array}+\begin{array}{c}
\text { cavity } \\
\text { height }
\end{array}+\underset{\text { flange }}{\text { top }}+\underset{\text { space }}{\text { ring }}+\underset{\text { plate }}{\text { dunnage }}+\underset{\text { hoist }}{\text { top end }}+\underset{\text { handle }}{\text { space }} \\
& 1.5+1.0+26.9425+1.0+0.5+1.5+0.3075
\end{aligned}
$$

Figure 2 shows an approximation of the total drum height and the inner drum height in relation to Figure 1. The handle located above the top end plate dunnage requires approximately $0.5 \mathrm{in}$. of vertical space. Even though this handle space puts the inner drum's height at greater than 32.75 in., it does not create an issue because the handle is at the center; the actual space available includes the spacing created by the upper curvature of the drum lid.

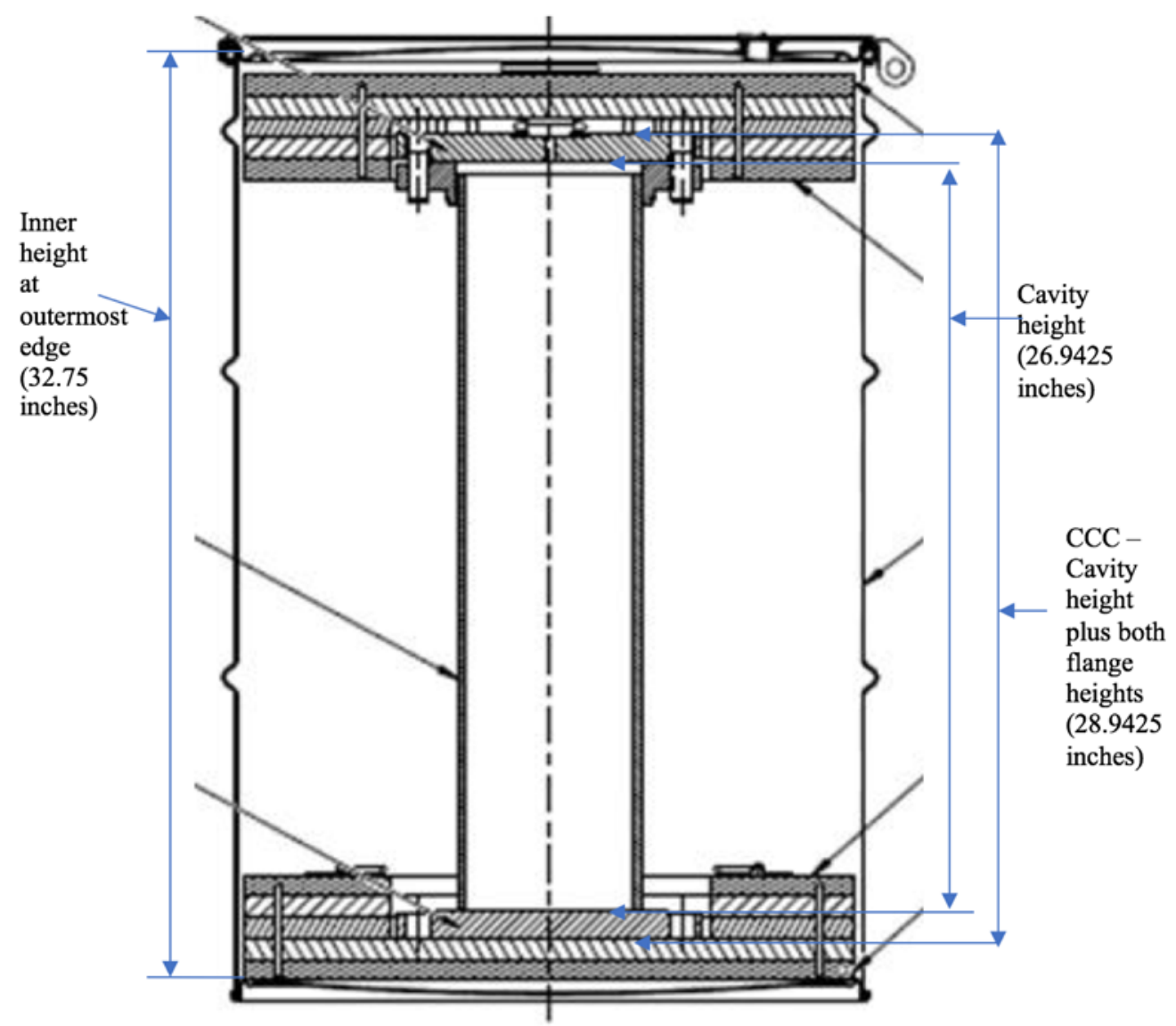

Figure 2. Criticality control overpack total and inner drum height specifics. 


\subsection{WASTE FORM}

The fissile material present in the waste form was quantified in terms of ${ }^{239} \mathrm{Pu}$ FGE and was specified in the calculational models as ${ }^{239} \mathrm{Pu}$. This is consistent with fissile material loadings specified in the TRUPACT-II Safety Analysis Report [3] and in the specifications and calculations in its associated documents and container analyses. ${ }^{239} \mathrm{Pu}$ was used to bound all fissile isotopes that could be present. For compliance purposes, fissile isotopes other than ${ }^{239} \mathrm{Pu}$ were converted to ${ }^{239} \mathrm{Pu}$ FGE using fissile gram equivalents that can be found in the Contact-Handled Transuranic Waste Authorized Methods for Payload Control, CH-TRAMPAC [4]. This is also considered bounding of decay and isotopic changes to the fissile material that would occur over the disposal period.

The waste form model in this analysis is more generic than the plutonium disposition waste form in Reference [1] and is more similar to the generic waste form in Reference [8] and Reference [9] as well as the other models used for analyses supporting the TRUPACT-II safety analysis [3]. All of the generic waste models supporting the TRUPACT-II safety analysis are a mixture of water and polyethylene with beryllium added to bound any special moderators that might be present. The water/polyethylene mixture is considered bounding of all types of waste; therefore, there are no restrictions or requirements on the specific makeup of the waste form outside of the fissile material, beryllium, and $\mathrm{B}_{4} \mathrm{C}$ content. The waste form modeled in this analysis is a mixture of $75 \%$ water and $25 \%$ polyethylene (modeled as $\mathrm{CH}_{2}$ ). Variations of $100 \%$ water and $100 \%$ polyethylene were also considered for comparison. The amount of fissile material per container is $380 \mathrm{FGE}{ }^{239} \mathrm{Pu}$, modeled as $\mathrm{PuO}_{2}$, mixed homogeneously with the other materials. The total amount of the water/polyethylene mixture per container is varied to determine the optimum moderation to fissile material $(\mathrm{H} / \mathrm{Pu})$ ratio. See Appendix A for discussions on how the material mixture make-up was determined.

The waste form in this analysis uses a base mixture of $75 \%$ water and $25 \%$ polyethylene, the total amount of which is varied to determine the optimum moderation to fissile material $(\mathrm{H} / \mathrm{Pu})$ ratio.

For closure scenarios, a neutron absorber is added to the models in order to ensure subcriticality. The neutron absorber is modeled as different amounts of $\mathrm{B}_{4} \mathrm{C}$ in support of process optimization considerations, with the boron content considered as natural boron $\left(19.9 \mathrm{wt} \%{ }^{10} \mathrm{~B}, 80.1 \mathrm{wt} \%{ }^{11} \mathrm{~B}\right)$.

Other waste containers typically allow beryllium to be included for up to $1 \%$ by weight of the waste content $[3,4,5]$ and may also be present in oxide form. As listed in Reference [4], the empty weight for a CCO was $104.3 \mathrm{~kg}(230 \mathrm{lb})$, with a maximum gross weight of $158.8 \mathrm{~kg}(350 \mathrm{lb})$, which resulted in a maximum waste weight of $54.5 \mathrm{~kg}$. The beryllium content ( $1 \%$ by weight) is based on the total allowed waste weight (does not include packaging and container weights). Therefore, the 1\%-by-weight limit for beryllium was determined to be $545 \mathrm{~g}$, which is consistent with other container limits. Cases were run with $545 \mathrm{~g}$ of beryllium per CCO intermixed in the waste form.

The waste form used for this criticality assessment can be described as follows:

- $\quad$ maximum of $380 \mathrm{FGE}{ }^{239} \mathrm{Pu}$ per $\mathrm{CCO}$;

- maximum beryllium content of $545 \mathrm{~g}$ per CCO;

- no restriction on the amount of water or polyethylene present in the CCO;

- minimum credited $\mathrm{B}_{4} \mathrm{C}$ content, intermixed within the waste form, of $50 \mathrm{~g}$ per $\mathrm{CCO}$; and 
- no restrictions or requirements on the specific makeup of the waste form outside of the fissile material, beryllium, and $\mathrm{B}_{4} \mathrm{C}$ content.

\subsection{BRINE INTRUSION}

The most significant potential for brine intrusion results from human intrusion events that would involve borehole drilling into the disposal area and a postulated underlying source of pressurized brine. See Section 5.3 for more details. Therefore, brine intrusion (flooding) scenarios modeled the intruding fluid as a saturated brine (water with salt). The saturated brine composition was modeled based on the geochemistry of the area [10], with a molality of $5.98 \mathrm{~mol}$ of salt $/ \mathrm{kg}$ of $\mathrm{H}_{2} \mathrm{O}$. See Appendix A for the number densities. 


\section{ASSUMPTIONS}

\subsection{SCENARIOS TO BE CONSIDERED/MODELED}

Assumption: Scenarios considered/modeled were post-closure scenarios involving changes to static storage after initial emplacement.

Basis: Utilizing same assumptions/justifications as in Reference [1].

\subsection{GEOMETRY AFTER ROOM CLOSURE}

Assumption: The CCC geometry was assumed to remain in a cylindrical configuration for the reconfigured dry room closure scenarios.

Basis: Utilizing same assumptions/justifications as in Reference [1]. 



\section{ANALYSIS DISCUSSION}

This report documents a supplemental analysis to Reference [1] to document the ability of the $50 \mathrm{~g} \mathrm{~B}_{4} \mathrm{C}$ to maintain a system $k_{\text {eff }}$ of less than 1.0 during post-closure conditions with no restrictions on the amount of water or polyethylene. This report investigates scenarios associated with long-term storage of the generic water/polyethylene waste form in CCOs at WIPP over a 10,000 year performance period following closure (after transport and initial emplacement). The configurations used to determine the system $k_{\text {eff }}$ for various amounts of moderation are provided in the subsequent sections.

\subsection{CONFIGURATIONS MODELED}

This investigation focuses on configurations after repository closure (same as Reference [1]), when the salt will creep/collapse around the containers [11]. The combination of room collapse and drum collapse results in an infinite number of possible changes to the geometric arrangement. Similar to what was done in Reference [1], this report analyzes uniform closure scenarios for two different configurations - infinite array and triangular-pitched array room models - to assess the impact of room closure effects on system $k_{\text {eff. }}$

Two scenarios were evaluated in Reference [1]: post-closure scenarios of room closure from salt creep (referred to as the reconfigured dry scenario), and flooding with brine [11] (referred to as the reconfigured wet scenario). Even though brine is expected to reduce the system $k_{\text {eff }}$, as shown in References [1] and [12], it is included in this report since it leads to further container degradation and array compaction which are expected to increase the system $k_{\text {eff. }}$ To support these investigations, some modeling simplifications were implemented that result in a net increase in the system $k_{\text {eff }}$ and are thus conservative for the intended application. They are the same simplifications used in Reference [1] and are summarized below.

Models are either an infinite array of CCOs or a defined room model (disposal room) filled with CCOs. Common modeling attributes of the different configuration categories are as follows:

- Salt (halite) floors and ceilings were included, with a nominal thickness of $10 \mathrm{ft}$ at a density of 135.2 $\mathrm{lb} / \mathrm{ft}^{3}\left(2.165 \mathrm{~g} / \mathrm{cm}^{3}\right)$; when included, walls were modeled in the same manner.

- A 25 in.-thick continuous layer of $\mathrm{MgO}$ was modeled above the top layer of drums, between the drums and the salt ceiling, at a density of $90.5 \mathrm{lb} / \mathrm{ft}^{3}\left(1.45 \mathrm{~g} / \mathrm{cm}^{3}\right)$, to account for the $\mathrm{MgO}$ supsersacks. This is consistent with the models used in the analysis for initial emplacement [8] and in Reference [1].

- Due to the exclusion of the carbon steel in the CCO drum and the plywood dunnage, the calculations documented in this report are simplified to model the waste containers as having the CCC height only. The actual initial CCO height (drum height) would also include voids created by the container structure (e.g., the bolt ring, lift attachments, curvature of the container top and bottom, as described and shown in Section 3). Substantial structure to maintain these spaces long term would be limited by the use of thin carbon steel. The omission of the plywood dunnage and the carbon steel CCO drum resulted in the drum height being modeled as the CCC height $(28.9425 \mathrm{in} .[73.514 \mathrm{~cm}])$.

- The 304 stainless steel of the CCC was modeled.

- The full flange diameter was not modeled. Instead, the flange was modeled with the diameter of the CCC. Since the flange diameter is larger than the pipe diameter, the presence of the full flange 
diameter would result in increased spacing between fissile material units and more material to interfere with neutron interaction, so omitting it is considered conservative for criticality analyses.

- $\quad$ The water/polyethylene waste form with $380 \mathrm{FGE}{ }^{239} \mathrm{Pu}$ was modeled in all CCCs.

- The waste form was centered axially in each CCC.

- CCCs were modeled as being stacked three high.

- No credit (i.e., negative reactivity benefit) was taken (modeled) for any inner, smaller metal containers.

Reference [1] showed two different configurations with the above simplifications - an infinite-array model and a triangular-pitched-array room model — as bounding of the scenarios analyzed. Brief descriptions of each model follow.

Infinite Array Model. Because the size of the disposal room is so large - approximately $33 \mathrm{ft}$ wide by $300 \mathrm{ft}$ long by $13 \mathrm{ft}$ high - this configuration represents the room as a triangular-pitched array infinite in the $x$ and $y$ directions. An infinite array was simulated by placing mirror reflection boundaries on the sides ( $x$ and $y$ directions) of the base unit. Figure 3 and Figure 4 show the top and side views, respectively, of the array base unit.

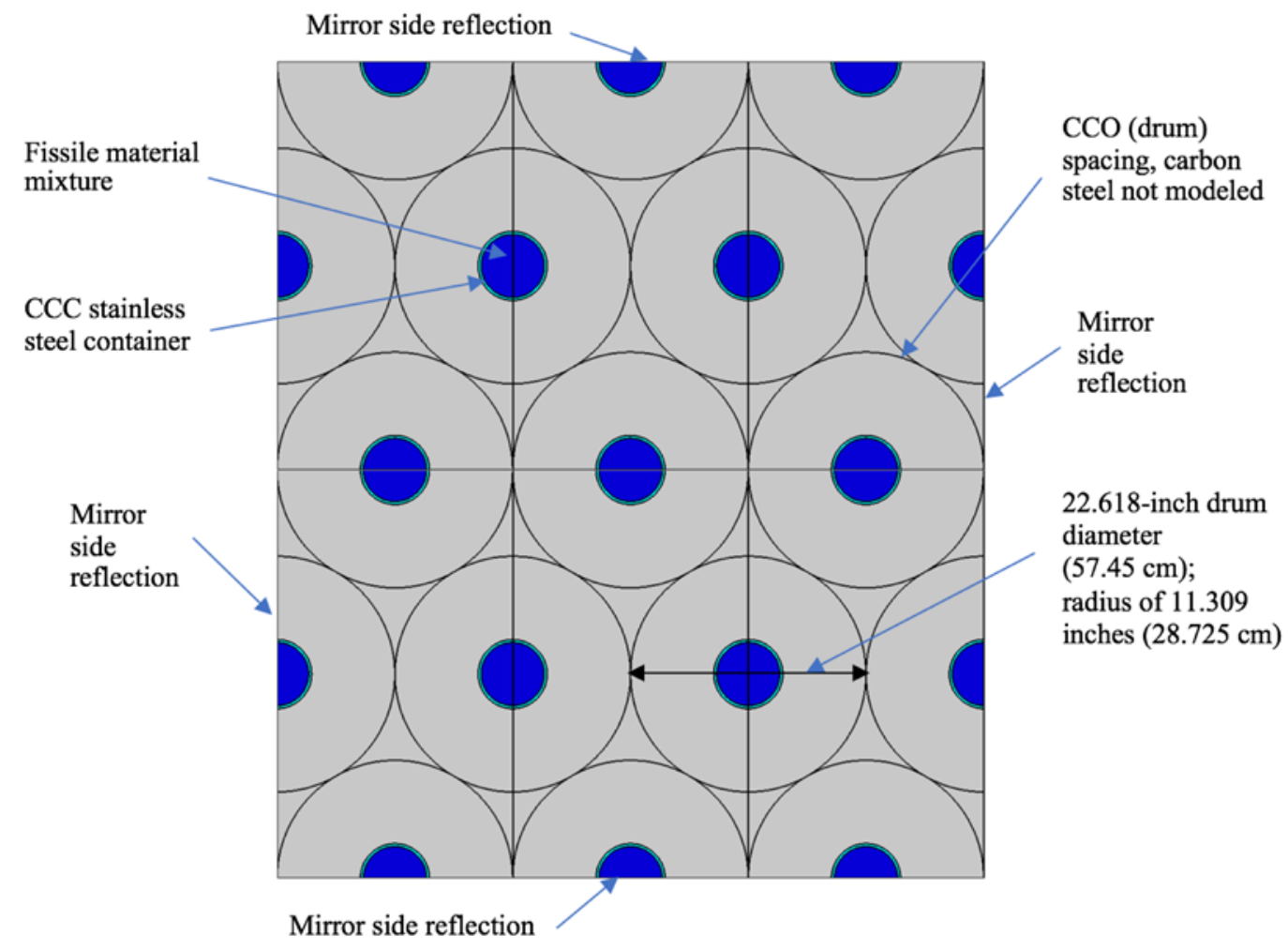

Figure 3. Top view of the base unit. 


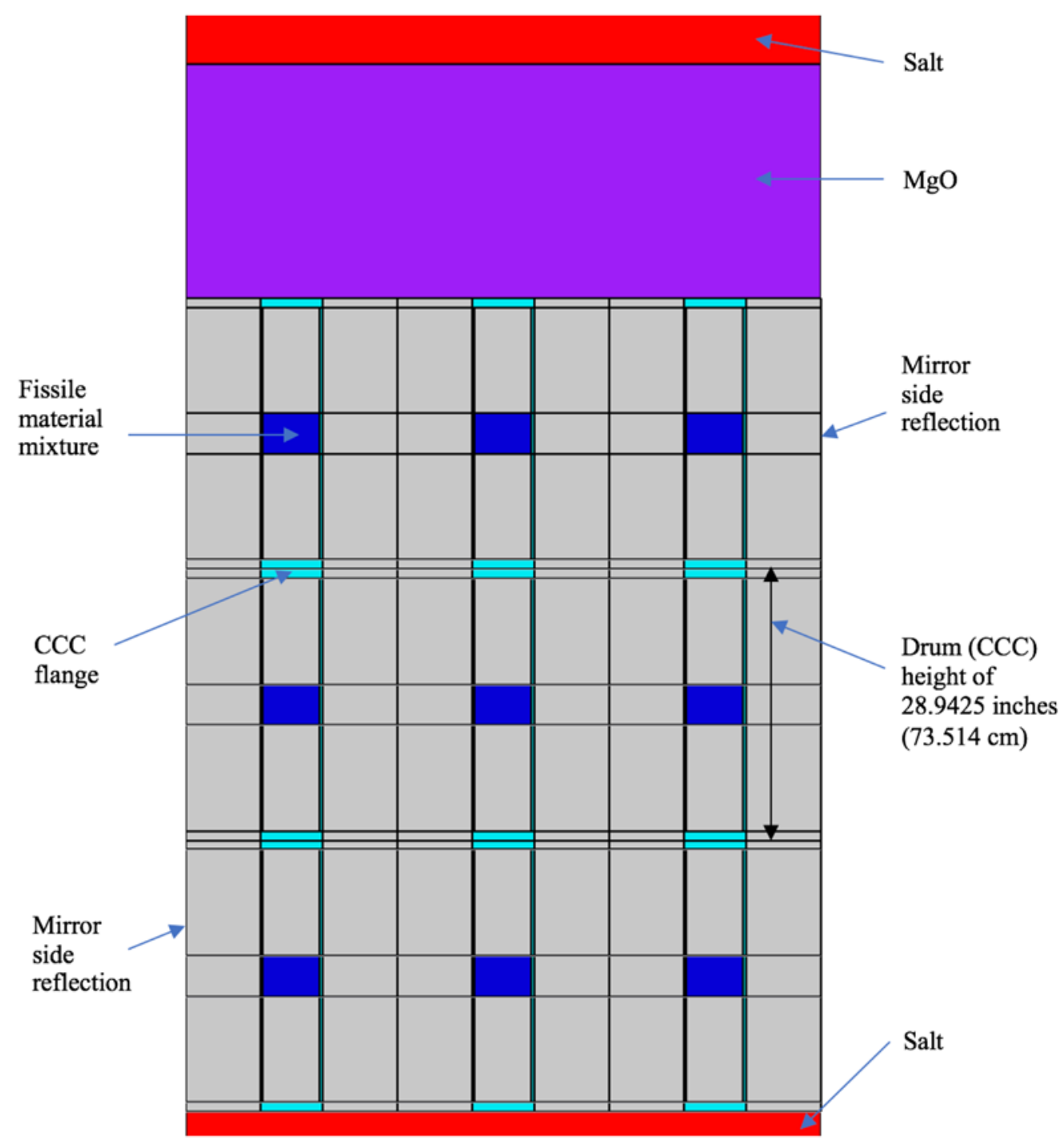

Figure 4. Side view of the base unit.

As shown in Figure 4, the fissile material waste form (or item) was modeled in the center of each CCC. This modeling arrangement is consistent with the existing analyses for handling and initial storage at the WIPP [9]. No credit (i.e., negative reactivity) was taken for the fissile material mixture container; no inner container(s) (inside the CCC) was/were modeled. The fissile material waste form was modeled as a cylinder with a diameter equal to the inner diameter of the CCC: $6.065 \mathrm{in}$. $(15.4052 \mathrm{~cm})$. This model does not account for neutron leakage in the $x$ or $y$ directions that would be caused by walls around a finite array (finite room model).

The modeled room height of $\sim 9.3 \mathrm{ft}$ was three times the modeled drum height $(\sim 7.2 \mathrm{ft}[220.6 \mathrm{~cm}])$ plus the $\mathrm{MgO}$ height $(\sim 2.1 \mathrm{ft}[63.5 \mathrm{~cm}])$ and was the same for all configurations.

Triangular-Pitched Array Room Model. This model takes the infinite array model and adds walls to account for side neutron leakage. The size of the modeled room is based on the initial room dimensions as described in Reference [1]. Figure 5 shows a partial top view of this configuration. 


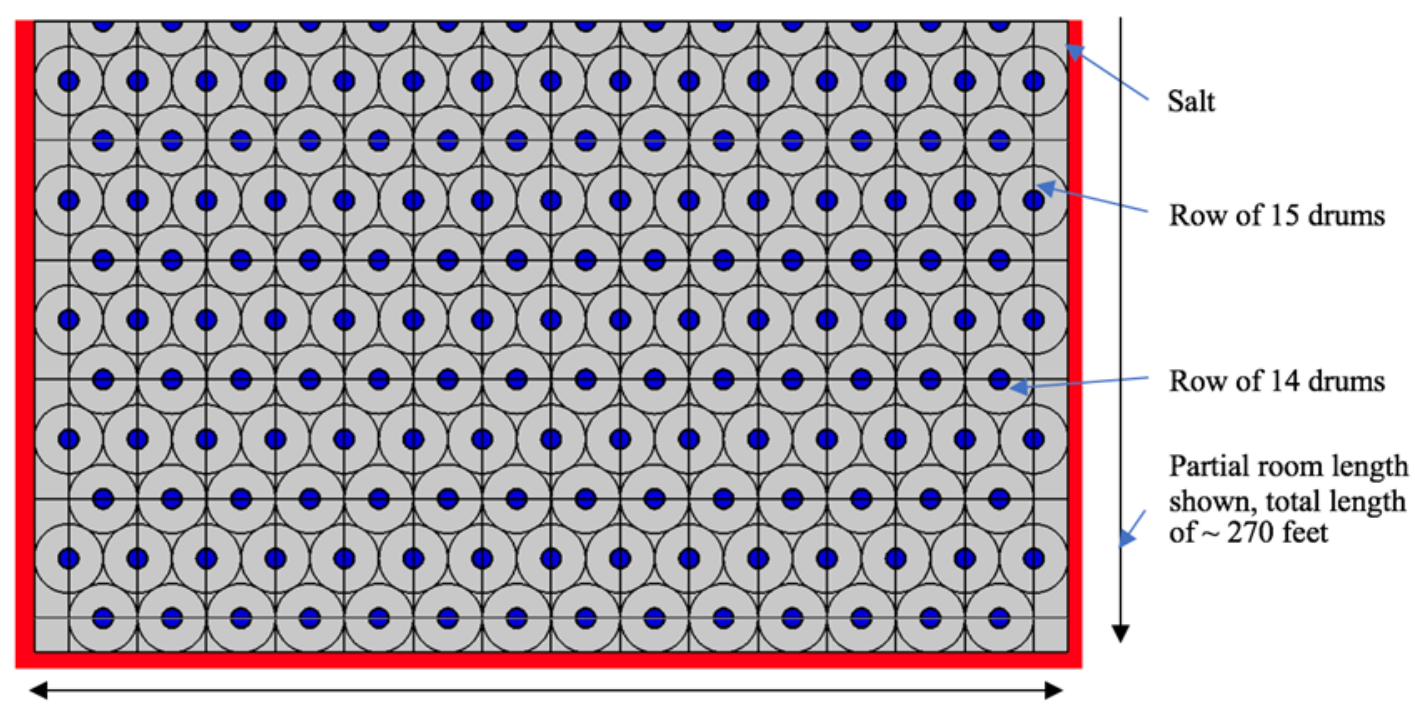

Room width of $\sim 28$ feet

Figure 5. Partial top view of triangular-pitched array in room.

The drums are arranged in alternating rows of 14 and 15 drums across. The room was modeled with a width of $\sim 28 \mathrm{ft}$ and includes 83 rows of drums 14 across, alternating with 82 rows of drums 15 across, which totals to $7,176 \mathrm{drums}$ and gives a room length of $\sim 270 \mathrm{ft}$.

Both the infinite-array and the triangular-pitched (room) array were modeled with the water/polyethylene waste model. The amount of the water/polyethylene mixture modeled per CCC was varied to show how the system $k_{\text {eff }}$ changed as the $\mathrm{H} / \mathrm{Pu}$ ratio was varied. Figure 6 shows the results.

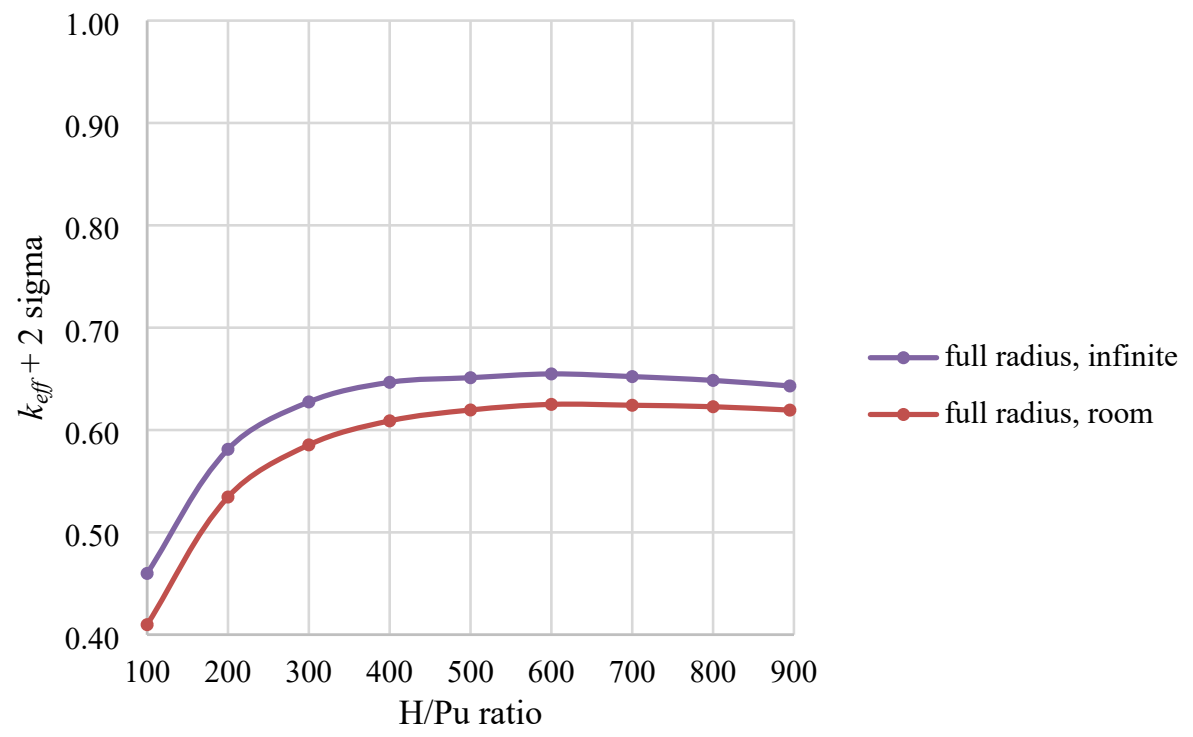

Figure 6. System $\boldsymbol{k}_{\text {eff }}$ as a function of the $\mathrm{H} / \mathrm{Pu}$ ratio with $50 \mathrm{~g}$ of $\mathrm{B}_{4} \mathrm{C}$ per $\mathrm{CCO}$.

As shown in Figure 6, the more realistic room configuration has a lower system $k_{\text {eff }}$, through out the range of $\mathrm{H} / \mathrm{Pu}$ ratios. 


\subsection{RECONFIGURED DRY SCENARIOS}

\subsubsection{CCOs}

Reference [1] showed that the system $k_{\text {eff }}$ increases with decreases in the $x$ and $y$ direction spacing and then increases further with decreases in the $z$ direction spacing. The dry scenarios modeled here show the same trend.

Evaluations were performed by starting with a geometric arrangement representative of the as-emplaced configuration and then incorporating the effects caused by salt pushing the containers together, compressing or compacting the model by decreasing the spacing between fissile materials. These cases assumed that the CCC remains intact (see Assumption 4.2) with the spacing changes in the radial direction. The infinite array easily bounds this scenario, but it does not account for neutron leakage at the room's walls. Hence it is considered overly conservative. The full room triangular-pitched array takes credit for the room leakage, so the three-high triangular-pitched array with CCC pitch at $16.8 \mathrm{~cm}$, in which CCCs are touching in vertical and radial directions, is identified as the limiting dry design basis configuration for simulating a disposal room full of CCOs. Figure 7 shows top and side views of this configuration. Due to dry conditions, no mechanism has been identified to degrade the CCC such that the vertical spacing would decrease in these dry scenarios. These cases are recognized as being very conservative since they do no credit any geomechanical models that demonstrate nonuniform closure with some spacing between CCOs. That analysis will be covered in other evaluations.

Radial compaction was modeled in steps: full radius (as shown in Figure 4 and Figure 5), radius decreased by $7 \mathrm{~cm}$, radius decreased by $14 \mathrm{~cm}$, and radius decreased by $20 \mathrm{~cm}$ (full compaction with CCCs touching, as shown in Figure 7). The amount of $\mathrm{B}_{4} \mathrm{C}$ added to the waste mixture was varied from zero to $200 \mathrm{~g}$ per CCC. The results are shown in Figure 8. These cases all use the room model with an $\mathrm{H} / \mathrm{Pu}$ of 200 . 

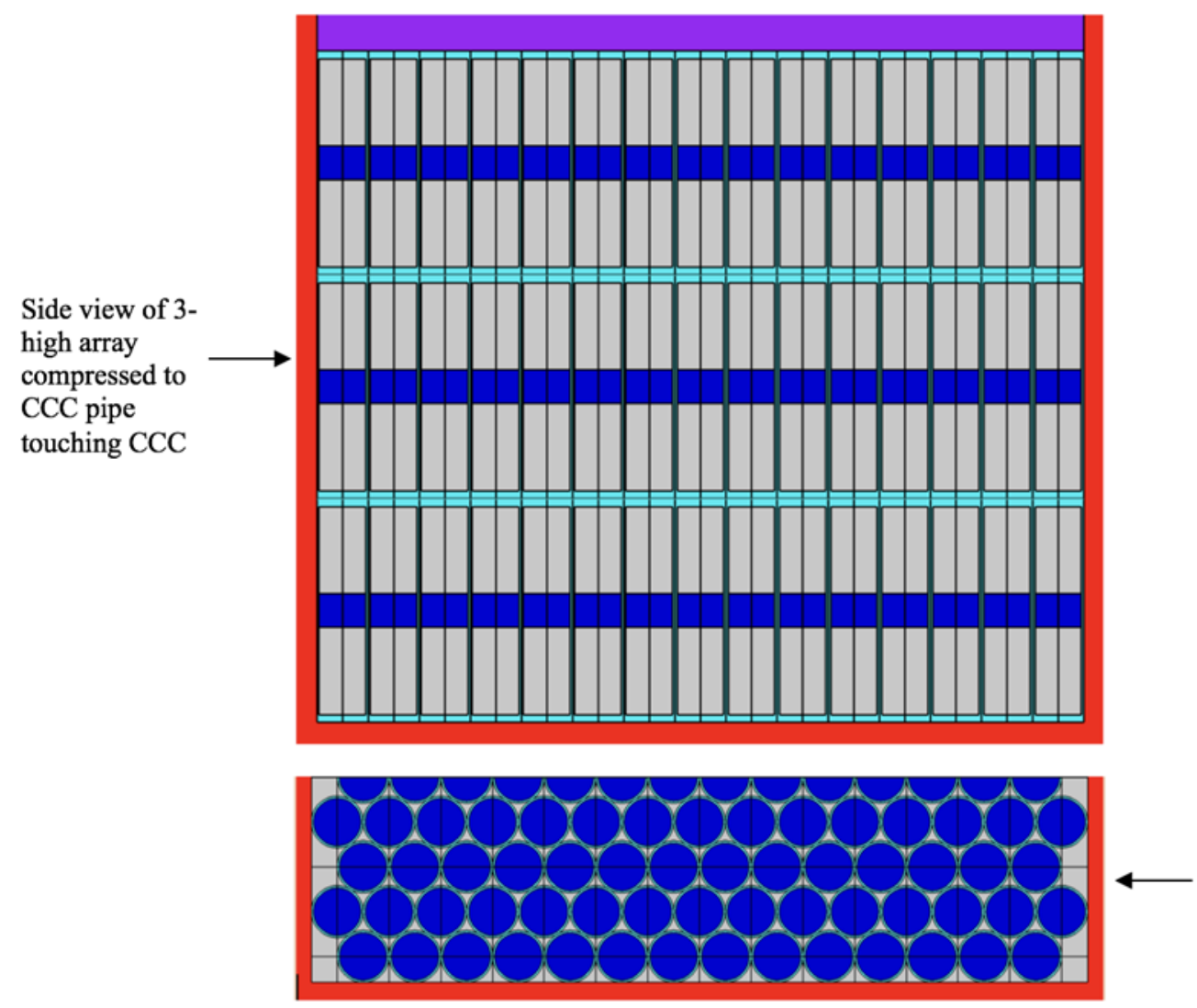

Top view cut-out of triangular-pitched array compressed to CCC pipe touching CCC pipe

Figure 7. Top and side views of full radial compaction configuration.

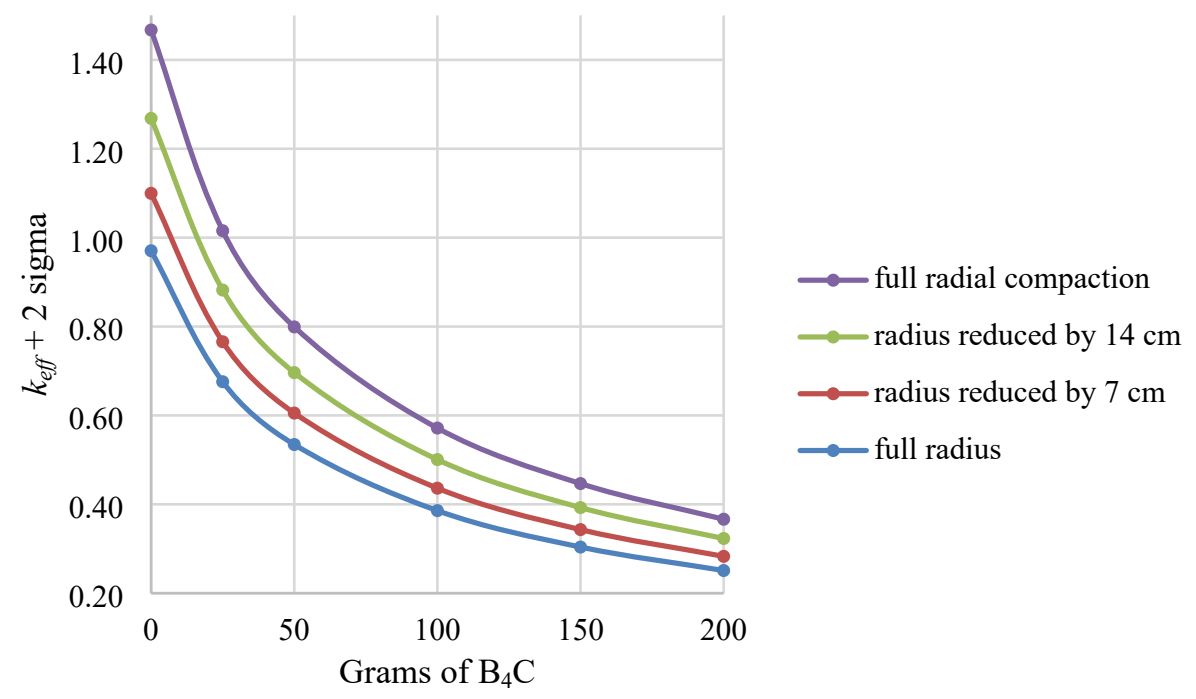

Figure 8. Results for incorporating $\mathrm{B}_{4} \mathrm{C}$ into the fissile material mixture (H/Pu of 200).

The cases presented in Figure 8 show that, with $50 \mathrm{~g}$ of $\mathrm{B}_{4} \mathrm{C}$ mixed with the waste form, the $k_{\text {eff }}$ for all spacing configurations is less than 1.0. 
For comparison, the full radial compaction room array model was analyzed at different $\mathrm{H} / \mathrm{Pu}$ ratios with different amounts of $\mathrm{B}_{4} \mathrm{C}$, ranging for 25 to $200 \mathrm{~g}$. Figure 9 shows how the results are clustered; the optimum $\mathrm{H} / \mathrm{Pu}$ ratio is approximately 300 (no vertical compaction).

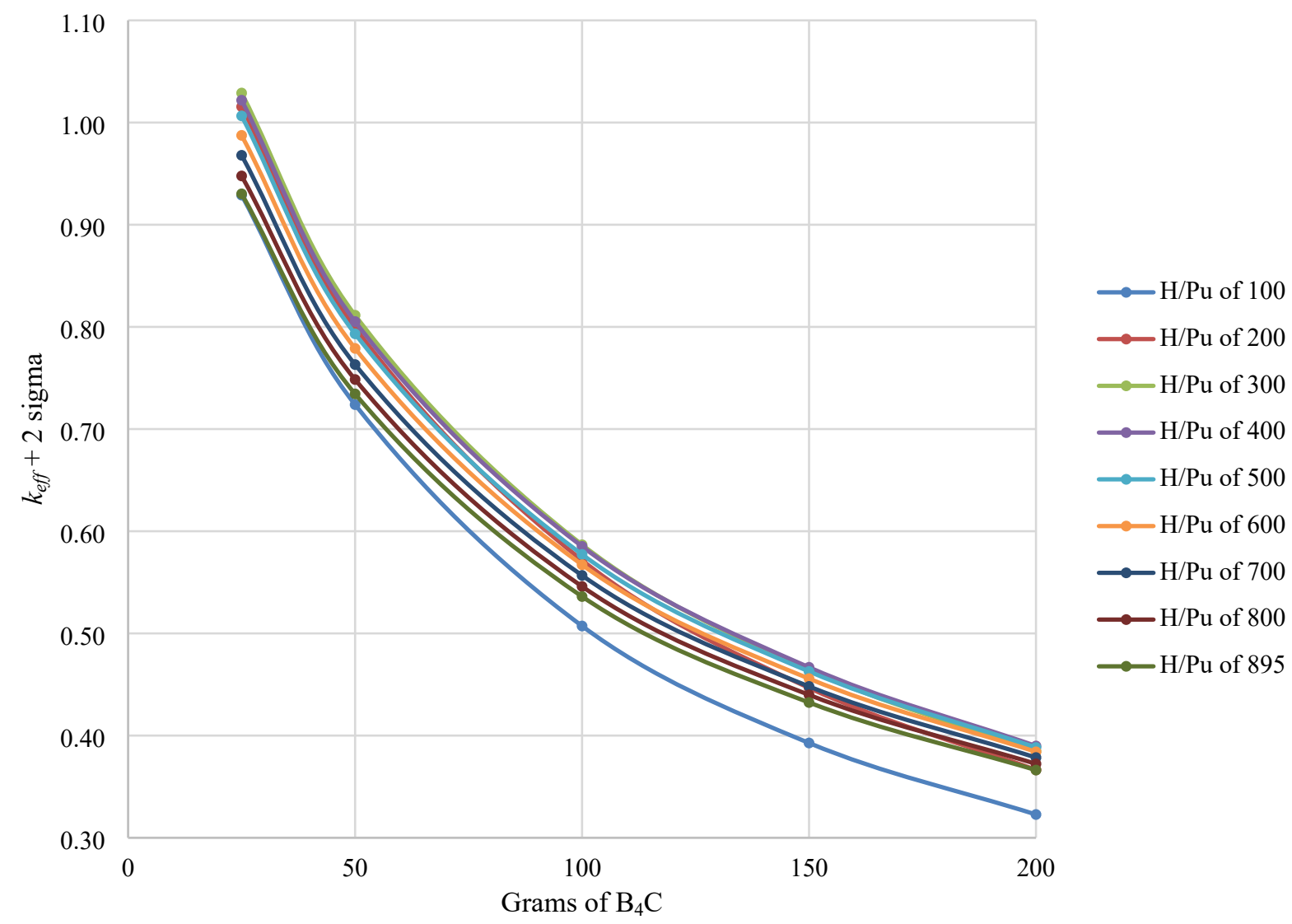

Figure 9. Results for different amounts $\mathrm{B}_{4} \mathrm{C}$ with different $\mathrm{H} / \mathrm{Pu}$ ratios.

\subsection{RECONFIGURED WET SCENARIOS}

Brine entry due to dewatering of the surrounding Salado halite allows brine to enter the disposal area. However, the most significant source of brine is from a human intrusion event that must be considered during long-term disposal. According to the 2014 Compliance Recertification Application [13], DOE identifies multiple scenarios for consideration. The scenarios that could lead to flooding in the disposal rooms are deep drilling scenarios. A deep drilling scenario would involve creation of one or more boreholes intersecting the disposal room, with at least one of these boreholes also penetrating a postulated underlying source of pressurized brine, so any resultant flooding would not involve "pure water," but would instead involve a saturated brine that may have other elements present in addition to salt.

Similar to Reference [1], the equilibrated brine composition as defined in Reference [10] and modeled here has a molality of $5.98 \mathrm{~mol}$ (moles per kilogram of $\mathrm{H}_{2} \mathrm{O}$ ). Three different brine intrusion scenarios were examined: (1) brine intrusion with the CCCs intact, (2) brine intrusion with the CCCs degraded, and (3) migration of disposal area materials to external areas after brine intrusion. 


\subsubsection{Brine Intrusion with CCCs Intact}

The first brine intrusion scenario involves modeling the void spaces in and/or around the CCCs as filled with saturated brine (equilibrated brine as defined in Reference [10]). Both the infinite array and room array models are analyzed in two scenarios (1) with brine outside the CCCs and (2) with brine also inside the CCCs and filling all voids. All models have full radial compaction. Figure 10 shows the results.

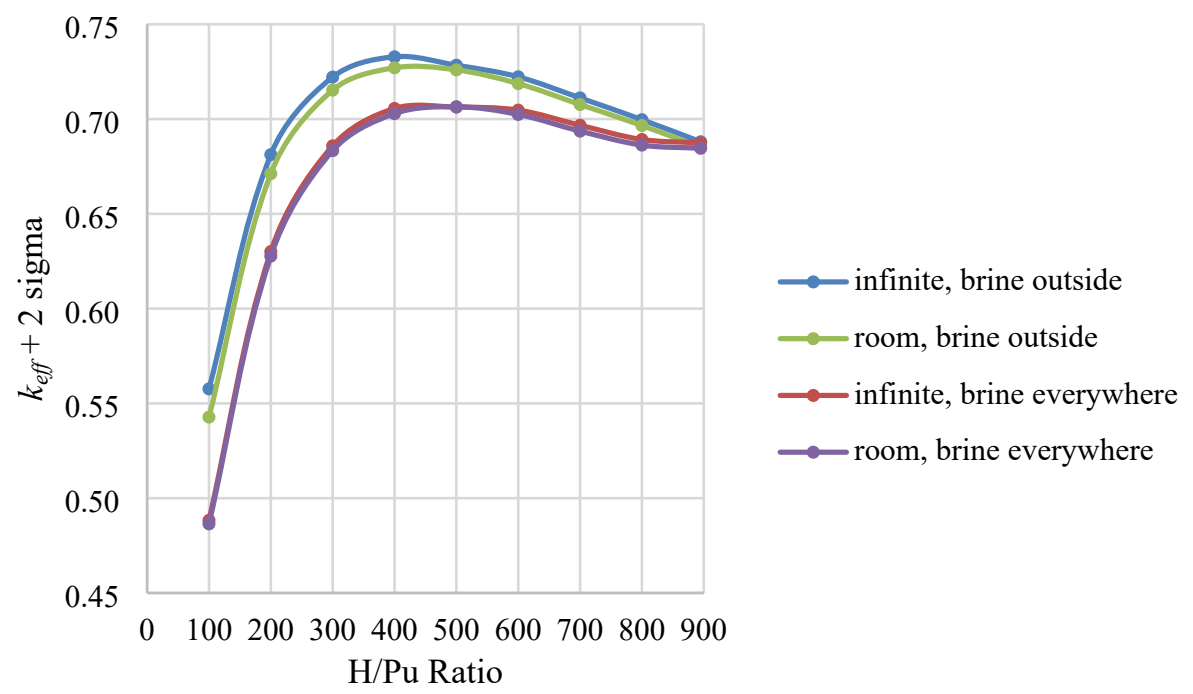

Figure 10. Results for flooding with brine.

Brine intrusion scenarios are presented in Reference [1], with the CCOs in the Triangular-Pitched Array Room Model. Similar to the results in Reference [1], these cases show that all configurations with equilibrated brine result in lower system $k_{\text {eff }} \mathrm{s}$ when compared with the cases involving dry configurations with the CCCs intact. The optimum moderation level has shifted to a slightly higher $\mathrm{H} / \mathrm{Pu}$ ratio compared to the dry configurations.

\subsubsection{Brine Intrusion with CCCs Degraded}

After the brine enters the repository, the waste container materials are expected to undergo corrosion and degradation. As the scenario progresses, a mixture of brine and corrosion products would surround the fissile material items in the room. This mixture is expected to continue to change over time as the waste container packaging corrodes and dissolves into the brine mixture. An infinite number of potential configurations could be modeled considering the different rates of reaction, resulting precipitation products, and the way these materials will change over the post-closure period. In this scenario, the corrosion of the packaging leads to vertical compaction with the potential degradation of the CCCs. To bound this and the drying-out period that may follow, the infinite-array and room-array configurations are modeled with full vertical compaction (no voids inside the CCCs) along with full radial compaction, as shown in Figure 11. 

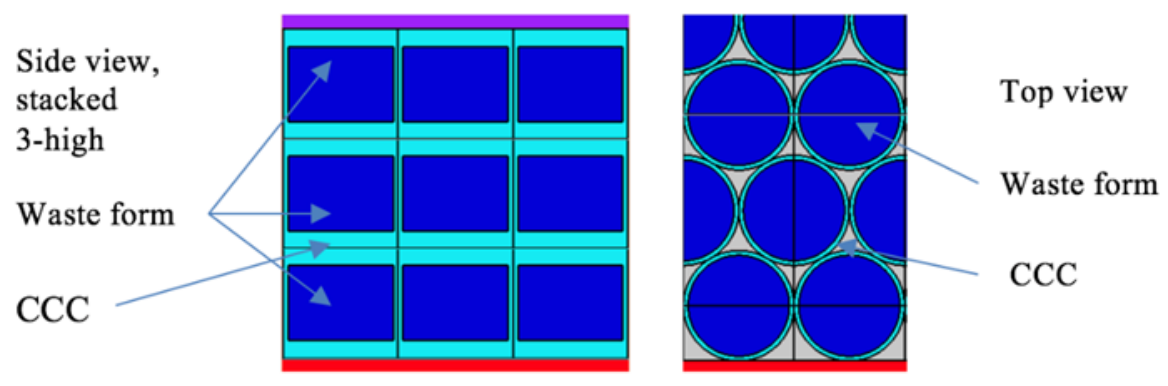

Figure 11. Top and side views of full vertical compaction along with full radial compaction.

The configurations are modeled with and without brine, with results shown in Figure 12.

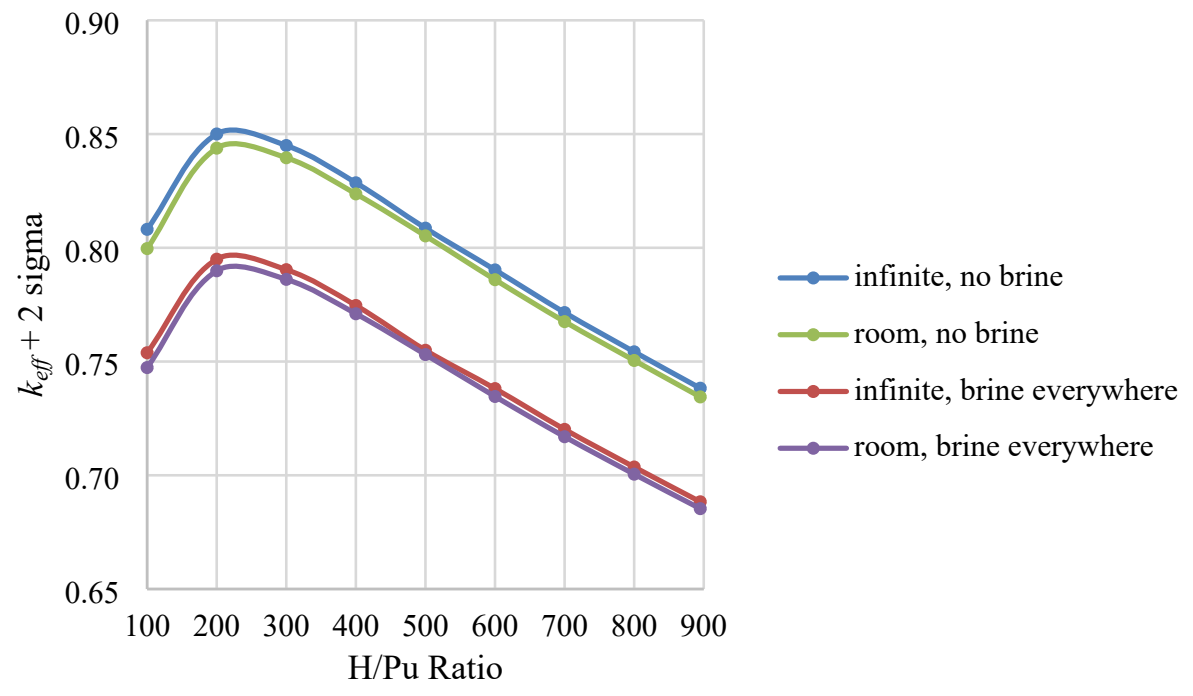

Figure 12. Results for full vertical and radial compaction, with and without brine.

These results have slightly higher system k-effectives, as expected with the vertical compaction. The optimum moderation is also at a slightly different $\mathrm{H} / \mathrm{Pu}$ ratio.

Configurations of the 3-tier room array collapsing to a 2-tier room array were also analyzed. Two scenarios were modeled. In the first scenario, the $3^{\text {rd }}$ tier combines with the $2^{\text {nd }}$ tier. In the second scenario, the $3^{\text {rd }}$ tier combines with the $1^{\text {st }}$ and $2^{\text {nd }}$ tier so that each tier has an equal number of CCOs. All of the cases modeled the CCOs with full vertical compaction, with an $\mathrm{H} / \mathrm{X}$ of 200 , with $50 \mathrm{~g}$ of $\mathrm{B}_{4} \mathrm{C}$ per $\mathrm{CCO}$, and with no brine present. For each scenario/configuration, the same number of rows are modeled; the combined CCOs are added to the width of each array.

For the first combined tier scenario of the $3^{\text {rd }}$ tier combining with the $2^{\text {nd }}$ tier, three configurations were modeled. For all three configurations the combined tier CCOs are modeled with full radial compaction. The bottom tier CCOs are modeled with first no radial compaction, second with enough compaction to approximate the width of the combined tier, and third with full radial compaction.

For the second combined tier scenario of the $3^{\text {rd }}$ tier CCOs equally split between the $1^{\text {st }}$ and $2^{\text {nd }}$ tiers, two configurations were modeled. In the first configuration, the CCOs had enough radial compaction so that the width of the compacted array was approximately the same as the original room width. In the second configuration all CCOs are modeled with full radial compaction. 
The results are listed in Table $\mathrm{X}$ and show the 3-tier array to be bounding of the 2-tier array configurations. The 3-tier array with full radial and vertical spacing and with full radial and vertical compaction are included for reference.

Table 2. Comparison of scenarios with USLs.

\begin{tabular}{|c|c|c|c|}
\hline Case Description & $\boldsymbol{k}_{\text {eff }}$ & sigma & $k_{e f f}+2 \sigma$ \\
\hline \multicolumn{4}{|l|}{ For reference } \\
\hline $\begin{array}{l}\text { Room array ( } 3 \text { tier), } \mathrm{H} / \mathrm{Pu} \text { of } 200,50 \mathrm{~g} \mathrm{~B}_{4} \mathrm{C} \text { per } \mathrm{CCO} \text {, } \\
\text { full radius (no compaction) }\end{array}$ & 0.5343 & 0.0001 & 0.5345 \\
\hline $\begin{array}{l}\text { Room array ( } 3 \text { tier), } \mathrm{H} / \mathrm{Pu} \text { of } 200,50 \mathrm{~g} \mathrm{~B}_{4} \mathrm{C} \text { per } \mathrm{CCO} \text {, } \\
\text { full radial and vertical compaction }\end{array}$ & 0.8436 & 0.0001 & 0.8438 \\
\hline \multicolumn{4}{|l|}{$3^{\text {rd }}$ tier combined with $2^{\text {nd }}$ tier } \\
\hline $\begin{array}{l}\text { Room array, } \mathrm{H} / \mathrm{Pu} \text { of } 200,50 \mathrm{~g} \mathrm{~B}_{4} \mathrm{C} \text { per } \mathrm{CCO} \\
\text { bottom tier with no radial compaction }\end{array}$ & 0.7733 & 0.0001 & 0.7735 \\
\hline $\begin{array}{l}\text { Room array, } \mathrm{H} / \mathrm{Pu} \text { of } 200,50 \mathrm{~g} \mathrm{~B} \mathrm{C}_{4} \text { per } \mathrm{CCO} \text {, } \\
\text { bottom tier radially compacted to combined tier width }\end{array}$ & 0.7843 & 0.0001 & 0.7845 \\
\hline $\begin{array}{l}\text { Room array, } \mathrm{H} / \mathrm{Pu} \text { of } 200,50 \mathrm{~g} \mathrm{~B}_{4} \mathrm{C} \text { per } \mathrm{CCO} \\
\text { bottom tier with full radial compaction }\end{array}$ & 0.8229 & 0.0001 & 0.8231 \\
\hline \multicolumn{4}{|l|}{$3^{\text {rd }}$ tier split between $2^{\text {nd }}$ and $1^{\text {st }}$ tier } \\
\hline $\begin{array}{l}\text { Room array, } \mathrm{H} / \mathrm{Pu} \text { of } 200,50 \mathrm{~g} \mathrm{~B}_{4} \mathrm{C} \text { per } \mathrm{CCO} \text {, } \\
\text { radially compacted to original room width }\end{array}$ & 0.6544 & 0.0001 & 0.6546 \\
\hline $\begin{array}{l}\text { Room array, } \mathrm{H} / \mathrm{Pu} \text { of } 200,50 \mathrm{~g} \mathrm{~B}{ }_{4} \mathrm{C} \text { per } \mathrm{CCO} \text {, } \\
\text { full radial compaction }\end{array}$ & 0.8259 & 0.0001 & 0.8261 \\
\hline
\end{tabular}

For additional comparison, the no brine room model cases (full radial and vertical compaction), were run with the waste mix composition varied. The $75 \%$ water, $25 \%$ polyethylene was replaced with $100 \%$ water, $100 \%$ polyethylene, and $100 \%$ polyethylene at twice the theoretical density. Figure 13 shows the results. Neither the $100 \%$ water or $100 \%$ polyethylene cases vary significantly from the $75 \%-25 \%$ mix, with the polyethylene density doubled, the peak $k_{\text {eff }}$ is only increased by about 0.01 .

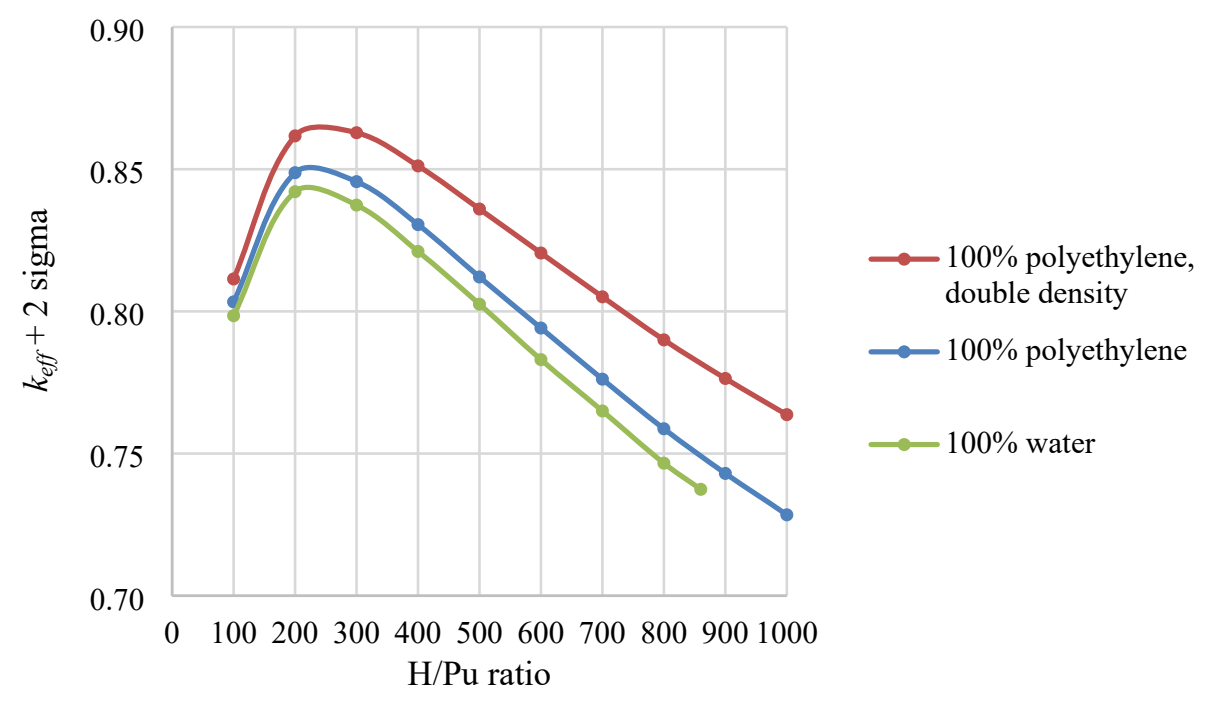

Figure 13. Results for varying the waste mix water/polyethylene content. 
The $\mathrm{MgO}$ sacks are expected to rupture over time; however, the above degradation cases do not consider the $\mathrm{MgO}$ sacks rupturing and spilling their contents between the CCOs. The exact amount of $\mathrm{MgO}$ that could end up between the CCOs is difficult to determine. It is not expected that there will be enough $\mathrm{MgO}$ to completely fill the space, but an accumulation is expected. To bound the scenario, cases (with the room configuration) were modeled with $\mathrm{MgO}$ completely filling the space in three arrangements: no compaction, full radial compaction, and full radial and vertical compaction. Figure 14 shows the results. The added $\mathrm{MgO}$ reflection does not have a significant effect on the system $k_{\text {eff. }}$.

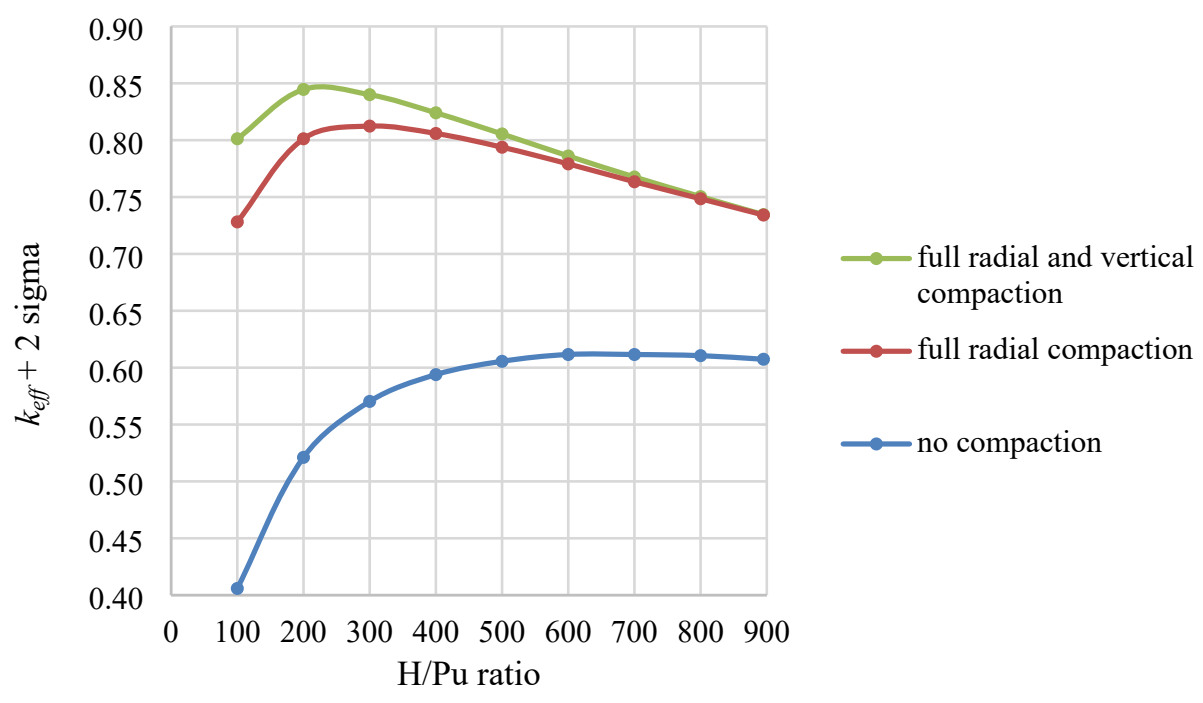

Figure 14. Results with $\mathrm{MgO}$ between the CCOs.

\subsubsection{Migration of Materials after Brine Intrusion to External Areas}

Once a room is flooded, the potential for material migration to other areas outside the disposal room must also be considered. Previous analyses $[14,15]$ have shown that criticality external to the repository is not credible due to three arguments: (1) the amount of fissile material transported over 10,000 years is predicted to be small, (2) there are insufficient spaces to provide sufficient thickness for precipitation of fissile material, and (3) there is no credible mechanism to counteract the natural tendency of the material to disperse during transport and instead concentrate fissile material in a small enough volume for it to form a critical concentration. All of those arguments are summarized in the performance assessment included in the Compliance Recertification Application [13].

The following information, stated in Low Probability of Criticality Following Disposal of Surplus Plutonium at the Waste Isolation Pilot Plant [16], is cited in considering the additional plutonium source inventory being addressed in this work: "Release of Pu at WIPP is solubility controlled; hence, an increase in the Pu inventory does not directly influence Pu release." Therefore, the existing justification for external subcriticality is still applicable. 



\section{CONCLUSIONS}

This report demonstrates that with the inclusion of $\mathrm{B}_{4} \mathrm{C}$, limits on moderator content (water and plastic content) are not necessary to demonstrate the subcriticality of fissile materials packaged using the $\mathrm{CCO}$ for disposal at WIPP. Criticality analysis results for multiple scenarios associated with post-closure of WIPP have been considered. Two scenario progressions were considered in this criticality assessment: the reconfigured dry scenario (i.e., room closure from salt creep) and the reconfigured wet scenario (i.e., flooding with brine). During the post-closure performance period at WIPP, the salt bed environment will slowly move over time to close and fill in fractures or holes between canisters. Vertical and horizontal closure may not occur at the same rate, and the forces exerted on the canisters will vary over time. Likewise, the rate of degradation of the waste containers or of their configuration is also not presumed to be known and will vary over the repository performance period. The waste configurations that could result from these closure scenarios are still being determined. Therefore, a conservative analysis approach was used.

Several configuration categories and waste form constituents were analyzed to assess the impact of the different types of changes that can occur after emplacement as a repository closure progresses. The objective was to evaluate a very conservative arrangement of waste container configurations with respect to impacts on criticality potential and to establish a limiting design basis configuration for the disposal criticality assessment. This report does not focus on the probability of any progression scenarios. Rather, it considers and bounds the most reactive credible scenarios that could occur.

The bounding configuration consists of a tight-packed triangular-pitched array of CCCs stacked three high. The analysis documented here supplements Reference [1] in demonstrating that for all scenarios, subcriticality is maintained when $50 \mathrm{~g}$ of $\mathrm{B}_{4} \mathrm{C}$ (acting as a neutron absorber) per CCC is intermixed within the waste form, with no restrictions on the maximum moderation content (amount of water and/or polyethene or water- and/or polyethylene-like materials).

None of the configurations or results from this report challenges the chemistry and/or arguments supporting the existing analyses or their corresponding results. Therefore, the flooded scenario of fissile material migrating to an external area is bounded by existing analyses $[14,15,16]$.

The calculational validation can be found in Appendix D. The validation results (bias and bias uncertainty) are used to develop upper subcritical limits (USLs). Calculated results below the USL are considered subcritical. Biases and bias uncertainties were determined by two different methods for comparison - by trending on correlation coefficients $(\mathrm{c}(\mathrm{k}) \mathrm{s})$ determined by sensitivity/uncertainty methods and by trending on the energy of average neutron lethargy causing fission (EALF). See Appendix D for further details. Table 3 lists the results.

Table 3. Comparison of scenarios with USLs.

\begin{tabular}{lccccc}
\hline \multicolumn{1}{c}{ Scenario } & $\begin{array}{c}\text { Bias based } \\
\text { on c(k) }\end{array}$ & $\begin{array}{c}\text { Bias } \\
\text { uncertainty }\end{array}$ & $\begin{array}{c}\text { Bias for beryllium } \\
\text { and chlorine }\end{array}$ & $\begin{array}{c}\text { Administrative } \\
\text { margin }\end{array}$ & USL \\
\hline Dry reconfigured & 0.0010 & 0.0294 & 0.0010 & 0.02 & 0.9486 \\
Wet reconfigured & 0.0005 & 0.0305 & 0.0014 & 0.02 & 0.9476 \\
\hline \multicolumn{2}{c}{ Scenario } & Bias based & Bias & Bias for beryllium & Administrative \\
on EALF* & uncertainty & and chlorine & margin & USL \\
\hline All & 0.0000 & 0.0159 & NA & 0.02 & 0.9641 \\
\hline *Positive bias set to 0 & & & & &
\end{tabular}

Based on the conservative USLs determined with $\mathrm{c}(\mathrm{k})$ trending, any dry scenario result $\left(k_{\text {eff }}+2 \sigma\right)$ less than 0.9486 and any wet scenario result less than 0.9476 can be considered to be subcritical. 



\section{REFERENCES}

[1] E. M. Saylor. 2017. Nuclear Criticality Safety Assessment of Potential Disposition at the Waste Isolation Plant, ORNL/TM-2017/751/R1, Oak Ridge National Laboratory, Oak Ridge, Tennessee.

[2] ORNL. 2018. SCALE Code System, ORNL/TM-2005/39, Version 6.2.3, Oak Ridge National Laboratory, Oak Ridge, Tennessee. Available from Radiation Safety Information Computational Center as CCC-834.

[3] DOE CBFO. 2013. TRUPACT-II Safety Analysis Report, Revision 23, US Department of Energy, Carlsbad Field Office, Carlsbad, New Mexico.

[4] DOE-CBFO. 2013. Contact-Handled Transuranic Waste Authorized Methods for Payload Control (CH-TRAMPAC), Revision 4, US Department of Energy, Carlsbad Field Office, Carlsbad, New Mexico.

[5] DOE-CBFO. 2013. CH-TRU Payload Appendices, Revision 3, US Department of Energy, Carlsbad Field Office, Carlsbad, New Mexico.

[6] NWP. 2015. Criticality Control Overpack, CCO-DWG-001, Revision 3, Nuclear Waste Partnership, LLC.

[7] NWP. 2013. Specification for Fabrication of the Criticality Control Overpack, CCO-SPC-0001, Revision 2, Nuclear Waste Partnership, LLC.

[8] AREVA. 2012. Criticality Control Overpack Criticality Analysis for TRUPACT-II and HalfPACT, 01937.01.M009-1, Revision 0, AREVA Federal Services LLC.

[9] NWP. 2015. Nuclear Criticality Safety Evaluation for Contact-Handled Transuranic Waste Containers at the Waste Isolation Pilot Plant, WIPP-016, Revision 5, Nuclear Waste Partnership LLC.

[10] SNL. 2008. Preparing Synthetic Brines for Geochemical Experiments, Rev. 2, Activity/Project Specific Procedures, SP 20-4, Carlsbad, New Mexico: Sandia National Laboratories.

[11] DOE-CBFO. 2014. Appendix SCR-2014 Feature, Event and Process Screening for PA, DOE/WIPP-14-3503, US Department of Energy, Carlsbad Field Office, Carlsbad, New Mexico.

[12] B. Brickner. 2019. Post Placement Nuclear Criticality Evaluations Involving 6- and 12-Inch Pipe Overpack TRU Waste Containers at the Waste Isolation Pilot Plant, ORNL/TM-2019/1222/R0, Oak Ridge National Laboratory, Oak Ridge, Tennessee.

[13] DOE-CBFO. 2014. Title 40 CFR Part 191 Subparts B and C Compliance Recertification Application 2014, DOE/WIPP-14-3503, US Department of Energy, Carlsbad Field Office, Carlsbad, New Mexico.

[14] R. Rechard, L. Sanchez, C. Stockman, Holly T. 2000. Consideration of Nuclear Criticality When Disposing of Transuranic Waste at the Waste Isolation Pilot Plant, SAND99-2898, Sandia National Laboratories, Albuquerque, New Mexico.

[15] SNL. 1996. RNT-1: Nuclear Criticality in Near Field and Far Field, WIPP Compliance Certification Application (CCA) Reference 535, Sandia National Laboratories, Albuquerque, New Mexico.

[16] Rechard, R., Sanchez, L., Stein, E. and Xiong, Y. 2018. Low Probability of Criticality Following Disposal of Surplus Plutonium at the Waste Isolation Pilot Plant, Sandia National Laboratories, Carlsbad, New Mexico. ERMS 570596. 



\section{APPENDIX A. MATERIAL DESCRIPTIONS}

\section{A.1 GENERIC WASTE FORM}

The waste form model is a generic waste form, similar to other generic waste models used for modeling waste. All of the generic waste models supporting the TRUPACT-II safety analysis are a mixture of water and polyethylene with beryllium added to bound any special moderators that might be present. The waterpolyethylene mixture is considered bounding of all types of waste; therefore, there are no restrictions or requirements on the specific makeup of the waste form outside of the fissile material, beryllium, and $\mathrm{B}_{4} \mathrm{C}$ content. The waste form modeled in this analysis is a mixture of $75 \%$ water and $25 \%$ polyethylene (modeled as $\mathrm{CH}_{2}$ ). Variations of $100 \%$ water and $100 \%$ polyethylene were also considered for comparison. The amount of fissile material per container is $380 \mathrm{FGE}{ }^{239} \mathrm{Pu}$, modeled as $\mathrm{PuO}_{2}$, mixed homogeneously with the other materials. The total amount of the water/polyethylene mixture per container is varied to determine the optimum moderation to fissile material $(\mathrm{H} / \mathrm{Pu})$ ratio.

For closure scenarios, a neutron absorber is added to the models in order to ensure subcriticality. The neutron absorber is modeled as different amounts of $\mathrm{B}_{4} \mathrm{C}$ in support of process optimization considerations, with the boron content considered as natural boron $\left(19.9 \mathrm{wt} \%{ }^{10} \mathrm{~B}, 80.1 \mathrm{wt} \%{ }^{11} \mathrm{~B}\right)$.

Other waste containers typically allow beryllium to be included for up to $1 \%$ by weight of the waste content [1, 2, 3], and may also be present in oxide form. As listed in [2], the empty weight for a criticality control overpack (CCO) was $104.3 \mathrm{~kg}(230 \mathrm{lb})$, with a maximum gross weight of $158.8 \mathrm{~kg}(350 \mathrm{lb})$, which resulted in a maximum waste weight of $54.5 \mathrm{~kg}$. The beryllium content ( $1 \%$ by weight) is based on the total allowed waste weight (does not include packaging and container weights). Therefore, the $1 \%$-byweight limit for beryllium was determined to be $545 \mathrm{~g}$, which is consistent with other container limits. Cases were run with $545 \mathrm{~g}$ of beryllium per CCO intermixed in the waste form.

Figure A-1 is a screenshot of a spreadsheet example demonstrating how the material weight percentages were determined for the calculational inputs. 


\begin{tabular}{|c|c|c|c|c|c|c|c|c|c|c|c|c|c|c|c|}
\hline \multirow[t]{5}{*}{ Pu } & 380 & $\mathrm{~g}$ & $\mathrm{H} 2 \mathrm{O}$ & amu & \multicolumn{2}{|c|}{ number per w/o } & \multirow{2}{*}{$\begin{array}{l}\mathrm{CH} 2 \\
\mathrm{C}\end{array}$} & \multirow{2}{*}{$\begin{array}{l}\text { amu } \\
\quad 12.0107\end{array}$} & \multicolumn{2}{|c|}{ number per w/o } & & & & & \\
\hline & 19.84 & $\mathrm{~g} / \mathrm{cc}$ & $\mathrm{H}$ & 1.0078 & 2 & 0.1119 & & & 1 & 0.8563 & & & & & \\
\hline & 19.15323 & $\mathrm{~cm} 3$ & $\mathrm{O}$ & 15.9949 & 1 & 0.8881 & $\mathrm{H}$ & 1.0078 & 2 & 0.1437 & & & & & \\
\hline & 239.0522 & $\mathrm{amu}$ & sum & 18.0105 & $\mathrm{~g} / \mathrm{mole}$ & & sum & 14.0263 & $\mathrm{~g} / \mathrm{mole}$ & & & & & & \\
\hline & 1.589611 & moles & density & 0.9982 & $\mathrm{~g} / \mathrm{cc}$ & & density & 0.92 & $\mathrm{~g} / \mathrm{cc}$ & & & & & & \\
\hline $\mathrm{PuO} 2$ & 430.851337 & $\mathrm{~g}$ & $\%$ H2O & 0.75 & & & $\%$ CH2 & 0.25 & & & & & & & \\
\hline \multirow[t]{2}{*}{$\mathrm{O}$} & 50.851337 & g & & & & & & & & & & & & & \\
\hline & & & $\mathrm{PuO} 2$ & amu & number per & w/o & B4C & amu & number per & $\mathrm{rw} / \mathrm{o}$ & & & & & \\
\hline \multirow[t]{4}{*}{$\mathbf{B e}$} & 545 & $\mathrm{~g}$ & $\mathrm{Pu}$ & 239.0522 & 1 & 0.8820 & B & 10.811 & 4 & 0.78 & & & & & \\
\hline & 1.85 & $\mathrm{~g} / \mathrm{cc}$ & O & 15.9949 & 2 & 0.1180 & C & 12.0107 & 1 & 0.22 & & & & & \\
\hline & 9.0122 & amu & sum & 271.042 & & & sum & 55.2547 & & & & & & & \\
\hline & & & density & 11.46 & $\mathrm{~g} / \mathrm{cc}$ & & density & 2.5 & $\mathrm{~g} / \mathrm{cc}$ & & & & & & \\
\hline & & & & & & & & & & & & & & & \\
\hline $\mathbf{H} / \mathbf{X}$ & 200 & & & grams & w/o & & & Composition & & & & & & full collap & \\
\hline \multirow[t]{2}{*}{ H moles } & 317.92219 & & $\mathrm{H}$ & 320.40199 & 0.085887 & 1001 & $\mathrm{H}$ & 1001 & 0.08589 & H & & & & & \\
\hline & & & $\mathrm{C}$ & 488.17700 & 0.130861 & 6000 & $\mathrm{C}$ & 6000 & 0.13086 & $\mathrm{C}$ & fim height & 16.6809 & & $\mathbf{0}$ & \\
\hline $\mathrm{H}$ from $\mathrm{H} 2 \mathrm{O}$ & 238.44165 & & O & 1957.77648 & 0.524805 & 8016 & O & 8016 & 0.52480 & 0 & flange & 2.54 & & 2.54 & \\
\hline $\mathrm{H} 2 \mathrm{O}$ moles & 119.22082 & & $\mathrm{Pu}$ & 380 & 0.101863 & 94239 & $\mathrm{Pu}$ & 94239 & 0.10186 & $\mathbf{P u}$ & flange & 2.54 & & 19.2209 & \\
\hline $\mathrm{H} 2 \mathrm{O}$ grams & 2147.22663 & $\mathrm{~g}$ & $\mathrm{Be}$ & 545 & 0.146094 & 4000 & $\mathrm{Be}$ & 4000 & 0.14609 & $\mathrm{Be}$ & total ht & 21.7609 & & 21.7609 & \\
\hline $\mathrm{H} 2 \mathrm{O} \mathrm{cm} 3$ & 2151.09861 & $\mathrm{~cm} 3$ & B & 39.13151 & 0.010490 & 5000 & B & 5000 & 0.01049 & B & & & & & \\
\hline $\mathrm{H}$ & 240.30149 & $\mathrm{~g}$ & & 3730.48698 & 1.000000 & & & & 1.0000 & & $\mathrm{x} 3$ & 65.2827 & $\mathrm{x} 3$ & 65.283 & \\
\hline \multirow[t]{2}{*}{ o } & 1906.92514 & $\mathrm{~g}$ & & & & & & total density & 1.1998 & $\mathrm{~g} / \mathrm{cc}$ & round up & 65 & round up & 65 & \\
\hline & & & Total & & frac of total & ind dens & & & & & & & & & \\
\hline $\mathrm{H}$ from $\mathrm{CH} 2$ & 79.48055 & & $\mathrm{PuO} 2$ & 430.85134 & 0.115495 & 11.46 & & total grams & 3730.4870 & $\mathrm{~g}$ & & & & & \\
\hline $\mathrm{CH} 2$ moles & 39.74027 & & $\mathrm{H} 2 \mathrm{O}$ & 2147.22663 & 0.575589 & 0.9982 & & & & & & & & & \\
\hline $\mathrm{CH} 2$ grams & 557.40901 & $\mathrm{~g}$ & $\mathrm{CH} 2$ & 557.40901 & 0.149420 & 0.92 & & total volume & 3109.1687 & ce & & & & & \\
\hline $\mathrm{CH} 3 \mathrm{~cm} 3$ & 605.87936 & $\mathrm{~cm} 3$ & $\mathrm{Be}$ & 545 & 0.146094 & 1.85 & & & & & & & & & \\
\hline C & 477.30851 & $\mathrm{~g}$ & B4C & 50 & 0.013403 & 2.5 & & \multicolumn{3}{|c|}{ Cylinder filling inside diameter } & Sphere & & & & \\
\hline \multirow[t]{2}{*}{$\mathrm{H}$} & 80.10050 & g & & 3730.48698 & 1 & & & radius & $\mathbf{7 . 7 0 2 6}$ & cm & radius & 9.0542 & $\mathrm{~cm}$ & & \\
\hline & & & & & & & & height & 16.6809 & $\mathrm{~cm}$ & Dr Center & upper h & lower h & & \\
\hline B4C & 50 & $g$ & mix density & 1.19983 & & & & h div by 2 & 8.3405 & & 36.757 & 45.0975 & 28.4165 & & \\
\hline B & 39.13151 & $\lg$ & & & & & & total inner ht & 68.434 & & & & & & \\
\hline \multirow[t]{2}{*}{ C } & 10.86849 & $\mathrm{~g}$ & & & & & & unfilled space & 51.7531 & & & & & & \\
\hline & & & & & & & & divided by 2 & 25.8765 & $\mathrm{~cm}$ & & & & & \\
\hline
\end{tabular}

Figure A-1. Screenshot of spreadsheet determining generic waste composition.

\section{A.2 BRINE IN FLOODED CONFIGURATIONS}

The only significant source of water is from brine-filled fractures in rock units below and/or around the repository, from saturated clay seams near the repository, or from drilling fluid resulting from a hypothetical drilling event.

The brine would include other materials in addition to salt $[4,5]$ for various brine elemental concentrations in the WIPP area. The stew-like mixture would contain even more materials/elements from the structural/material degradation. The exact nature and amounts of these contaminants are difficult to quantify, so developing a bounding model is also difficult. Conservatively, the cases in this effort only modeled water with salt. The brine composition modeled is a representation of equilibrated brine based on the geochemistry of the area [5]. Reference [5] lists two equilibrated brine concentrations. The chlorine in the salt is expected to act as a neutron absorber and lower the multiplication of the system. Therefore, the lower equilibrated brine chlorine composition, with a molality of $5.98 \mathrm{~mol}\left(\mathrm{moles} / \mathrm{kg} \mathrm{of}_{2} \mathrm{O}\right)$, was modeled here. Screenshots of the spreadsheet used to determine the number densities are shown in Figure A-2. 


\begin{tabular}{|l|r|l|l|}
\hline \multicolumn{3}{|l|}{ salt (halite) in water } & \\
& $\begin{array}{l}\text { grams per } \\
\text { mole }\end{array}$ & density & \\
\hline & $\mathrm{g} / \mathrm{cm} 3$ & \\
\hline $\mathrm{H}$ & 1.0079 & & \\
\hline $\mathrm{O}$ & 15.9994 & & \\
\hline $\mathrm{H} 2 \mathrm{O}$ & 18.0152 & 0.9982 & \\
\hline & & & \multicolumn{2}{|c|}{ wt \% } \\
\hline $\mathrm{Na}$ & 22.9898 & & 0.3934 \\
\hline $\mathrm{Cl}$ & 35.453 & & 0.6066 \\
\hline $\mathrm{NaCl}$ & 58.4428 & 2.165 & \\
\hline
\end{tabular}

\begin{tabular}{|c|c|c|c|c|c|c|c|c|c|c|c|c|}
\hline & & & & & & & & density & & & & \\
\hline $\mathrm{NaCl}$ & $\mathrm{NaCl}$ & $\mathrm{H} 2 \mathrm{O}$ & $\mathrm{H} 2 \mathrm{O}$ & $\mathrm{H} 2 \mathrm{O}$ & Total & Total & Total & total g/ & & & & \\
\hline grams & $\mathrm{cm} 3$ & liter & $\mathrm{cm} 3$ & $\mathrm{~g}$ & $\mathrm{~g}$ & $\mathrm{~cm} 3$ & liter & total $\mathrm{cm} 3$ & & & & \\
\hline \multirow[t]{4}{*}{349} & 161.2009 & 1 & 1000 & 998.2 & 1347 & 1161.2009 & 1.1612 & 1.1602 & $\mathrm{~N}(\mathrm{NaCl})$ & 0.0030969 & $\mathrm{~N}(\mathrm{Na})$ & 0.003097 \\
\hline & & & & & & & & & & & $\mathbf{N}(\mathrm{Cl})$ & 0.003097 \\
\hline & & & & & & & & & $\mathrm{N}(\mathrm{H} 2 \mathrm{O})$ & 0.028735 & $\mathbf{N}(\mathbf{H})$ & 0.057470 \\
\hline & & & & & & & & & & & $\mathbf{N}(0)$ & 0.028735 \\
\hline
\end{tabular}

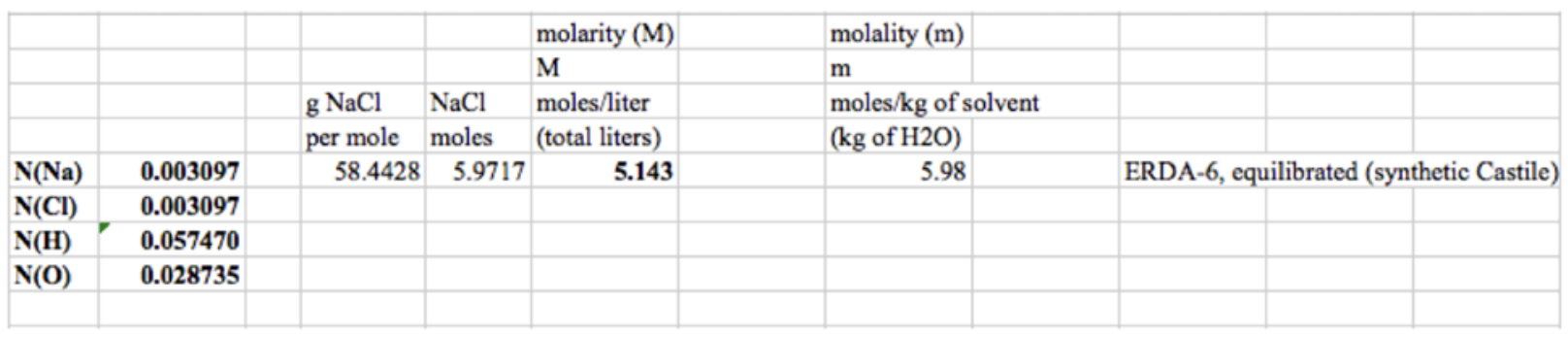

Figure A-2. Screenshots of spreadsheet determining brine compositions.

\section{A.3 REFERENCES}

[1] DOE CBFO. 2013. TRUPACT-II Safety Analysis Report, Revision 23, US Department of Energy, Carlsbad Field Office, Carlsbad, New Mexico.

[2] DOE-CBFO. 2013. Contact-Handled Transuranic Waste Authorized Methods for Payload Control (CH-TRAMPAC), Revision 4, US Department of Energy, Carlsbad Field Office, Carlsbad, New Mexico.

[3] DOE-CBFO. 2013. CH-TRU Payload Appendices, Revision 3, US Department of Energy, Carlsbad Field Office, Carlsbad, New Mexico.

[4] R. Rechard, L. Sanchez, C. Stockman, Holly T. 2000. Consideration of Nuclear Criticality When Disposing of Transuranic Waste at the Waste Isolation Pilot Plant, SAND99-2898, Sandia National Laboratories, Albuquerque, New Mexico.

[5] SNL. 2008. Preparing Synthetic Brines for Geochemical Experiments, Rev. 2, Activity/Project Specific Procedures, SP 20-4, Carlsbad, New Mexico: Sandia National Laboratories. 



\section{APPENDIX B. RESULTS}

Table B.1 lists the data used to generate the figures in the body of this report. Tables are arranged by figure with each table containing case descriptions with the varying parameters identified. Peak k-effective values $\left(k_{e f f} \mathrm{~s}\right)$, ranging from 0.80 to 0.85 , tend to have an $\mathrm{H} / \mathrm{Pu}$ ratio of 200 to 400 , with EALFs of about 0.42 . Some scenarios have peak k-effective values $\left(k_{e f f} s\right)$ with higher $\mathrm{H} / \mathrm{Pu}$ ratios and lower EALFs; however they are not considered bounding cases with their respective $k_{e f f} s$ lower than 0.80 .

Table B-1. Data for Figures ES-1 and 6.

\begin{tabular}{|c|c|c|c|c|c|c|}
\hline $\begin{array}{r}\text { Legend entry on figure } \\
\text { Case }\end{array}$ & Description & $\mathbf{H} / \mathbf{P u}$ & $\boldsymbol{k}_{\text {eff }}$ & sigma & $k_{e f f}+2 \sigma$ & EALF \\
\hline \multicolumn{7}{|l|}{ full radial compaction, infinite } \\
\hline g380infgenhx0100b050rd20vdcc & \multirow{9}{*}{$\begin{array}{l}\text { Infinite array, } \\
\text { varying } \mathrm{H} / \mathrm{Pu}, \\
50 \mathrm{~g} \mathrm{~B}_{4} \mathrm{C} \text { per } \mathrm{CCO}, \\
\text { ll radial compaction }\end{array}$} & 100 & 0.76797 & 0.00010 & 0.76816 & 1.21809 \\
\hline g380infgenhx0200b050rd20vdcc & & 200 & 0.82529 & 0.00010 & 0.82549 & 0.42457 \\
\hline g380infgenhx0300b050rd20vdcc & & 300 & 0.82852 & 0.00009 & 0.82870 & 0.26286 \\
\hline g380infgenhx0400b050rd20vdcc & & 400 & 0.81734 & 0.00009 & 0.81751 & 0.19522 \\
\hline g380infgenhx0500b050rd20vdcc & & 500 & 0.80083 & 0.00008 & 0.80099 & 0.15837 \\
\hline g380infgenhx0600b050rd20vdcc & & 600 & 0.78523 & 0.00007 & 0.78537 & 0.13504 \\
\hline g380infgenhx0700b050rd20vdcc & & 700 & 0.76865 & 0.00008 & 0.76880 & 0.11913 \\
\hline g380infgenhx0800b050rd20vdcc & & 800 & 0.75281 & 0.00008 & 0.75296 & 0.10748 \\
\hline g380infgenhx0895b050rd20vdcc & & 895 & 0.73553 & 0.00007 & 0.73567 & 0.09924 \\
\hline \multicolumn{7}{|l|}{ full radial compaction, room } \\
\hline g380rmgenhx0100b050rd20vdcc & \multirow{9}{*}{$\begin{array}{l}\text { Room array, } \\
\text { varying } \mathrm{H} / \mathrm{Pu} \text {, } \\
0 \mathrm{~g} \mathrm{~B}_{4} \mathrm{C} \text { per } \mathrm{CCO} \text {, } \\
\text { ll radial compaction }\end{array}$} & 100 & 0.72377 & 0.00008 & 0.72392 & 1.24552 \\
\hline g380rmgenhx0200b050rd20vdcc & & 200 & 0.79903 & 0.00008 & 0.79919 & 0.42759 \\
\hline g380rmgenhx0300b050rd20vdcc & & 300 & 0.81120 & 0.00009 & 0.81138 & 0.26378 \\
\hline g380rmgenhx0400b050rd20vdcc & & 400 & 0.80509 & 0.00006 & 0.80521 & 0.19560 \\
\hline g380rmgenhx0500b050rd20vdcc & & 500 & 0.79308 & 0.00007 & 0.79322 & $\mathbf{0 . 1 5 8 3 8}$ \\
\hline g380rmgenhx0600b050rd20vdcc & & 600 & 0.77882 & 0.00006 & 0.77894 & 0.13513 \\
\hline g380rmgenhx0700b050rd20vdcc & & 700 & 0.76299 & 0.00007 & 0.76312 & 0.11921 \\
\hline g380rmgenhx0800b050rd20vdcc & & 800 & 0.74839 & 0.00005 & 0.74850 & 0.10755 \\
\hline g380rmgenhx0895b050rd20vdcc & & 895 & 0.73429 & 0.00006 & 0.73440 & 0.09920 \\
\hline \multicolumn{7}{|l|}{ full radius, infinite } \\
\hline g380infgenhx0100b050rdfrvdcc & \multirow{9}{*}{$\begin{array}{l}\text { Infinite array, } \\
\text { varying } \mathrm{H} / \mathrm{Pu} \text {, } \\
0 \mathrm{~g} \mathrm{~B} \mathrm{~B}_{4} \mathrm{C} \text { per } \mathrm{CCO}, \\
\text { adius (no compaction) }\end{array}$} & 100 & 0.45966 & 0.00012 & 0.45990 & 1.40873 \\
\hline g380infgenhx0200b050rdfrvdcc & & 200 & 0.58091 & 0.00013 & 0.58117 & 0.44959 \\
\hline g380infgenhx0300b050rdfrvdcc & & 300 & 0.62722 & 0.00011 & 0.62744 & 0.27219 \\
\hline g380infgenhx0400b050rdfrvdcc & & 400 & 0.64637 & 0.00011 & 0.64659 & 0.20032 \\
\hline g380infgenhx0500b050rdfrvdcc & & 500 & 0.65090 & 0.00010 & 0.65110 & 0.16177 \\
\hline g380infgenhx0600b050rdfrvdcc & & 600 & 0.65461 & 0.00010 & 0.65481 & 0.13744 \\
\hline g380infgenhx0700b050rdfrvdcc & & 700 & 0.65200 & 0.00009 & 0.65219 & 0.12099 \\
\hline g380infgenhx0800b050rdfrvdcc & & 800 & 0.64829 & 0.00009 & 0.64847 & 0.10895 \\
\hline g380infgenhx0895b050rdfrvdcc & & 895 & 0.63338 & 0.00009 & 0.63355 & 0.10059 \\
\hline \multicolumn{7}{|l|}{ full radius, room } \\
\hline g380rmgenhx0100b050rdfrudcc & \multirow{9}{*}{$\begin{array}{l}\text { Room array, } \\
\text { varying } \mathrm{H} / \mathrm{Pu} \text {, } \\
0 \mathrm{~g} \mathrm{~B}_{4} \mathrm{C} \text { per } \mathrm{CCO}, \\
\text { adius (no compaction) }\end{array}$} & 100 & 0.40966 & 0.00009 & 0.40983 & 1.51608 \\
\hline g380rmgenhx0200b050rdfrvdcc & & 200 & 0.53433 & 0.00010 & 0.53453 & 0.46160 \\
\hline g380rmgenhx0300b050rdfrvdcc & & 300 & 0.58531 & 0.00008 & 0.58548 & 0.27637 \\
\hline g380rmgenhx0400b050rdfrvdcc & & 400 & 0.60880 & 0.00008 & 0.60896 & 0.20229 \\
\hline g380rmgenhx0500b050rdfrvdcc & & 500 & 0.61943 & 0.00007 & 0.61958 & 0.16278 \\
\hline g380rmgenhx0600b050rdfrvdcc & & 600 & 0.62488 & 0.00009 & 0.62505 & 0.13822 \\
\hline g380rmgenhx0700b050rdfrvdcc & & 700 & 0.62406 & 0.00007 & 0.62419 & 0.12164 \\
\hline g380rmgenhx0800b050rdfrvdcc & & 800 & 0.62261 & 0.00008 & 0.62276 & 0.10947 \\
\hline g380rmgenhx0895b050rdfrvdcc & & 895 & 0.61932 & 0.00007 & 0.61946 & 0.10078 \\
\hline
\end{tabular}


Table B-2. Data for Figures ES-2 and 8.

\begin{tabular}{|c|c|c|c|c|c|c|}
\hline $\begin{array}{c}\text { Legend entry on figure } \\
\text { Case }\end{array}$ & Description & $\begin{array}{c}\mathrm{B}_{4} \mathrm{C} \\
\text { (grams) }\end{array}$ & $\boldsymbol{k}_{\text {eff }}$ & sigma & $k_{\text {eff }}+2 \sigma$ & EALF \\
\hline \multicolumn{7}{|l|}{ full radial compaction } \\
\hline g380rmgenhx0200rd20vdcc & & 0 & 1.46694 & 0.00015 & 1.46724 & 0.16768 \\
\hline g380rmgenhx0200b025rd20vdcc & Room array, & 25 & 1.01534 & 0.00009 & 1.01551 & 0.29107 \\
\hline g380rmgenhx0200b050rd20vdcc & $\mathrm{H} / \mathrm{Pu}$ of 200 & 50 & 0.79903 & 0.00008 & 0.79919 & 0.42759 \\
\hline g380rmgenhx0200b100rd20vdcc & varying $\mathrm{B}_{4} \mathrm{C}$ per $\mathrm{CCO}$, & 100 & 0.57151 & 0.00005 & 0.57161 & 0.75325 \\
\hline g380rmgenhx0200b150rd20vdcc & full radial compaction & 150 & 0.44657 & 0.00005 & 0.44666 & 1.18309 \\
\hline g380rmgenhx0200b200rd20vdcc & & 200 & 0.36636 & 0.00004 & 0.36645 & 1.76112 \\
\hline \multicolumn{7}{|l|}{ radius reduced by $14 \mathrm{~cm}$} \\
\hline g380rmgenhx0200rd14vdcc & \multirow{6}{*}{$\begin{array}{l}\text { Room array, } \\
\mathrm{H} / \mathrm{Pu} \text { of } 200, \\
\text { ing } \mathrm{B}_{4} \mathrm{C} \text { per } \mathrm{CCO}, \\
\text { radius reduced by } 14 \\
\mathrm{~cm}\end{array}$} & 0 & 1.26807 & 0.00014 & 1.26835 & 0.17168 \\
\hline g380rmgenhx0200b025rd14vdcc & & 25 & 0.88192 & 0.00010 & 0.88213 & 0.29846 \\
\hline g380rmgenhx0200b050rd14vdcc & & 50 & 0.69622 & 0.00008 & 0.69639 & 0.43864 \\
\hline g380rmgenhx0200b100rd14vdcc & & 100 & 0.50052 & 0.00007 & 0.50065 & 0.77295 \\
\hline g380rmgenhx0200b150rd14vdcc & & 150 & 0.39256 & 0.00005 & 0.39267 & 1.21303 \\
\hline g380rmgenhx0200b200rd14vdcc & & 200 & 0.32303 & 0.00004 & 0.32312 & 1.80343 \\
\hline \multicolumn{7}{|l|}{ radius reduced by $7 \mathrm{~cm}$} \\
\hline g380rmgenhx0200rd07vdcc & & 0 & 1.09936 & 0.00016 & 1.09968 & 0.17461 \\
\hline g380rmgenhx0200b025rd07vdcc & Room array, & 25 & 0.76552 & 0.00011 & 0.76574 & 0.30481 \\
\hline g380rmgenhx0200b050rd07vdcc & $\mathrm{H} / \mathrm{Pu}$ of 200 & 50 & 0.60515 & 0.00010 & 0.60535 & 0.44947 \\
\hline g380rmgenhx0200b100rd07vdcc & varying $\mathrm{B}_{4} \mathrm{C}$ per $\mathrm{CCO}$, & 100 & 0.43617 & 0.00007 & 0.43630 & 0.79581 \\
\hline g380rmgenhx0200b150rd07vdcc & $\mathrm{CCO}$ radius reduced by $7 \mathrm{~cm}$ & 150 & 0.34298 & 0.00005 & 0.34309 & 1.25338 \\
\hline g380rmgenhx0200b200rd07vdcc & & 200 & 0.28281 & 0.00005 & 0.28291 & 1.86678 \\
\hline \multicolumn{7}{|l|}{ full radius } \\
\hline g380rmgenhx0200rdfrvdcc & & 0 & 0.97011 & 0.00018 & 0.97047 & 0.17729 \\
\hline g380rmgenhx0200b025rdfrvdcc & Room array, & 25 & 0.67556 & 0.00011 & 0.67578 & 0.31160 \\
\hline g380rmgenhx0200b050rdfrvdcc & $\mathrm{H} / \mathrm{Pu}$ of 200 & 50 & 0.53433 & 0.00010 & 0.53453 & 0.46160 \\
\hline g380rmgenhx0200b100rdfrvdcc & varying $\mathrm{B}_{4} \mathrm{C}$ per $\mathrm{CCO}$, & 100 & 0.38568 & 0.00006 & 0.38581 & 0.82336 \\
\hline g380rmgenhx0200b150rdfrvdcc & full radius (no compaction) & 150 & 0.30377 & 0.00005 & 0.30388 & 1.30273 \\
\hline g380rmgenhx0200b200rdfrvdcc & & 200 & 0.25094 & 0.00004 & 0.25103 & 1.94959 \\
\hline
\end{tabular}


Table B-3. Data for Figure 9

\begin{tabular}{|c|c|c|c|c|c|c|}
\hline $\begin{array}{l}\text { Legend entry on figure } \\
\text { Case }\end{array}$ & Description & $\begin{array}{c}\mathbf{B}_{4} \mathbf{C} \\
\text { (grams) }\end{array}$ & $\boldsymbol{k}_{\text {eff }}$ & sigma & $k_{e f f}+2 \sigma$ & EALF \\
\hline \multicolumn{7}{|l|}{$\mathrm{H} / \mathrm{Pu}$ of 100} \\
\hline g380rmgenhx $0100 \mathrm{~b} 025 \mathrm{rd} 20 \mathrm{vdcc}$ & \multirow{5}{*}{$\begin{array}{l}\text { Room array, } \\
\mathrm{H} / \mathrm{Pu} \text { of } 100, \\
\text { varying } \mathrm{B}_{4} \mathrm{C} \text { per } \mathrm{CCO}, \\
\text { full radial compaction }\end{array}$} & 25 & 0.92875 & 0.00010 & 0.92895 & 0.75359 \\
\hline g380rmgenhx0100b050rd20vdcc & & 50 & 0.72377 & 0.00008 & 0.72392 & 1.24552 \\
\hline g380rmgenhx0100b100rd20vdcc & & 100 & 0.50713 & 0.00005 & 0.50724 & 2.78162 \\
\hline g380rmgenhx0100b150rd20vdcc & & 150 & 0.39265 & 0.00005 & 0.39275 & 5.44041 \\
\hline g380rmgenhx $0100 \mathrm{~b} 200 \mathrm{rd} 20 \mathrm{vdcc}$ & & 200 & 0.32266 & 0.00004 & 0.32274 & 9.71412 \\
\hline \multicolumn{7}{|l|}{$\mathrm{H} / \mathrm{Pu}$ of 200} \\
\hline g380rmgenhx $0200 \mathrm{~b} 025 \mathrm{rd} 20 \mathrm{vdcc}$ & \multirow{5}{*}{$\begin{array}{l}\text { Room array, } \\
\mathrm{H} / \mathrm{Pu} \text { of } 200 \text {, } \\
\text { varying } \mathrm{B}_{4} \mathrm{C} \text { per } \mathrm{CCO} \text {, } \\
\text { full radial compaction }\end{array}$} & 25 & 1.01534 & 0.00009 & 1.01551 & 0.29107 \\
\hline g380rmgenhx 0200b050rd20vdcc & & 50 & 0.79903 & 0.00008 & 0.79919 & 0.42759 \\
\hline g380rmgenhx0200b100rd20vdcc & & 100 & 0.57151 & 0.00005 & 0.57161 & 0.75325 \\
\hline g380rmgenhx0200b150rd20vdcc & & 150 & 0.44657 & 0.00005 & 0.44666 & 1.18309 \\
\hline g380rmgenhx0200b200rd20vdcc & & 200 & 0.36636 & 0.00004 & 0.36645 & 1.76112 \\
\hline \multicolumn{7}{|l|}{$\mathrm{H} / \mathrm{Pu}$ of 300} \\
\hline g380rmgenhx0300b025rd20vdcc & \multirow{5}{*}{$\begin{array}{l}\text { Room array, } \\
\mathrm{H} / \mathrm{Pu} \text { of } 300, \\
\text { varying } \mathrm{B}_{4} \mathrm{C} \text { per } \mathrm{CCO}, \\
\text { full radial compaction }\end{array}$} & 25 & 1.02872 & 0.00009 & 1.02890 & 0.18744 \\
\hline g380rmgenhx0300b050rd20vdcc & & 50 & 0.81120 & 0.00009 & 0.81138 & 0.26378 \\
\hline g380rmgenhx0300b100rd20vdcc & & 100 & 0.58663 & 0.00005 & 0.58674 & 0.43048 \\
\hline g380rmgenhx0300b150rd20vdcc & & 150 & 0.46429 & 0.00004 & 0.46438 & 0.62313 \\
\hline g380rmgenhx $0300 \mathrm{~b} 200 \mathrm{rd} 20 \mathrm{vdcc}$ & & 200 & 0.38455 & 0.00004 & 0.38463 & 0.85315 \\
\hline \multicolumn{7}{|l|}{$\mathrm{H} / \mathrm{Pu}$ of 400} \\
\hline g380rmgenhx0400b025rd20vdcc & \multirow{6}{*}{$\begin{array}{l}\text { Room array, } \\
\mathrm{H} / \mathrm{Pu} \text { of } 400, \\
\text { varying } \mathrm{B}_{4} \mathrm{C} \text { per } \mathrm{CCO}, \\
\text { full radial compaction }\end{array}$} & 25 & 1.02169 & 0.00008 & 1.02185 & 0.14281 \\
\hline g380rmgenhx0400b050rd20vdcc & & 50 & 0.80509 & 0.00006 & 0.80521 & 0.19560 \\
\hline g380rmgenhx0400b100rd20vdcc & & 100 & 0.58504 & 0.00005 & 0.58515 & 0.30727 \\
\hline g380rmgenhx $0400 \mathrm{~b} 150 \mathrm{rd} 20 \mathrm{vdcc}$ & & 150 & 0.46674 & 0.00004 & 0.46682 & 0.42835 \\
\hline g380rmgenhx $0400 \mathrm{~b} 200 \mathrm{rd} 20 \mathrm{vdcc}$ & & 200 & 0.38972 & 0.00004 & 0.38980 & 0.56359 \\
\hline \multicolumn{6}{|l|}{$\mathrm{H} / \mathrm{Pu}$ of 500} & \\
\hline g380rmgenhx $0500 \mathrm{~b} 025 \mathrm{rd} 20 \mathrm{vdcc}$ & \multirow{5}{*}{$\begin{array}{l}\text { Room array, } \\
\mathrm{H} / \mathrm{Pu} \text { of } 500, \\
\text { rying } \mathrm{B}_{4} \mathrm{C} \text { per } \mathrm{CCO} \text {, } \\
\text { 11 radial compaction }\end{array}$} & 25 & 1.00637 & 0.00008 & 1.00653 & 0.11829 \\
\hline g380rmgenhx $0500 \mathrm{~b} 050 \mathrm{rd} 20 \mathrm{vdcc}$ & & 50 & 0.79308 & 0.00007 & 0.79322 & 0.15838 \\
\hline g380rmgenhx0500b100rd20vdcc & & 100 & 0.57719 & 0.00005 & 0.57729 & 0.24253 \\
\hline g380rmgenhx $0500 \mathrm{~b} 150 \mathrm{rd} 20 \mathrm{vdcc}$ & & 150 & 0.46267 & 0.00004 & 0.46276 & 0.33104 \\
\hline g380rmgenhx0500b200rd20vdcc & & 200 & 0.38827 & 0.00004 & 0.38834 & 0.42609 \\
\hline \multicolumn{7}{|l|}{$\mathrm{H} / \mathrm{Pu}$ of 600} \\
\hline g380rmgenhx0600b025rd20vdcc & \multirow{5}{*}{$\begin{array}{l}\text { Room array, } \\
\mathrm{H} / \mathrm{Pu} \text { of } 600, \\
\text { rying } \mathrm{B}_{4} \mathrm{C} \text { per } \mathrm{CCO}, \\
\text { ll radial compaction }\end{array}$} & 25 & 0.98730 & 0.00008 & 0.98745 & 0.10288 \\
\hline g380rmgenhx0600b050rd20vdcc & & 50 & 0.77882 & 0.00006 & 0.77894 & 0.13513 \\
\hline g380rmgenhx $0600 \mathrm{~b} 100 \mathrm{rd} 20 \mathrm{vdcc}$ & & 100 & 0.56710 & 0.00005 & 0.56719 & 0.20248 \\
\hline g380rmgenhx $0600 \mathrm{~b} 150 \mathrm{rd} 20 \mathrm{vdcc}$ & & 150 & 0.45565 & 0.00004 & 0.45573 & 0.27266 \\
\hline g380rmgenhx $0600 \mathrm{~b} 200 \mathrm{rd} 20 \mathrm{vdcc}$ & & 200 & 0.38402 & 0.00004 & 0.38410 & 0.34599 \\
\hline \multicolumn{7}{|l|}{$\mathrm{H} / \mathrm{Pu}$ of 700} \\
\hline g380rmgenhx0700b025rd20vdcc & \multirow{5}{*}{$\begin{array}{l}\text { Room array, } \\
\mathrm{H} / \mathrm{Pu} \text { of } 700, \\
\text { varying } \mathrm{B}_{4} \mathrm{C} \text { per } \mathrm{CCO} \text {, } \\
\text { full radial compaction }\end{array}$} & 25 & 0.96779 & 0.00007 & 0.96793 & 0.09224 \\
\hline g380rmgenhx $0700 \mathrm{~b} 050 \mathrm{rd} 20 \mathrm{vdcc}$ & & 50 & 0.76299 & 0.00007 & 0.76312 & 0.11921 \\
\hline g380rmgenhx0700b100rd20vdcc & & 100 & 0.55665 & 0.00004 & 0.55673 & 0.17528 \\
\hline g380rmgenhx0700b150rd20vdcc & & 150 & 0.44801 & 0.00004 & 0.44810 & 0.23335 \\
\hline g380rmgenhx0700b200rd20vdcc & & 200 & 0.37842 & 0.00003 & 0.37849 & 0.29345 \\
\hline \multicolumn{7}{|l|}{$\mathrm{H} / \mathrm{Pu}$ of 800} \\
\hline g380rmgenhx0800b025rd20vdcc & \multirow{5}{*}{$\begin{array}{l}\text { Room array, } \\
\mathrm{H} / \mathrm{Pu} \text { of } 800, \\
\text { varying } \mathrm{B}_{4} \mathrm{C} \text { per } \mathrm{CCO}, \\
\text { full radial compaction }\end{array}$} & 25 & 0.94760 & 0.00007 & 0.94774 & 0.08457 \\
\hline g380rmgenhx $0800 \mathrm{~b} 050 \mathrm{rd} 20 \mathrm{vdcc}$ & & 50 & 0.74839 & 0.00005 & 0.74850 & 0.10755 \\
\hline g380rmgenhx0800b100rd20vdcc & & 100 & 0.54586 & 0.00004 & 0.54595 & 0.15567 \\
\hline g380rmgenhx $0800 \mathrm{~b} 150 \mathrm{rd} 20 \mathrm{vdcc}$ & & 150 & 0.43975 & 0.00005 & 0.43984 & 0.20527 \\
\hline g380rmgenhx0800b200rd20vdcc & & 200 & 0.37225 & 0.00003 & 0.37231 & 0.25617 \\
\hline \multicolumn{7}{|l|}{$\mathrm{H} / \mathrm{Pu}$ of 895} \\
\hline g380rmgenhx0895b025rd20vdcc & Room array, & 25 & 0.93009 & 0.00007 & 0.93023 & 0.07885 \\
\hline g380rmgenhx0895b050rd20vdcc & $\mathrm{H} / \mathrm{Pu}$ of 89 & 50 & 0.73429 & 0.00006 & 0.73440 & 0.09920 \\
\hline g380rmgenhx0895b100rd20vdcc & H/Pu & 100 & 0.53601 & 0.00004 & 0.53610 & 0.14144 \\
\hline g380rmgenhx $0895 \mathrm{~b} 150 \mathrm{rd} 20 \mathrm{vdcc}$ & & 150 & 0.43229 & 0.00004 & 0.43237 & 0.18490 \\
\hline g380rmgenhx0895b200rd20vdcc & full radial compaction & 200 & 0.36617 & 0.00003 & 0.36622 & 0.22960 \\
\hline
\end{tabular}


Table B-4. Data for Figure 10

\begin{tabular}{|c|c|c|c|c|c|c|}
\hline $\begin{array}{l}\text { Legend entry on figure } \\
\text { Case }\end{array}$ & Description & $\mathbf{H} / \mathbf{P u}$ & $\boldsymbol{k}_{\text {eff }}$ & sigma & $k_{e f f}+2 \sigma$ & EALF \\
\hline \multicolumn{7}{|l|}{ infinite, brine outside } \\
\hline g380infgenhx0100b050rd20vdccbo & & 100 & 0.55741 & 0.00013 & 0.55767 & 1.01464 \\
\hline g380infgenhx0200b050rd20vdccbo & & 200 & 0.68099 & 0.00011 & 0.68121 & 0.38976 \\
\hline g380infgenhx0300b050rd20vdccbo & Infinite array, & 300 & 0.72191 & 0.00011 & 0.72213 & 0.24761 \\
\hline g380infgenhx0400b050rd20vdccbo & varying $\mathrm{H} / \mathrm{Pu}$, & 400 & 0.73263 & 0.00010 & 0.73283 & 0.18634 \\
\hline g380infgenhx0500b050rd20vdccbo & $50 \mathrm{~g} \mathrm{~B}_{4} \mathrm{C}$ per $\mathrm{CCO}$ & 500 & 0.72821 & 0.00009 & 0.72839 & 0.15229 \\
\hline g380infgenhx0600b050rd20vdccbo & full radial compaction, & 600 & 0.72208 & 0.00010 & 0.72227 & 0.13070 \\
\hline g380infgenhx0700b050rd20vdccbo & brine outside of CCO & 700 & 0.71099 & 0.00009 & 0.71116 & 0.11591 \\
\hline g380infgenhx0800b050rd20vdccbo & & 800 & 0.69951 & 0.00008 & 0.69967 & 0.10500 \\
\hline g380infgenhx0895b050rd20vdccbo & & 895 & 0.68493 & 0.00009 & 0.68510 & 0.09732 \\
\hline \multicolumn{7}{|l|}{ room, brine outside } \\
\hline g380rmgenhx0100b050rd20vdccbo & & 100 & 0.54261 & 0.00009 & 0.54279 & 1.03203 \\
\hline g380rmgenhx0200b050rd20vdccbo & & 200 & 0.67100 & 0.00009 & 0.67119 & 0.39159 \\
\hline g380rmgenhx0300b050rd20vdccbo & Room array, & 300 & 0.71509 & 0.00008 & 0.71526 & 0.24817 \\
\hline g380rmgenhx0400b050rd20vdccbo & varying $\mathrm{H} / \mathrm{Pu}$, & 400 & 0.72689 & 0.00008 & 0.72704 & 0.18648 \\
\hline g380rmgenhx0500b050rd20vdccbo & $50 \mathrm{~g} \mathrm{~B}_{4} \mathrm{C}$ per $\mathrm{CCO}$ & 500 & 0.72580 & 0.00007 & 0.72594 & 0.15232 \\
\hline g380rmgenhx0600b050rd20vdccbo & full radial compaction, & 600 & 0.71856 & 0.00007 & 0.71869 & 0.13079 \\
\hline g380rmgenhx0700b050rd20vdccbo & brine outside of $\mathrm{CCO}$ & 700 & 0.70752 & 0.00007 & 0.70766 & 0.11593 \\
\hline g380rmgenhx0800b050rd20vdccbo & & 800 & 0.69647 & 0.00006 & 0.69659 & 0.10502 \\
\hline g380rmgenhx0895b050rd20vdccbo & & 895 & 0.68499 & 0.00006 & 0.68511 & 0.09719 \\
\hline \multicolumn{7}{|l|}{ infinite, brine everywhere } \\
\hline g380infgenhx0100b050rd20vdccbe & & 100 & 0.48807 & 0.00012 & 0.48831 & 0.93052 \\
\hline g380infgenhx0200b050rd20vdccbe & Infinite array, & 200 & 0.62982 & 0.00013 & 0.63008 & 0.37733 \\
\hline g380infgenhx0300b050rd20vdccbe & varying $\mathrm{H} / \mathrm{Pu}$, & 300 & 0.68560 & 0.00013 & 0.68586 & 0.24315 \\
\hline g380infgenhx0400b050rd20vdccbe & $50 \mathrm{~g} \mathrm{~B}_{4} \mathrm{C}$ per $\mathrm{CCO}$ & 400 & 0.70535 & 0.00011 & 0.70557 & 0.18395 \\
\hline g380infgenhx0500b050rd20vdccbe & full radial compaction, & 500 & 0.70610 & 0.00011 & 0.70632 & 0.15081 \\
\hline g380infgenhx0600b050rd20vdccbe & brine everywhere & 600 & 0.70449 & 0.00010 & 0.70469 & 0.12974 \\
\hline g380infgenhx0700b050rd20vdccbe & (inside and outside of & 700 & 0.69652 & 0.00010 & 0.69672 & 0.11502 \\
\hline g380infgenhx0800b050rd20vdccbe & $\mathrm{CCO})$ & 800 & 0.68901 & 0.00010 & 0.68921 & 0.10416 \\
\hline g380infgenhx0895b050rd20vdccbe & & 895 & 0.68436 & 0.00008 & 0.68452 & 0.09714 \\
\hline \multicolumn{7}{|l|}{ room, brine everywhere } \\
\hline g380rmgenhx0100b050rd20vdccbe & & 100 & 0.48628 & 0.00010 & 0.48647 & 0.93335 \\
\hline g380rmgenhx0200b050rd20vdccbe & Room array, & 200 & 0.62753 & 0.00009 & 0.62770 & 0.37763 \\
\hline g380rmgenhx0300b050rd20vdccbe & varying $\mathrm{H} / \mathrm{Pu}$, & 300 & 0.68316 & 0.00010 & 0.68335 & 0.24326 \\
\hline g380rmgenhx0400b050rd20vdccbe & $50 \mathrm{~g} \mathrm{~B}_{4} \mathrm{C}$ per $\mathrm{CCO}$ & 400 & 0.70268 & 0.00009 & 0.70286 & 0.18406 \\
\hline g380rmgenhx0500b050rd20vdccbe & full radial compaction, & 500 & 0.70633 & 0.00007 & 0.70647 & 0.15086 \\
\hline g380rmgenhx0600b050rd20vdccbe & brine everywhere & 600 & 0.70227 & 0.00008 & 0.70243 & 0.12974 \\
\hline g380rmgenhx0700b050rd20vdccbe & (inside and outside of & 700 & 0.69352 & 0.00007 & 0.69365 & 0.11507 \\
\hline g380rmgenhx0800b050rd20vdccbe & $\mathrm{CCO})$ & 800 & 0.68616 & 0.00006 & 0.68627 & 0.10420 \\
\hline g380rmgenhx0895b050rd20vdccbe & & 895 & 0.68447 & 0.00006 & 0.68458 & 0.09705 \\
\hline
\end{tabular}


Table B-5. Data for Figure 12.

\begin{tabular}{|c|c|c|c|c|c|c|}
\hline $\begin{array}{l}\text { Legend entry on figure } \\
\text { Case }\end{array}$ & Description & $\mathbf{H} / \mathbf{P u}$ & $\boldsymbol{k}_{\text {eff }}$ & sigma & $k_{e f f}+2 \sigma$ & EALF \\
\hline \multicolumn{7}{|l|}{ infinite, no brine } \\
\hline g380infgenhx0100b050rd20vdfc & \multirow{9}{*}{$\begin{array}{l}\text { Infinite array, } \\
\text { varying } \mathrm{H} / \mathrm{Pu} \text {, } \\
0 \mathrm{~g} \mathrm{~B}_{4} \mathrm{C} \text { per } \mathrm{CCO} \text {, } \\
1 \text { radial compaction, } \\
\text { vertical compaction } \\
\text { (full collapse) }\end{array}$} & 100 & 0.80793 & 0.00009 & 0.80812 & 1.19443 \\
\hline g380infgenhx0200b050rd20vdfc & & 200 & 0.84985 & 0.00009 & 0.85003 & 0.42140 \\
\hline g380infgenhx0300b050rd20vdfc & & 300 & 0.84478 & 0.00009 & 0.84496 & 0.26172 \\
\hline g380infgenhx0400b050rd20vdfc & & 400 & 0.82839 & 0.00009 & 0.82857 & 0.19463 \\
\hline g380infgenhx0500b050rd20vdfc & & 500 & 0.80848 & 0.00008 & 0.80864 & 0.15804 \\
\hline g380infgenhx0600b050rd20vdfc & & 600 & 0.79013 & 0.00007 & 0.79028 & 0.13490 \\
\hline g380infgenhx0700b050rd20vdfc & & 700 & 0.77136 & 0.00009 & 0.77153 & 0.11903 \\
\hline g380infgenhx0800b050rd20vdfc & & 800 & 0.75412 & 0.00008 & 0.75427 & 0.10743 \\
\hline g380infgenhx0895b050rd20vdfc & & 895 & 0.73810 & 0.00009 & 0.73828 & 0.09913 \\
\hline \multicolumn{7}{|l|}{ room, no brine } \\
\hline g380rmgenhx0100b050rd20vdfc & \multirow{9}{*}{$\begin{array}{l}\text { Room array, } \\
\text { varying } \mathrm{H} / \mathrm{Pu}, \\
50 \mathrm{~g} \mathrm{~B}_{4} \mathrm{C} \text { per } \mathrm{CCO}, \\
11 \text { radial compaction, } \\
1 \text { vertical compaction } \\
\text { (full collapse) }\end{array}$} & 100 & 0.79950 & 0.00008 & 0.79965 & 1.20113 \\
\hline g380rmgenhx0200b050rd20vdfc & & 200 & 0.84364 & 0.00008 & 0.84380 & 0.42192 \\
\hline g380rmgenhx0300b050rd20vdfc & & 300 & 0.83945 & 0.00007 & 0.83958 & 0.26204 \\
\hline g380rmgenhx0400b050rd20vdfc & & 400 & 0.82358 & 0.00006 & 0.82369 & 0.19486 \\
\hline g380rmgenhx0500b050rd20vdfc & & 500 & 0.80511 & 0.00006 & 0.80523 & 0.15798 \\
\hline g380rmgenhx0600b050rd20vdfc & & 600 & 0.78586 & 0.00006 & 0.78598 & 0.13494 \\
\hline g380rmgenhx0700b050rd20vdfc & & 700 & 0.76742 & 0.00006 & 0.76754 & 0.11910 \\
\hline g380rmgenhx0800b050rd20vdfc & & 800 & 0.75036 & 0.00006 & 0.75047 & 0.10749 \\
\hline g380rmgenhx0895b050rd20vdfc & & 895 & 0.73433 & 0.00006 & 0.73445 & 0.09919 \\
\hline \multicolumn{7}{|l|}{ infinite, brine everywhere } \\
\hline g380infgenhx0100b050rd20vdfcbo & & 100 & 0.75366 & 0.00010 & 0.75386 & 1.03741 \\
\hline g380infgenhx0200b050rd20vdfcbo & Infinite array, & 200 & 0.79479 & 0.00010 & 0.79499 & 0.39144 \\
\hline g380infgenhx0300b050rd20vdfcbo & varying $\mathrm{H} / \mathrm{Pu}$, & 300 & 0.79020 & 0.00010 & 0.79039 & 0.24854 \\
\hline g380infgenhx0400b050rd20vdfcbo & $50 \mathrm{~g} \mathrm{~B}_{4} \mathrm{C}$ per $\mathrm{CCO}$ & 400 & 0.77445 & 0.00009 & 0.77464 & 0.18686 \\
\hline g380infgenhx0500b050rd20vdfcbo & full radial compaction, & 500 & 0.75477 & 0.00009 & 0.75495 & 0.15278 \\
\hline g380infgenhx0600b050rd20vdfcbo & full vertical compaction & 600 & 0.73792 & 0.00009 & 0.73811 & 0.13103 \\
\hline g380infgenhx0700b050rd20vdfcbo & (full collapse), brine & 700 & 0.72002 & 0.00008 & 0.72018 & 0.11609 \\
\hline g380infgenhx0800b050rd20vdfcbo & everywhere & 800 & 0.70346 & 0.00009 & 0.70363 & 0.10513 \\
\hline g380infgenhx0895b050rd20vdfcbo & & 895 & 0.68819 & 0.00008 & 0.68835 & 0.09718 \\
\hline \multicolumn{7}{|l|}{ room, brine everywhere } \\
\hline g380rmgenhx0100b050rd20vdfcbo & & 100 & 0.74720 & 0.00008 & 0.74735 & 1.04199 \\
\hline g380rmgenhx0200b050rd20vdfcbo & Room array, & 200 & 0.78974 & 0.00008 & 0.78990 & 0.39216 \\
\hline g380rmgenhx0300b050rd20vdfcbo & varying $\mathrm{H} / \mathrm{Pu}$, & 300 & 0.78596 & 0.00008 & 0.78613 & 0.24879 \\
\hline g380rmgenhx0400b050rd20vdfcbo & $50 \mathrm{~g} \mathrm{~B}_{4} \mathrm{C}$ per $\mathrm{CCO}$ & 400 & 0.77087 & 0.00007 & 0.77100 & 0.18704 \\
\hline g380rmgenhx0500b050rd20vdfcbo & full radial compaction, & 500 & 0.75294 & 0.00006 & 0.75307 & 0.15273 \\
\hline g380rmgenhx0600b050rd20vdfcbo & full vertical compaction & 600 & 0.73450 & 0.00007 & 0.73464 & 0.13106 \\
\hline g380rmgenhx0700b050rd20vdfcbo & (full collapse), & 700 & 0.71683 & 0.00006 & 0.71695 & 0.11613 \\
\hline g380rmgenhx0800b050rd20vdfcbo & brine everywhere & 800 & 0.70037 & 0.00006 & 0.70049 & 0.10511 \\
\hline g380rmgenhx0895b050rd20vdfcbo & & 895 & 0.68522 & 0.00006 & 0.68534 & 0.09719 \\
\hline
\end{tabular}


Table B-6. Data for Table 2.

\begin{tabular}{|c|c|c|c|c|c|}
\hline Case & Description & $\boldsymbol{k}_{\text {eff }}$ & sigma & $k_{e f f}+2 \sigma$ & EALF \\
\hline \multicolumn{6}{|l|}{ For reference } \\
\hline g380rmgenhx0200b050rdfrvdcc & $\begin{array}{l}\text { Room array (3 tier), } \mathrm{H} / \mathrm{Pu} \text { of } 200, \\
50 \mathrm{~g} \mathrm{~B}_{4} \mathrm{C} \text { per } \mathrm{CCO}, \\
\text { full radius (no compaction) }\end{array}$ & 0.53433 & 0.00010 & 0.53453 & 0.46160 \\
\hline g380rmgenhx0200b050rd20vdfc & $\begin{array}{l}\text { Room array, } \mathrm{H} / \mathrm{Pu} \text { of } 200 \text {, } \\
50 \mathrm{~g} \mathrm{~B}_{4} \mathrm{C} \text { per } \mathrm{CCO} \text {, } \\
\text { full radial and vertical compaction }\end{array}$ & 0.84364 & 0.00008 & 0.84380 & 0.42192 \\
\hline \multicolumn{6}{|l|}{$3^{\text {rd }}$ tier combined with $2^{\text {nd }}$ tier } \\
\hline $\begin{array}{l}\text { g380rmgenhx0200b050rdvarvdf } \\
\text { c_2high_fr }\end{array}$ & $\begin{array}{c}\text { Room array ( } 3 \text { tier), } \mathrm{H} / \mathrm{Pu} \text { of } 200, \\
50 \mathrm{~g} \mathrm{~B}_{4} \mathrm{C} \text { per } \mathrm{CCO}, \\
\text { bottom tier with no radial } \\
\text { compaction }\end{array}$ & 0.77330 & 0.00008 & 0.77345 & 0.42392 \\
\hline $\begin{array}{l}\text { g380rmgenhx0200b050rdvarvdf } \\
\text { c_2high_rd119 }\end{array}$ & $\begin{array}{c}\text { Room array, } \mathrm{H} / \mathrm{Pu} \text { of } 200, \\
50 \mathrm{~g} \mathrm{~B}_{4} \mathrm{C} \text { per } \mathrm{CCO}, \\
\text { bottom tier radially compacted to } \\
\text { combined tier width }\end{array}$ & 0.78431 & 0.00007 & 0.78445 & 0.42442 \\
\hline $\begin{array}{l}\text { g380rmgenhx } 0200 \mathrm{~b} 050 \mathrm{rd} 20 \mathrm{vdfc} \\
\text { 2high_rd20 }\end{array}$ & $\begin{array}{c}\text { Room array, } \mathrm{H} / \mathrm{Pu} \text { of } 200, \\
50 \mathrm{~g} \mathrm{~B}_{4} \mathrm{C} \text { per } \mathrm{CCO} \\
\text { bottom tier with full radial } \\
\text { compaction }\end{array}$ & 0.82290 & 0.00007 & 0.82303 & 0.42198 \\
\hline \multicolumn{6}{|l|}{$3^{\text {rd }}$ tier split between $2^{\text {nd }}$ and $1^{\text {st }}$ tier } \\
\hline $\begin{array}{l}\text { g380rmgenhx0200b050rd10vdfc } \\
\text { _2high_equal }\end{array}$ & $\begin{array}{l}\text { Room array, } \mathrm{H} / \mathrm{Pu} \text { of } 200, \\
50 \mathrm{~g} \mathrm{~B}_{4} \mathrm{C} \text { per } \mathrm{CCO}, \\
\text { radially compacted to original } \\
\text { room width }\end{array}$ & 0.65443 & 0.00010 & 0.65443 & 0.43699 \\
\hline $\begin{array}{l}\text { g380rmgenhx0200b050rd20vdfc } \\
\text { _2high_equal }\end{array}$ & $\begin{array}{l}\text { Room array, } \mathrm{H} / \mathrm{Pu} \text { of } 200 \\
50 \mathrm{~g} \mathrm{~B}_{4} \mathrm{C} \text { per } \mathrm{CCO} \\
\text { full radial compaction }\end{array}$ & 0.82593 & 0.00007 & 0.82593 & 0.42182 \\
\hline
\end{tabular}


Table B-7. Data for Figure 13.

\begin{tabular}{|c|c|c|c|c|c|c|}
\hline $\begin{array}{r}\text { Legend entry on figure } \\
\text { Case }\end{array}$ & Description & $\mathbf{H} / \mathbf{P u}$ & $\boldsymbol{k}_{\text {eff }}$ & sigma & $k_{e f f}+2 \sigma$ & EALF \\
\hline \multicolumn{7}{|l|}{$100 \%$ polyethylene, double density } \\
\hline g380rmpol2hx0100b050rd20vdfc & & 100 & 0.81126 & 0.00007 & 0.81141 & 1.18219 \\
\hline g380rmpol2hx0200b050rd20vdfc & & 200 & 0.86157 & 0.00007 & 0.86172 & 0.41330 \\
\hline g380rmpol2hx0300b050rd20vdfc & & 300 & 0.86270 & 0.00006 & 0.86283 & 0.25510 \\
\hline g380rmpol2hx0400b050rd20vdfc & & 400 & 0.85103 & 0.00007 & 0.85116 & 0.18885 \\
\hline g380rmpol2hx0500b050rd20vdfc & & 500 & 0.83588 & 0.00006 & 0.83600 & 0.15271 \\
\hline g380rmpol2hx0600b050rd20vdfc & & 600 & 0.82040 & 0.00006 & 0.82052 & 0.12992 \\
\hline g380rmpol2hx0700b050rd20vdfc & & 700 & 0.80501 & 0.00005 & 0.80512 & 0.11432 \\
\hline g380rmpol2hx0800b050rd20vdfc & & 800 & 0.78986 & 0.00006 & 0.78998 & 0.10309 \\
\hline g380rmpol2hx0900b050rd20vdfc & \multirow{5}{*}{$\begin{array}{c}\text { Room array, } \\
\text { waste mix is } 100 \% \\
\text { polyethylene at double } \\
\text { density, } \\
\text { varying } \mathrm{H} / \mathrm{Pu},\end{array}$} & 900 & 0.77629 & 0.00006 & 0.77641 & 0.09447 \\
\hline g380rmpol2hx1000b050rd20vdfc & & 1000 & 0.76358 & 0.00005 & 0.76368 & 0.08771 \\
\hline g380rmpol2hx1100b050rd20vdfc & & 1100 & 0.75123 & 0.00005 & 0.75134 & 0.08233 \\
\hline g380rmpol2hx1200b050rd20vdfc & & 1200 & 0.73842 & 0.00005 & 0.73851 & 0.07799 \\
\hline g380rmpol2hx1300b050rd20vdfc & & 1300 & 0.72773 & 0.00005 & 0.72783 & 0.07425 \\
\hline g380rmpol2hx1400b050rd20vdfc & \multirow{10}{*}{$\begin{array}{l}50 \mathrm{~g} \mathrm{~B}_{4} \mathrm{C} \text { per } \mathrm{CCO} \text {, } \\
\text { full radial compaction, }\end{array}$} & 1400 & 0.71713 & 0.00006 & 0.71724 & 0.07113 \\
\hline g380rmpol2hx1500b050rd20vdfc & & 1500 & 0.70706 & 0.00004 & 0.70715 & 0.06843 \\
\hline g380rmpol2hx1600b050rd20vdfc & & 1600 & 0.69707 & 0.00006 & 0.69718 & 0.06612 \\
\hline g380rmpol2hx1700b050rd20vdfc & & 1700 & 0.68678 & 0.00005 & 0.68688 & 0.06416 \\
\hline g380rmpol2hx1800b050rd20vdfc & & 1800 & 0.67702 & 0.00004 & 0.67710 & 0.06241 \\
\hline g380rmpol2hx1900b050rd20vdfc & & 1900 & 0.66913 & 0.00005 & 0.66923 & 0.06076 \\
\hline g380rmpol2hx2000b050rd20vdfc & & 2000 & 0.65973 & 0.00005 & 0.65983 & 0.05937 \\
\hline g380rmpol2hx2100b050rd20vdfc & & 2100 & 0.65214 & 0.00005 & 0.65224 & 0.05808 \\
\hline g380rmpol2hx2200b050rd20vdfc & & 2200 & 0.64411 & 0.00005 & 0.64420 & 0.05693 \\
\hline g380rmpol2hx2225b050rd20vdfc & & 2225 & 0.64281 & 0.00005 & 0.64290 & 0.05663 \\
\hline \multicolumn{7}{|l|}{$100 \%$ polyethylene } \\
\hline g380rmpolhx0100b050rd20vdfc & \multirow{11}{*}{$\begin{array}{c}\text { Room array, } \\
\text { waste mix is } 100 \% \\
\text { polyethylene, } \\
\text { varying } \mathrm{H} / \mathrm{Pu}, \\
50 \mathrm{~g} \mathrm{~B}_{4} \mathrm{C} \text { per } \mathrm{CCO}, \\
\text { full radial compaction, }\end{array}$} & 100 & 0.80319 & 0.00008 & 0.80334 & 1.18866 \\
\hline g380rmpolhx0200b050rd20vdfc & & 200 & 0.84862 & 0.00008 & 0.84877 & 0.41799 \\
\hline g380rmpolhx0300b050rd20vdfc & & 300 & 0.84549 & 0.00007 & 0.84563 & 0.25934 \\
\hline g380rmpolhx0400b050rd20vdfc & & 400 & 0.83037 & 0.00007 & 0.83051 & 0.19273 \\
\hline g380rmpolhx0500b050rd20vdfc & & 500 & 0.81199 & 0.00006 & 0.81210 & 0.15633 \\
\hline g380rmpolhx0600b050rd20vdfc & & 600 & 0.79403 & 0.00006 & 0.79414 & 0.13334 \\
\hline g380rmpolhx0700b050rd20vdfc & & 700 & 0.77605 & 0.00006 & 0.77616 & 0.11763 \\
\hline g380rmpolhx0800b050rd20vdfc & & 800 & 0.75857 & 0.00007 & 0.75872 & 0.10627 \\
\hline g380rmpolhx0900b050rd20vdfc & & 900 & 0.74290 & 0.00006 & 0.74301 & 0.09755 \\
\hline g380rmpolhx1000b050rd20vdfc & & 1000 & 0.72834 & 0.00006 & 0.72846 & 0.09069 \\
\hline g380rmpolhx1023b050rd20vdfc & & 1023 & 0.72443 & 0.00005 & 0.72453 & 0.08941 \\
\hline \multicolumn{7}{|l|}{$100 \%$ water } \\
\hline g380rmwathx0100b050rd20vdfc & & 100 & 0.79834 & 0.00007 & 0.79848 & 1.20520 \\
\hline g380rmwathx0200b050rd20vdfc & & 200 & 0.84196 & 0.00007 & 0.84209 & 0.42340 \\
\hline g380rmwathx0300b050rd20vdfc & Room array, & 300 & 0.83725 & 0.00007 & 0.83738 & 0.26307 \\
\hline g380rmwathx0400b050rd20vdfc & waste mix is $100 \%$ water, & 400 & 0.82098 & 0.00006 & 0.82109 & 0.19572 \\
\hline g380rmwathx0500b050rd20vdfc & varying $\mathrm{H} / \mathrm{Pu}$ & 500 & 0.80239 & 0.00007 & 0.80253 & 0.15867 \\
\hline g380rmwathx0600b050rd20vdfc & $50 \mathrm{~g} \mathrm{~B}_{4} \mathrm{C}$ per $\mathrm{CCO}$ & 600 & 0.78293 & 0.00006 & 0.78304 & 0.13551 \\
\hline g380rmwathx0700b050rd20vdfc & full radial compaction, & 700 & 0.76483 & 0.00007 & 0.76498 & 0.11954 \\
\hline g380rmwathx0800b050rd20vdfc & & 800 & 0.74650 & 0.00006 & 0.74662 & 0.10808 \\
\hline g380rmwathx0860b050rd20vdfc & & 860 & 0.73731 & 0.00006 & 0.73743 & 0.10243 \\
\hline
\end{tabular}


Table B-8. Data for Figure 14.

\begin{tabular}{|c|c|c|c|c|c|c|}
\hline $\begin{array}{r}\text { Legend entry on figure } \\
\text { Case }\end{array}$ & Description & $\mathbf{H} / \mathbf{P u}$ & $\boldsymbol{k}_{\text {eff }}$ & sigma & $k_{e f f}+2 \sigma$ & EALF \\
\hline \multicolumn{7}{|l|}{ full radial and vertical compaction } \\
\hline g380rmgenhx0100b050rd20vdfcmgo & \multirow{9}{*}{$\begin{array}{c}\text { Room array, } \\
\text { varying } \mathrm{H} / \mathrm{Pu}, \\
50 \mathrm{~g} \mathrm{~B}_{4} \mathrm{C} \text { per } \mathrm{CCO}, \\
\text { full radial compaction, } \\
\text { full vertical compaction } \\
\text { (full collapse), } \\
\mathrm{MgO} \text { surrounding the } \\
\text { CCOs }\end{array}$} & 100 & 0.80111 & 0.00007 & 0.80125 & 1.19191 \\
\hline g380rmgenhx0200b050rd20vdfcmgo & & 200 & 0.84448 & 0.00007 & 0.84462 & 0.42034 \\
\hline g380rmgenhx 0300b050rd20vdfcmgo & & 300 & 0.83988 & 0.00007 & 0.84001 & 0.26132 \\
\hline g380rmgenhx0400b050rd20vdfcmgo & & 400 & 0.82394 & 0.00006 & 0.82406 & 0.19441 \\
\hline g380rmgenhx0500b050rd20vdfcmgo & & 500 & 0.80535 & 0.00007 & 0.80548 & 0.15775 \\
\hline g380rmgenhx0600b050rd20vdfcmgo & & 600 & 0.78599 & 0.00006 & 0.78612 & 0.13472 \\
\hline g380rmgenhx0700b050rd20vdfemgo & & 700 & 0.76753 & 0.00005 & 0.76764 & 0.11894 \\
\hline g380rmgenhx0800b050rd20vdfcmgo & & 800 & 0.75028 & 0.00006 & 0.75039 & 0.10736 \\
\hline g380rmgenhx0895b050rd20vdfcmgo & & 895 & 0.73443 & 0.00006 & 0.73454 & 0.09907 \\
\hline \multicolumn{7}{|l|}{ full radial compaction } \\
\hline g380rmgenhx0100b050rd20vdccmgo & \multirow{9}{*}{$\begin{array}{l}\text { Room array, } \\
\text { varying } \mathrm{H} / \mathrm{Pu} \text {, } \\
50 \mathrm{~g} \mathrm{~B}_{4} \mathrm{C} \text { per } \mathrm{CCO} \text {, } \\
11 \text { radial compaction, } \\
\text { IgO surrounding the } \\
\text { CCOs }\end{array}$} & 100 & 0.72801 & 0.00008 & 0.72817 & 1.21709 \\
\hline g380rmgenhx0200b050rd20vdccmgo & & 200 & 0.80109 & 0.00007 & 0.80123 & 0.42405 \\
\hline g380rmgenhx0300b050rd20vdccmgo & & 300 & 0.81221 & 0.00009 & 0.81238 & 0.26256 \\
\hline g380rmgenhx0400b050rd20vdccmgo & & 400 & 0.80576 & 0.00006 & 0.80589 & 0.19497 \\
\hline g380rmgenhx0500b050rd20vdccmgo & & 500 & 0.79367 & 0.00007 & 0.79380 & 0.15801 \\
\hline g380rmgenhx0600b050rd20vdccmgo & & 600 & 0.77903 & 0.00007 & 0.77916 & 0.13487 \\
\hline g380rmgenhx0700b050rd20vdccmgo & & 700 & 0.76331 & 0.00007 & 0.76344 & 0.11902 \\
\hline g380rmgenhx0800b050rd20vdccmgo & & 800 & 0.74837 & 0.00006 & 0.74849 & 0.10740 \\
\hline g380rmgenhx0895b050rd20vdccmgo & & 895 & 0.73408 & 0.00006 & 0.73419 & 0.09905 \\
\hline \multicolumn{7}{|l|}{ no compaction } \\
\hline g380rmgenhx0100b050rdfrvdccmgo & & 100 & 0.40573 & 0.00009 & 0.40590 & 0.94761 \\
\hline g380rmgenhx0200b050rdfrvdccmgo & Room array, & 200 & 0.52091 & 0.00011 & 0.52113 & 0.37017 \\
\hline g380rmgenhx0300b050rdfrvdccmgo & varying $\mathrm{H} / \mathrm{Pu}$, & 300 & 0.57015 & 0.00009 & 0.57033 & 0.23712 \\
\hline g380rmgenhx0400b050rdfrvdccmgo & $50 \mathrm{~g} \mathrm{~B}_{4} \mathrm{C}$ per $\mathrm{CCO}$ & 400 & 0.59371 & 0.00009 & 0.59389 & 0.17951 \\
\hline g380rmgenhx0500b050rdfrvdccmgo & full radius (no & 500 & 0.60542 & 0.00008 & 0.60558 & 0.14733 \\
\hline g380rmgenhx0600b050rdfrvdccmgo & compaction), & 600 & 0.61143 & 0.00007 & 0.61157 & 0.12695 \\
\hline g380rmgenhx0700b050rdfrvdccmgo & $\mathrm{MgO}$ surrounding the & 700 & 0.61140 & 0.00008 & 0.61155 & 0.11288 \\
\hline g380rmgenhx0800b050rdfrvdccmgo & $\mathrm{CCOs}$ & 800 & 0.61042 & 0.00007 & 0.61056 & 0.10250 \\
\hline g380rmgenhx0895b050rdfrvdccmgo & & 895 & 0.60723 & 0.00008 & 0.60738 & 0.09503 \\
\hline
\end{tabular}





\section{APPENDIX C. ELECTRONIC FILES}

The following spreadsheets contain the material composition derivations and dimensions used in the calculations.

\section{Spreadsheet name:}

NF Mix Composition.xlsx

k5 geom dec array sp w ccc struc.xlsx

\section{Description:}

Contains the waste form material composition and dimension derivations

Contains the dimension derivations for array geometries modeled in KENO V.a

The majority of the calculational files (input files ending in ".inp" and output files ending in ".out") are arranged in folders, with the folder name identifying the respective table in which the calculational results are reported. Included in each table folder is a summary text file (ending in ".dat") of the $k_{\text {eff }}$ values and EALF (energy of average neutron lethargy causing fission) values. The validation calculational files are in the folder entitled Validation. The validation files include input and output files, sensitivity files (ending in ".sdf"), and the USLSTATS files (contained in folders ending in ".uslstats"). 



\section{APPENDIX D. CALCULATIONAL VALIDATION}

The calculations for this report were performed using the SCALE code system, version 6.2.3. The Criticality Safety Analysis Sequence (CSAS) with KENO V.a (CSAS5) was used to calculate effective neutron multiplication factors, or k-effective $\left(k_{e f f}\right)$ values, for the various scenarios analyzed. As with any computer code or calculation used in relation to safety analyses and assessments, the ability of the calculation methodology to prove a configuration subcritical is obtained through a validation process.

The validation process assesses how well a computational method predicts reality (e.g., whether a system that was calculated to be subcritical is in reality subcritical). Applicable industry standards, such as the American National Standards Institute (ANSI)/American Nuclear Society (ANS)-8 standards, $A n$ American National Standard for Nuclear Criticality Safety in Operations with Fissionable Materials Outside Reactors, ANSI/ANS-8.1-2014 [1], and An American National Standard for Validation on Neutron Transport Methods for Nuclear Criticality Safety Calculations, ANSI/ANS-8.24-2017 [2], require validation to be conducted through comparisons of computed results with experimental data. Typically, well-documented critical experiments (critical benchmarks) are used for these comparisons. Documented critical experiments can be found in a variety of resources, including the International Handbook of Evaluated Criticality Safety Benchmark Experiments [3]. Ideally, models of critical experiments would calculate results that are exactly equal to experimental results. In reality, calculational results do not exactly match experimental results because of simplifications and approximations made in the computational models to facilitate solutions on computer systems. Furthermore, the nuclear data used may include errors associated with the measurement, evaluation, and/or representation of the data. The validation process provides an understanding of the difference between calculated and experimental results, or bias, and the uncertainty in this difference, or bias uncertainty.

For a validation to yield an appropriate bias and bias uncertainty, the critical experiments used for comparison must be as similar as possible to the application being validated. Critical experiments are arrangements of fissile material and structural materials usually performed to support operational needs and processes. Validation of waste disposal operations can be challenging due to the difficulty in finding experiments similar in nature to waste disposal materials and operations.

The validation results (bias and bias uncertainty) are used to determine an upper subcritical limit (USL). Calculated results (including calculational uncertainty, $k_{\text {eff-calc }}+2 \sigma_{\text {calc }}$ ) below the USL are considered subcritical; results above the USL (even those below 1.0) are not considered to be subcritical. Determination of the USL can also include an additional margin of subcriticality to account for dissimilarities between the experiments used and the application and identified gaps in the nuclear data. The USL can be considered as the magnitude of the sum of the biases, uncertainties, and administrative and/or statistical margins applied to a set of critical benchmarks. Because a positive bias may be nonconservative, all positive biases are set to zero. An allowance to use a positive bias, if the cause of the positive bias is well understood and justified, has been established in [2], but is not typical. The USL can be represented by the following:

$$
\begin{gathered}
\mathrm{USL}=1.0+\text { bias }- \text { bias uncertainty }- \text { administrative margin } \\
k_{\text {eff-calc }}+2 \sigma_{\text {calc }}<\text { USL }
\end{gathered}
$$

Historically, the expected computational bias is established with the use of trending analyses of the bias for the critical experiments as a function of their physical characteristics such as $\mathrm{H} / \mathrm{X}$ or energy of average neutron lethargy causing fission (EALF). The bias uncertainty is then determined through a statistical analysis of the trend, taking into account the uncertainty in each $k_{\text {eff }}$ data point and the distribution of the data. The trending analysis can also be done with sensitivity/uncertainty $(\mathrm{S} / \mathrm{U})$ tools. The $\mathrm{S} / \mathrm{U}$ tools are 
used to determine correlation coefficients $\left(\mathrm{c}_{\mathrm{k}}\right.$ value or $\left.\mathrm{c}(\mathrm{k})\right)$ for trending analysis. This report uses both $\mathrm{c}(\mathrm{k})$ and EALF values for trending analyses.

For the S/U method, the TSUNAMI sequence included in the SCALE code system was used to quantify the similarity of each selected critical experiment and application model pair. This technique provides a physics-based approach to benchmark critical experiment selection. The TSUNAMI methods are based on the premise that the primary source of computational biases are the errors in the cross section data as bounded by their uncertainties, which can be tabulated in cross section covariance data. The TSUNAMI3D sequence was used to compute sensitivity data for the applications and for each selected critical experiment. The TSUNAMI-IP sequence was then used to compare the sensitivity data between the application and the critical experiments, giving greater weight to comparisons of sensitivities for nuclides and reactions with the highest nuclear data uncertainties. For each model, TSUNAMI-IP combined the sensitivity data and the cross section covariance data to generate nuclide-, reaction-, and energydependent $k_{\text {eff }}$ uncertainty data. A correlation coefficient, $\mathrm{c}_{\mathrm{k}}$ value or $\mathrm{c}(\mathrm{k})$, was calculated, indicating the degree to which each application and critical experiment model pair share $k_{\text {eff }}$ uncertainty. A high $\mathrm{c}_{\mathrm{k}}$ value (approaching one) would indicate that the two compared systems share a similar sensitivity to the same nuclear data uncertainty. Based on the assumption that computational biases are due primarily to nuclear data errors and that the nuclear data uncertainty values should indicate the potential for such nuclear data errors, two highly correlated systems should exhibit the same computational bias. The Upper Subcritical Limit Statistics (USLSTATS) program, a statistical analysis program distributed with SCALE, was then used to perform a trending analysis on the $\mathrm{c}(\mathrm{k})$ values and calculate the final bias, bias uncertainty, and resulting USL. USLSTATS was also used with the EALF values as the trending parameter for comparison.

For this analysis, the applications were the cases with the highest calculated system $k_{e f f} \mathrm{~s}$, with consideration of both a dry and wet scenario. The criticality experiments chosen are from The SCALE Verified, Archived Library of Inputs and Data-VALID [4], with all of the chosen experiments also included in the International Handbook of Evaluated Criticality Safety Benchmark Experiments [3]. There were 81 experiments chosen from the plutonium-solution-thermal category (PST), 21 from the mixed-composition-thermal category (MCT), and 10 from the mixed-solution-thermal category (MST), with an EALF range of 0.04 to $0.95 \mathrm{eV}$. The experiments are similar to the applications in the ${ }^{239} \mathrm{Pu}$ content with an average of $>95 \%{ }^{239} \mathrm{Pu}$ in the $\mathrm{Pu}$ content. The plutonium solution experiments are water moderated and are in the thermal energy region. The mixed composition and mixed solution experiments systems cover more of the upper thermal into intermediate energy regions. Most of the important isotopes from the application systems are included in the experiments chosen (e.g., hydrogen, boron, and carbon), the exceptions being beryllium and chlorine.

To account for the potential bias from the beryllium and chlorine, their respective nuclear data uncertainties were used to develop a bounding estimate of their bias. This methodology is described in $A n$ Approach for Validating Actinide and Fission Product Burnup Credit Criticality Safety AnalysesCriticality $\left(k_{\text {eff }}\right)$ Predictions [5]. The sensitivity files generated by the TSUNAMI-3D sequence lists the uncertainty for each nuclide reaction. The total uncertainties for beryllium and chlorine are determined by combining the individual nuclide reaction uncertainties. This uncertainty is then combined with the bias and bias uncertainty determined by USLSTATS. Per Reference [5], three times the nuclear data uncertainty is a conservative bounding estimate for the bias.

\section{D.1 RECONFIGURED DRY SCENARIO}

For the dry scenario, the case chosen is g380infgenhx0200b050rd20vdcc, which has $50 \mathrm{~g}$ of $\mathrm{B}_{4} \mathrm{C}$ and $545 \mathrm{~g}$ of beryllium into the waste form with a $k_{\text {eff }}+2 \sigma$ of 0.82549 and an EALF of $0.42 \mathrm{eV}$. The case is an infinite array with full radial compaction. The TSUNAMI-IP calculated $\mathrm{c}(\mathrm{k})$ values are provided in Table 
D.1. From the compared critical experiments, the $\mathrm{c}(\mathrm{k})$ values ranged from 0.63 to 0.78 . Ideally, benchmark experiments should have a $\mathrm{c}(\mathrm{k})$ greater than 0.8 to be considered for validation. However, experiments that model materials similar to this waste form do not exist.

Table D-1. Reconfigured dry scenario $\mathrm{c}(\mathrm{k})$ values.

\begin{tabular}{|c|c|c|c|c|c|c|c|}
\hline Experiment & $\begin{array}{c}\mathbf{c}(\mathbf{k}) \\
\text { value }\end{array}$ & Experiment & $\begin{array}{c}\mathbf{c}(\mathbf{k}) \\
\text { value }\end{array}$ & Experiment & $\begin{array}{c}\mathbf{c}(\mathbf{k}) \\
\text { value }\end{array}$ & Experiment & $\begin{array}{c}\mathbf{c}(\mathbf{k}) \\
\text { value }\end{array}$ \\
\hline MCT-002-004S & 0.77 & PST-005-007 & 0.66 & PST-003-002 & 0.65 & PST-007-005 & 0.64 \\
\hline MCT-002-006S & 0.76 & PST-005-001 & 0.66 & PST-011-012 & 0.65 & PST-007-004 & 0.64 \\
\hline MST-007-002 & 0.71 & PST-004-007 & 0.66 & PST-003-001 & 0.65 & PST-007-008 & 0.64 \\
\hline MST-007-001 & 0.71 & PST-004-009 & 0.66 & PST-011-007 & 0.65 & MCT-004-010 & 0.64 \\
\hline MCT-001-001 & 0.71 & PST-020-002 & 0.66 & PST-011-011 & 0.65 & MCT-004-003 & 0.64 \\
\hline MCT-001-002 & 0.69 & PST-020-009 & 0.66 & PST-011-008 & 0.65 & PST-007-006 & 0.64 \\
\hline MST-002-003 & 0.68 & PST-004-008 & 0.66 & PST-011-009 & 0.65 & PST-007-007 & 0.64 \\
\hline MST-007-003 & 0.68 & PST-004-012 & 0.66 & PST-011-006 & 0.65 & MCT-004-007 & 0.64 \\
\hline MCT-001-003 & 0.68 & PST-004-013 & 0.66 & PST-007-001 & 0.65 & MCT-004-005 & 0.64 \\
\hline MCT-002-002S & 0.68 & PST-004-006 & 0.66 & PST-002-005 & 0.65 & PST-020-008 & 0.64 \\
\hline MST-002-001 & 0.68 & PST-020-015 & 0.66 & PST-002-004 & 0.65 & PST-011-003 & 0.64 \\
\hline MCT-001-004 & 0.68 & PST-020-001 & 0.66 & PST-002-001 & 0.65 & MCT-004-002 & 0.64 \\
\hline MST-002-002 & 0.68 & PST-020-010 & 0.66 & МСТ-004-009 & 0.65 & PST-020-007 & 0.64 \\
\hline PST-020-005 & 0.67 & PST-004-011 & 0.66 & PST-002-002 & 0.65 & PST-020-013 & 0.64 \\
\hline PST-020-012 & 0.67 & PST-004-005 & 0.66 & PST-001-004 & 0.65 & PST-011-002 & 0.64 \\
\hline PST-006-003 & 0.67 & PST-004-003 & 0.66 & PST-001-003 & 0.65 & PST-003-008 & 0.64 \\
\hline PST-006-002 & 0.67 & PST-020-003 & 0.66 & PST-001-005 & 0.65 & PST-003-007 & 0.64 \\
\hline PST-006-001 & 0.67 & PST-004-004 & 0.66 & PST-001-006 & 0.65 & PST-011-001 & 0.64 \\
\hline MST-007-004 & 0.67 & PST-020-004 & 0.66 & МСТ-004-006 & 0.65 & МСТ-004-004 & 0.64 \\
\hline PST-020-006 & 0.67 & PST-020-011 & 0.66 & MCT-004-011 & 0.65 & PST-011-004 & 0.64 \\
\hline PST-005-005 & 0.66 & PST-004-002 & 0.66 & PST-002-006 & 0.65 & PST-020-014 & 0.64 \\
\hline PST-005-004 & 0.66 & PST-004-001 & 0.66 & PST-002-007 & 0.65 & MST-007-006 & 0.64 \\
\hline PST-005-006 & 0.66 & MST-007-005 & 0.66 & PST-002-003 & 0.65 & MCT-004-001 & 0.63 \\
\hline PST-005-009 & 0.66 & PST-011-010 & 0.66 & PST-007-002 & 0.65 & PST-011-005 & 0.63 \\
\hline PST-005-003 & 0.66 & PST-003-004 & 0.66 & PST-007-003 & 0.65 & MCT-002-005S & 0.63 \\
\hline PST-005-002 & 0.66 & PST-003-005 & 0.66 & PST-001-002 & 0.65 & MST-007-007 & 0.63 \\
\hline PST-005-008 & 0.66 & PST-003-003 & 0.66 & PST-001-001 & 0.65 & MCT-002-001S & 0.63 \\
\hline PST-004-010 & 0.66 & PST-003-006 & 0.66 & MCT-004-008 & 0.64 & MCT-002-003S & 0.62 \\
\hline
\end{tabular}

Figure D-1 is the trending analysis plot generated by the USLSTATS program with no additional administrative margin. 


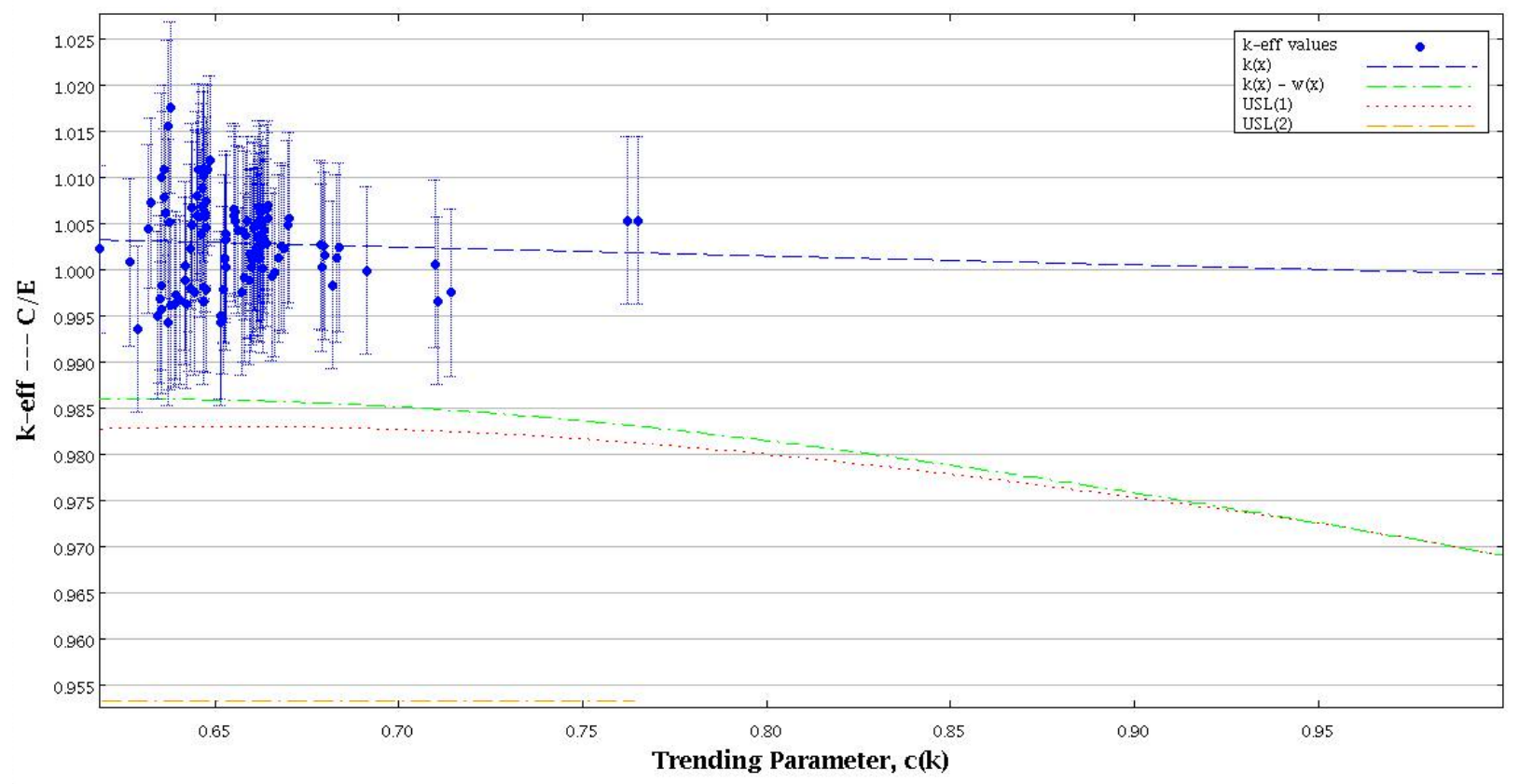

Figure D-1. Trending analysis plot of $c(k)$ for reconfigured dry scenario.

The critical experiments used for benchmarking include, to the extent possible, configurations having neutronics and geometric characteristics comparable to those of the proposed design basis configurations. Because the application models are slightly outside the range of applicability of the benchmark experiments, as indicated by the $\mathrm{c}(\mathrm{k})$ values being less than optimal, an administrative margin of 0.02 is added to account for deficiencies in matching the critical experiments used for validation with the bounding models for this analysis. An additional margin is added to account for the potential bias from beryllium and chlorine, determined as described above using the uncertainty data for the beryllium and chlorine reactions from the sensitivity file. The respective numbers used to determine the USL along with the resultant USL are listed below:
Bias (from USLSTATS):
0.0010
Uncertainty in the bias (from USLSTATS): $\quad 0.0294$
Margin for beryllium and chlorine:
0.0010
Administrative margin:
0.02
Resulting USL:
0.9486

\section{D.2 RECONFIGURED WET SCENARIO}

For the reconfigured wet scenario, the case chosen is g380infgenhx0200b050rd20vdfcbo, which has $50 \mathrm{~g}$ of $\mathrm{B}_{4} \mathrm{C}$ and $545 \mathrm{~g}$ of beryllium into the waste form with a $k_{\text {eff }}+2 \sigma$ of 0.79499 and an EALF of $0.39 \mathrm{eV}$. The case is an infinite flooded (with brine) array with full radial and vertical compaction. The TSUNAMI-IP calculated $\mathrm{c}(\mathrm{k})$ values are given in Table D-2. From the compared critical experiments, the $\mathrm{c}(\mathrm{k})$ values ranged from 0.63 to 0.78 Ideally, benchmark experiments should have a $\mathrm{c}(\mathrm{k})$ greater than 0.8 to be considered for validation. However, experiments that model materials similar to this waste form do not exist. 
Table D-2. Reconfigured wet scenario $\mathrm{c}(\mathrm{k})$ values.

\begin{tabular}{|c|c|c|c|c|c|c|c|}
\hline Experiment & $\begin{array}{c}\mathbf{c}(\mathbf{k}) \\
\text { value }\end{array}$ & Experiment & $\begin{array}{c}\mathbf{c}(\mathbf{k}) \\
\text { value }\end{array}$ & Experiment & $\begin{array}{c}\mathbf{c}(\mathbf{k}) \\
\text { value }\end{array}$ & Experiment & $\begin{array}{r}\mathbf{c}(\mathbf{k}) \\
\text { value }\end{array}$ \\
\hline MCT-002-004S & 0.78 & PST-004-009 & 0.68 & PST-003-006 & 0.67 & MCT-004-003 & 0.66 \\
\hline MCT-002-006S & 0.78 & PST-004-010 & 0.68 & PST-011-008 & 0.67 & MCT-004-007 & 0.66 \\
\hline MST-007-002 & 0.73 & MST-007-004 & 0.68 & PST-011-011 & 0.67 & PST-007-005 & 0.66 \\
\hline MST-007-001 & 0.72 & PST-005-007 & 0.68 & PST-011-009 & 0.67 & PST-007-004 & 0.66 \\
\hline MCT-001-001 & 0.72 & PST-004-008 & 0.68 & MST-007-005 & 0.67 & PST-007-002 & 0.65 \\
\hline MCT-001-002 & 0.70 & PST-004-012 & 0.68 & PST-011-006 & 0.67 & PST-007-008 & 0.65 \\
\hline MST-002-003 & 0.70 & PST-004-013 & 0.68 & PST-003-002 & 0.67 & MCT-004-005 & 0.65 \\
\hline MST-002-001 & 0.70 & PST-020-002 & 0.68 & PST-003-001 & 0.67 & PST-020-008 & 0.65 \\
\hline MST-002-002 & 0.70 & PST-004-006 & 0.68 & МСТ-004-009 & 0.66 & PST-007-007 & 0.65 \\
\hline MST-007-003 & 0.69 & PST-020-009 & 0.68 & MCT-004-011 & 0.66 & PST-007-006 & 0.65 \\
\hline MCT-001-003 & 0.69 & PST-020-015 & 0.68 & МСТ-004-006 & 0.66 & PST-011-003 & 0.65 \\
\hline МCТ-001-004 & 0.69 & PST-020-010 & 0.68 & PST-002-001 & 0.66 & PST-003-008 & 0.65 \\
\hline MCT-002-002S & 0.69 & PST-004-005 & 0.68 & PST-002-005 & 0.66 & PST-011-002 & 0.65 \\
\hline PST-006-003 & 0.68 & PST-004-003 & 0.67 & PST-002-002 & 0.66 & PST-003-007 & 0.65 \\
\hline PST-006-002 & 0.68 & PST-020-001 & 0.67 & PST-002-004 & 0.66 & PST-020-013 & 0.65 \\
\hline PST-006-001 & 0.68 & PST-004-004 & 0.67 & МСТ-004-008 & 0.66 & MCT-004-002 & 0.65 \\
\hline PST-020-005 & 0.68 & PST-020-003 & 0.67 & MCT-004-010 & 0.66 & PST-011-001 & 0.65 \\
\hline PST-020-012 & 0.68 & PST-004-011 & 0.67 & PST-002-003 & 0.66 & PST-011-004 & 0.65 \\
\hline PST-020-006 & 0.68 & PST-004-002 & 0.67 & PST-002-006 & 0.66 & PST-020-007 & 0.65 \\
\hline PST-005-004 & 0.68 & PST-004-001 & 0.67 & PST-002-007 & 0.66 & MCT-004-004 & 0.65 \\
\hline PST-005-005 & 0.68 & PST-011-010 & 0.67 & PST-007-001 & 0.66 & PST-020-014 & 0.65 \\
\hline PST-005-009 & 0.68 & PST-020-004 & 0.67 & PST-001-003 & 0.66 & MCT-004-001 & 0.65 \\
\hline PST-005-006 & 0.68 & PST-020-011 & 0.67 & PST-001-004 & 0.66 & PST-011-005 & 0.65 \\
\hline PST-005-002 & 0.68 & PST-003-004 & 0.67 & PST-001-005 & 0.66 & MCT-002-005S & 0.65 \\
\hline PST-005-003 & 0.68 & PST-003-003 & 0.67 & PST-001-006 & 0.66 & MST-007-006 & 0.65 \\
\hline PST-005-008 & 0.68 & PST-011-012 & 0.67 & PST-001-001 & 0.66 & MST-007-007 & 0.64 \\
\hline PST-005-001 & 0.68 & PST-003-005 & 0.67 & PST-007-003 & 0.66 & MCT-002-001S & 0.64 \\
\hline PST-004-007 & 0.68 & PST-011-007 & 0.67 & PST-001-002 & 0.66 & MCT-002-003S & 0.63 \\
\hline PST-004-007 & 0.68 & PST-011-007 & 0.67 & PST-001-002 & 0.66 & MCT-002-003S & 0.63 \\
\hline
\end{tabular}

Figure D-2 is the trending analysis plot generated by the USLSTATS program with no additional administrative margin. 


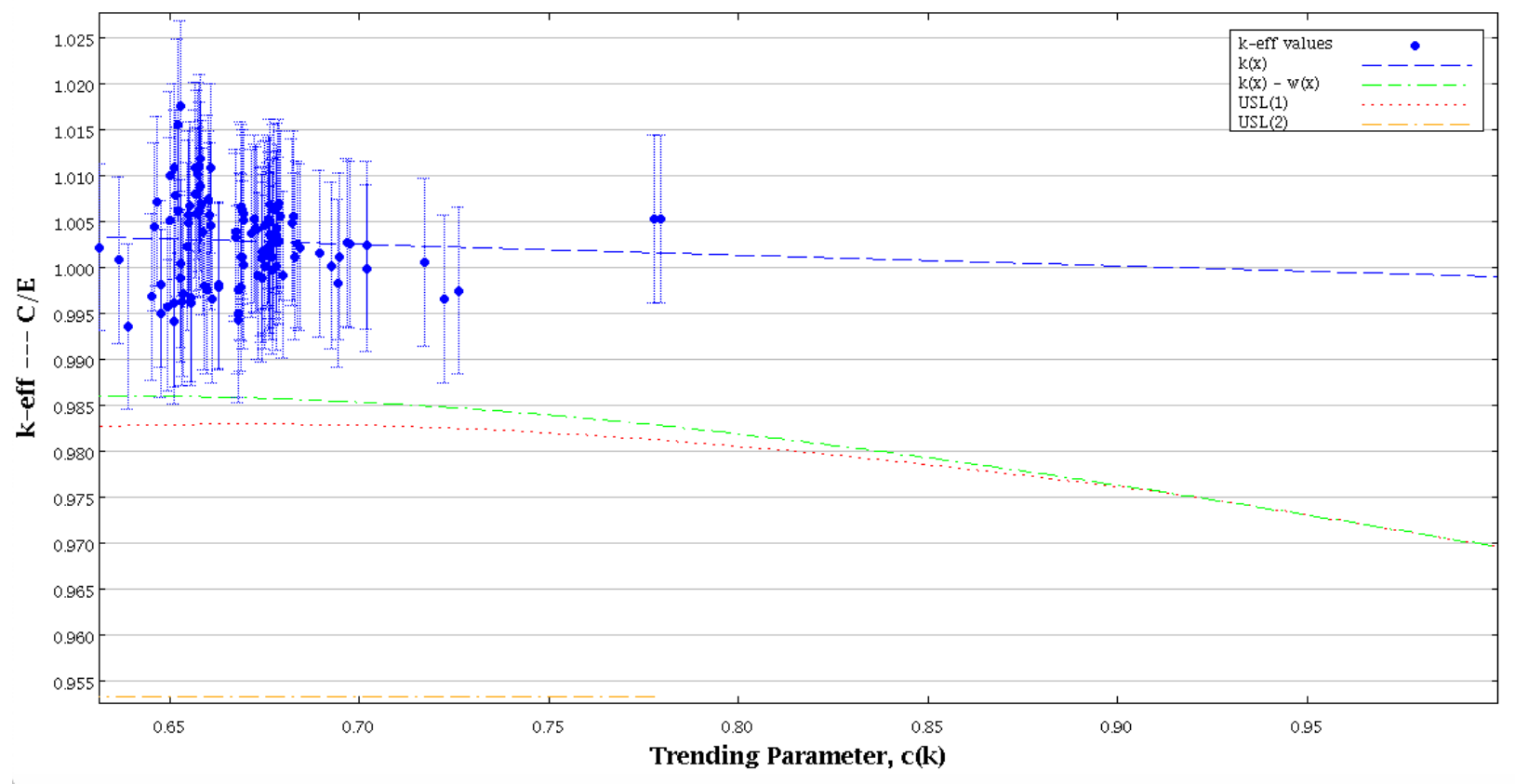

Figure D-2. Trending analysis plot of $c(k)$ for reconfigured wet scenario.

The critical experiments used for benchmarking include, to the extent possible, configurations having neutronics and geometric characteristics comparable to those of the proposed design basis configurations. Because the application models are slightly outside the range of applicability of the benchmark experiments, as indicated by the $\mathrm{c}(\mathrm{k})$ values being less than optimal, an administrative margin of 0.02 is added to account for deficiencies in matching the critical experiments used for validation with the bounding models for this analysis. An additional margin is added to account for the potential bias from beryllium and chlorine, determined using the uncertainty data for the beryllium and chlorine reactions from the sensitivity file. The respective numbers used to determine the USL along with the resultant USL are listed below:
Bias (from USLSTATS):
0.0005
Uncertainty in the bias (from USLSTATS): $\quad 0.0305$
Margin for beryllium and chlorine:
0.0014
Administrative margin:
0.02
Resulting USL:
0.9476

\section{D.3 USING EALF FOR VALIDATION}

For comparison, EALFs were also used as a trending parameter in USLSTATS, with the same 112 benchmarks. The benchmarks have EALFs ranging from 0.04 to 0.95 and are listed in Table D-3. Appendix $\mathrm{B}$ lists all the evaluation case results, including the respective EALFs, with the bounding cases in each table bolded. For cases having $50 \mathrm{~g} \mathrm{~B}_{4} \mathrm{C}$ or less, the EALFs range from 0.05 to $1.52 \mathrm{eV}$ (including both dry and wet scenarios). 
Table D-3. Dry mixed container array with minimum credited spacing c(k) values.

\begin{tabular}{|c|c|c|c|c|c|c|c|}
\hline Experiment & $\begin{array}{c}\text { EALF } \\
\text { value }\end{array}$ & Experiment & $\begin{array}{c}\text { EALF } \\
\text { value }\end{array}$ & Experiment & $\begin{array}{c}\text { EALF } \\
\text { value }\end{array}$ & Experiment & $\begin{array}{c}\text { EALF } \\
\text { value }\end{array}$ \\
\hline МCT-001-001 & 0.95 & MCT-001-004 & 0.11 & PST-002-002 & 0.07 & PST-011-011 & 0.06 \\
\hline MCT-002-002S & 0.72 & PST-007-006 & 0.11 & PST-002-001 & 0.07 & PST-005-009 & 0.06 \\
\hline MCT-002-001S & 0.54 & PST-007-007 & 0.11 & PST-003-006 & 0.07 & PST-005-003 & 0.06 \\
\hline PST-001-006 & 0.34 & PST-007-004 & 0.11 & PST-005-007 & 0.07 & PST-005-008 & 0.06 \\
\hline MCT-002-004S & 0.27 & PST-007-005 & 0.11 & PST-004-011 & 0.07 & PST-005-002 & 0.06 \\
\hline MCT-001-002 & 0.27 & PST-007-003 & 0.11 & PST-011-004 & 0.07 & PST-004-008 & 0.06 \\
\hline PST-007-001 & 0.27 & PST-001-002 & 0.11 & PST-011-003 & 0.07 & PST-004-004 & 0.06 \\
\hline PST-007-002 & 0.25 & PST-020-014 & 0.10 & PST-005-006 & 0.07 & PST-004-007 & 0.06 \\
\hline MCT-002-003S & 0.19 & PST-007-008 & 0.10 & PST-020-001 & 0.06 & PST-004-012 & 0.06 \\
\hline MST-007-007 & 0.18 & PST-020-007 & 0.10 & PST-003-005 & 0.06 & PST-004-013 & 0.06 \\
\hline MCT-002-006S & 0.18 & PST-002-007 & 0.10 & PST-020-009 & 0.06 & PST-005-001 & 0.06 \\
\hline MST-007-006 & 0.18 & MCT-004-007 & 0.09 & PST-020-002 & 0.06 & PST-006-003 & 0.05 \\
\hline MCT-001-003 & 0.16 & PST-002-006 & 0.09 & PST-011-002 & 0.06 & PST-011-010 & 0.05 \\
\hline MST-007-005 & 0.16 & MCT-004-008 & 0.09 & PST-004-010 & 0.06 & PST-004-006 & 0.05 \\
\hline PST-001-005 & 0.16 & MCT-004-009 & 0.09 & PST-005-005 & 0.06 & PST-004-003 & 0.05 \\
\hline MST-007-004 & 0.15 & PST-001-001 & 0.09 & PST-011-001 & 0.06 & PST-004-005 & 0.05 \\
\hline PST-001-004 & 0.15 & PST-002-005 & 0.08 & PST-003-004 & 0.06 & PST-004-002 & 0.05 \\
\hline MST-007-003 & 0.15 & PST-002-004 & 0.08 & PST-003-003 & 0.06 & PST-011-012 & 0.05 \\
\hline MCT-004-001 & 0.14 & MCT-004-010 & 0.08 & PST-020-006 & 0.06 & PST-006-002 & 0.05 \\
\hline MCT-004-002 & 0.14 & MCT-004-011 & 0.08 & PST-003-008 & 0.06 & PST-004-001 & 0.05 \\
\hline MCT-004-003 & 0.14 & PST-020-012 & 0.08 & PST-005-004 & 0.06 & PST-011-009 & 0.05 \\
\hline MCT-002-005S & 0.14 & PST-020-005 & 0.08 & PST-003-002 & 0.06 & PST-006-001 & 0.05 \\
\hline PST-001-003 & 0.13 & PST-002-003 & 0.08 & PST-003-007 & 0.06 & PST-011-007 & 0.05 \\
\hline MST-007-002 & 0.13 & PST-020-004 & 0.08 & PST-020-003 & 0.06 & PST-011-008 & 0.05 \\
\hline MCT-004-004 & 0.12 & PST-020-013 & 0.08 & PST-020-010 & 0.06 & PST-011-006 & 0.05 \\
\hline MST-007-001 & 0.12 & PST-020-008 & 0.08 & PST-004-009 & 0.06 & MST-002-003 & 0.04 \\
\hline MCT-004-005 & 0.12 & PST-020-011 & 0.07 & PST-020-015 & 0.06 & MST-002-001 & 0.04 \\
\hline MCT-004-006 & 0.12 & PST-011-005 & 0.07 & PST-003-001 & 0.06 & MST-002-002 & 0.04 \\
\hline
\end{tabular}

Figure D-3 is the trending analysis plot generated by the USLSTATS program with no additional administrative margin. 


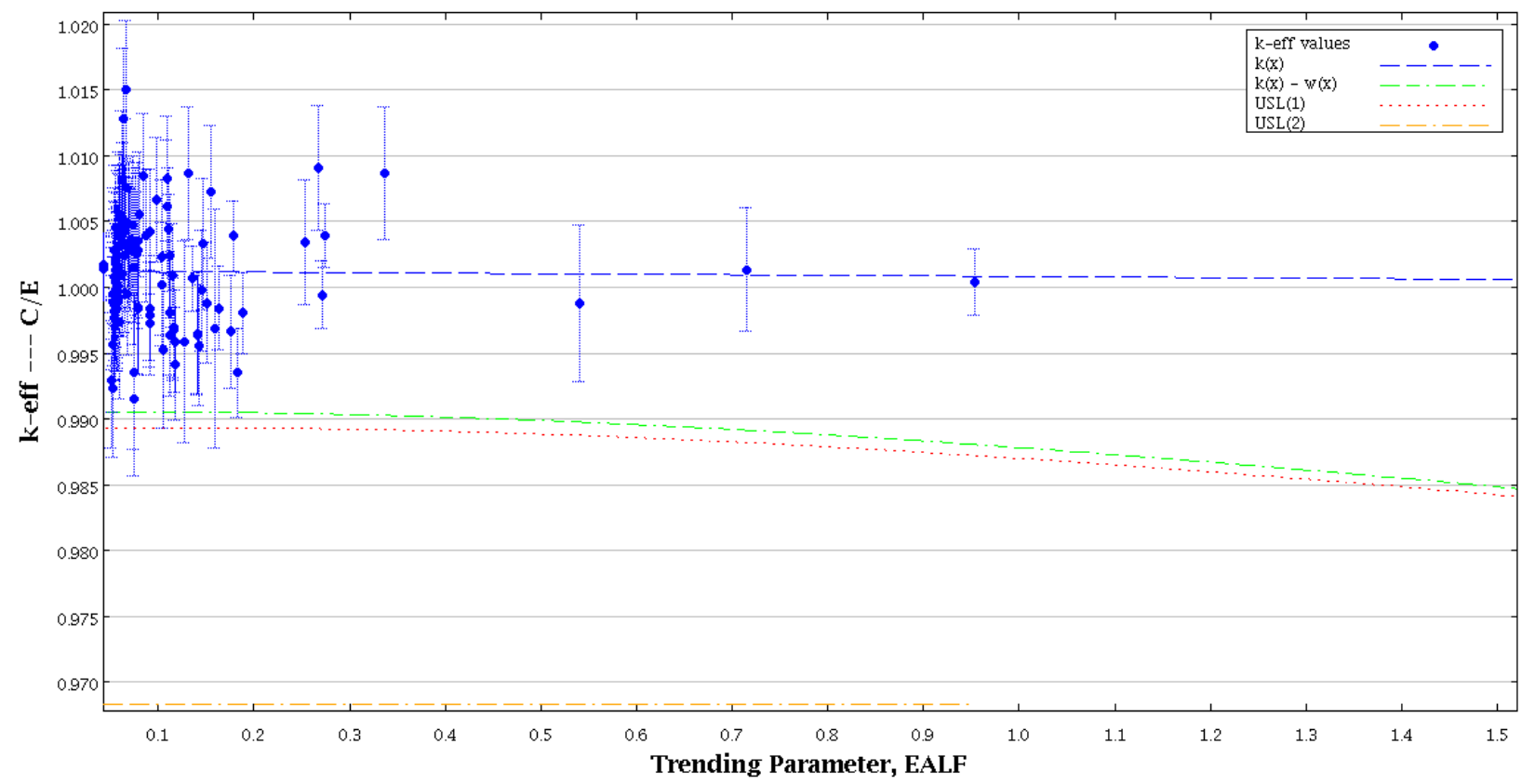

Figure D-3. Trending analysis plot using EALF values.

A majority of the EALFs are below the range of evaluation case EALFs. To account for those outside the range, an administrative margin of 0.02 is added to account for deficiencies in matching the critical experiments used for validation with the bounding models for this analysis. The respective numbers used to determine the USL along with the resultant USL are listed below (bounding values used).

Bias (from USLSTATS):

Uncertainty in the bias (from USLSTATS):

Administrative margin:

Resulting USL:
0.0000 (set to zero since it is positive)

0.0159

0.02

0.9641

\section{D.4 SUMMARY OF USLS}


Table D-4 lists the respective scenarios, their respective biases (positive biases set to zero), bias uncertainties from USLSTATS, additional administrative margin, and the calculated USLs. As illustrated, they both result in comparable biases. The critical experiments used for benchmarking included, to the extent possible, configurations having neutronics and geometric characteristics comparable to those of the proposed design basis configurations. Because the application models are slightly outside the range of applicability of the benchmark experiments, an administrative margin of 0.02 has been applied to determine final USLs. This additional margin accounts for deficiencies in matching the critical experiments used for validation with the bounding models for this analysis. 
Table D-4. USL summary.

\begin{tabular}{lccccc}
\hline \multicolumn{1}{c}{ Scenario } & $\begin{array}{c}\text { Bias based } \\
\text { on c(k)* }\end{array}$ & $\begin{array}{c}\text { Bias } \\
\text { uncertainty }\end{array}$ & $\begin{array}{c}\text { Bias for beryllium } \\
\text { and chlorine }\end{array}$ & $\begin{array}{c}\text { Administrative } \\
\text { margin }\end{array}$ & USL \\
\hline Dry reconfigured & 0.0010 & 0.0294 & 0.0010 & 0.02 & 0.9486 \\
Wet reconfigured & 0.0005 & 0.0305 & 0.0014 & 0.02 & 0.9476 \\
\hline \multirow{2}{*}{ Scenario } & $\begin{array}{c}\text { Bias based } \\
\text { on EALF* }\end{array}$ & $\begin{array}{c}\text { Bias } \\
\text { uncertainty }\end{array}$ & $\begin{array}{c}\text { Bias for beryllium } \\
\text { and chlorine }\end{array}$ & $\begin{array}{c}\text { Administrative } \\
\text { margin }\end{array}$ & USL \\
\hline All & 0.0000 & 0.0159 & NA & 0.02 & 0.9641 \\
\hline$*$ * & & & & &
\end{tabular}

Based on the conservative USLs determined with $\mathrm{c}(\mathrm{k})$ trending, any dry scenario result $\left(k_{e f f}+2 \sigma\right)$ less than 0.9486 and any wet scenario result less than 0.9476 can be considered to be subcritical.

\section{D.5 REFERENCES}

[1] American National Standards Institute (ANSI). 2014. An American National Standard for Nuclear Criticality Safety in Operations with Fissionable Materials Outside Reactors, ANSI/ANS-8.1-2014, La Grange Park, IL: American National Standards Institute, Inc.

[2] ANSI. 2017. An American National Standard for Validation on Neutron Transport Methods for Nuclear Criticality Safety Calculations, ANSI/ANS-8.24-2017, La Grange Park, IL: American National Standards Institute, Inc.

[3] Nuclear Energy Agency (NEA). 2016. International Handbook of Evaluated Criticality Safety Benchmark Experiments, NEA/NSC/DOC(95)03, NEA Nuclear Science Committee.

[4] ORNL. 2013. The SCALE Verified, Archived Library of Inputs and Data - VALID, Oak Ridge National Laboratory, transactions of ANS NCSD 2013, Wilmington, NC, September 29 October 31, 2013.

[5] Nuclear Regulatory Commission (NRC). 2012. An Approach for Validating Actinide and Fission Product Burnup Credit Criticality Safety Analyses-Criticality $\left(k_{\text {eff }}\right)$ Predictions, US Nuclear Regulatory Commission, NUREG/CR-7109. Oak Ridge National Laboratory, Oak Ridge, Tennessee. 